\title{
Recruitment of the intertidal barnacle Semibalanus balanoides; metamorphosis and survival from daily to seasonal timescales
}

By

\author{
Jonathan N. Blythe
}

B.S., University of California, Santa Barbara, 2002

Submitted in partial fulfillment of the requirements for the degree of

Doctor of Philosophy

at the

\section{MASSACHUSETTS INSTITUTE OF TECHNOLOGY}

and the

\section{WOODS HOLE OCEANOGRAPHIC INSTITUTION}

September 2008

\section{Copyright (C) 2008, Jonathan N. Blythe \\ All rights reserved.}

The author hereby grants to MIT and WHOI permission to reproduce and to distribute publicly paper and electronic copies of this thesis document in whole or in part in any medium now known or hereafter created.

Joint Program in Oceanography/Applied Ocean Science and Engineering Massachusetts Institute of Technology and Woods Hole Oceanographic Institution

August 27, 2008

Certified by

Jesús Pineda Thesis Supervisor

Accepted by

Edward DeLong

Chair, Joint Committee for Biological Oceanography Woods Hole Oceanographic Institution 


\title{
Recruitment of the intertidal barnacle Semibalanus balanoides; metamorphosis and survival from daily to seasonal timescales
}

\author{
By \\ Jonathan N. Blythe \\ Submitted to the MIT/WHOI Joint Program in Applied Ocean Science and Engineering \\ on August 27, 2008, in partial fulfillment of the requirements for the Degree of \\ Doctor of Philosophy in Biological Oceanography
}

\begin{abstract}
The benthic habitat is the terminal destination for marine animals in terms of their reproductive lifecycle. Recruitment dynamics relating to seasonal changes in the benthic habitat may be the best source of information for predicting recruit abundance and for marine resources management. The transition from the pelagic to the benthic phases is the last stage in the connectivity between benthic populations. The transition to the benthos may be a process that dominates recruitment dynamics to the exclusion of other characteristics of larvae such as their quality and their density. Recruitment of benthic marine animals is influenced by two seasonally varying factors of the benthic habitat. First, the availability of suitable habitat for recruitment can in large part determine the survival probability for settlers, a trend that is most pronounced for low or no survival when the settlement substrate is saturated by conspecifics from a recruitment cohort. Preemption is caused by the presence of current occupants from a recruit cohort, and it influences the settlement rate or the survival probability of conspecifics. Descriptive statistics (Chapter 2) and a field experiment (Chapter 4) highlight the role of preemption on barnacle recruitment. The second factor results from seasonal changes in environmental conditions that settlers experience in the benthic habitat, which could affect the physiology and survival probability of barnacle settlers. Highly unpredictable features of recruitment dynamics also play a role, such as wind that enhances wave action in the rocky intertidal that has been linked to the rate of settlement. Day to day variability in wind may cause patterns of settlement to be highly unpredictable. Predator induced mortality is spatially aggregated, and the random pattern of mortality in space is highly unpredictable. In contrast to these high frequency sources of recruitment variability, seasonal factors that vary at lower frequencies and that often change monotonically lend great predictive ability for recruitment dynamics. It appears that barnacles have evolved to compete for suitable habitat and have mechanisms to cope with seasonally varying environmental conditions in the benthic habitat, which may be the basis for why these features dominate the barnacle recruitment dynamic.

Thesis Supervisor: Jesús Pineda

Title: $\quad$ Associate Scientist
\end{abstract}




\section{Acknowledgements}

I am grateful for fellowships from the Ocean Life Institute at the Woods Hole Oceanographic Institution (WHOI), the American Society for Engineering Education, and the Academic Programs Office at WHOI. I am thankful for funding for research supplies and equipment from a National Science Foundation grant to Jesús Pineda, and two grants from the Coastal Ocean Institute at WHOI. Jesús Pineda was an excellent mentor and advisor, whose thoughtfulness and energy allowed me to constructively channel my creativity. Also, many of his ideas became such a core part of my research that I find it difficult to identify which were originally my ideas and which I had adopted from discussions with him. My other committee members, Becky Gast, Glenn Flierl, and Dan Rothman, all played central roles as I defined myself and my research interests in graduate school. Others that have been influential to my thesis work are Jim Thomson who is a co-author on the third chapter, and Vicke Starczak who has expertise in areas that I studied, often sharing her perspective.

I would like to recognize my family for their support throughout the years. They have given definition to my personality and values. To my wife, Heidi, we have been together for as long as I have been pursuing the barnacle research. Your patience exceeded all of my expectations. The only reason why I feel good about pouring so much of myself into this thesis is that I often had you by my side or at least in the back of my mind. I am grateful to find you on a clear and sunny day - with joy and happiness and endless possibility. 


\section{Table of contents}

$\begin{array}{ll}\text { 1. General introduction. } & \text { p. } 6\end{array}$

$\begin{array}{ll}\text { 1.1. References. } & \text { p. } 11\end{array}$

2. Preemptive competition and the time that recruits

settle in the intertidal barnacle Semibalanus balanoides. p. 13

2.1. Summary. p. 13

2.2. Introduction. p. 14

2.3. Methods. p. 16

2.3.1. Site and quadrat selection p. 16

2.3.2. Photographic monitoring of settlement
and survival quadrats.

2.3.3. Analysis of settlement and recruitment data. p. 20

2.4. Results. p. 24

2.5. Discussion. p. 27

2.6. Acknowledgements. p. 32

2.7. Literature cited. p. 33

3. Wave energy drives settlement in the

intertidal barnacle, Semibalanus balanoides. p. 45

$\begin{array}{ll}\text { 3.1. Abstract. } & \text { p. } 45\end{array}$

3.2. Introduction. p. 45

$\begin{array}{ll}\text { 3.3. Methods. } & \text { p. } 48\end{array}$

3.4. Results. p. 53

3.5. Discussion. p. 56

3.6. Acknowledgements. p. 60

$\begin{array}{ll}\text { 3.7. References. } & \text { p. } 60\end{array}$

4. The Recruitment Window, a novel tool to address

the role of seasonally changing influences in benthic

$\begin{array}{ll}\text { marine invertebrate recruitment. } & \text { p. } 69\end{array}$

$\begin{array}{ll}\text { 4.1. Abstract. p. } 69 & \text { p. }\end{array}$

4.2. Introduction. p. 70

$\begin{array}{ll}\text { 4.3. Methods. } & \text { p. } 75\end{array}$

4.3.1. Natural substrate monitoring. p. 75

4.3.2. Lipid experiment. p. 76

4.3.3. Smother plate experiment. p. 79

$\begin{array}{ll}\text { 4.4. Results. } & \text { p. } 84\end{array}$

4.5. Discussion. p. 92

4.6. Future directions. p. 98

4.7. Acknowledgements. p. 103

4.8. References. p. 104

5. Conclusion. p. 122

$\begin{array}{ll}\text { 5.1. References. } & \text { p. } 125\end{array}$ 


\section{Chapter 1}

\section{General introduction}

Several aspects of the natural history of the rocky intertidal barnacle can explain why it has long been exploited as an example of marine animal recruitment. The adult barnacle is sessile and does not move after the transition from the larval to the juvenile stage. Therefore, researchers can track the fate of individual barnacles in ways that would be difficult for non-sessile marine animals. Even among sessile animals, the barnacle is easiest to track because it grows on rocks in the rocky intertidal. A sizable portion of the rocky intertidal barnacle's day is spent in a pseudo-terrestrial environment, and whole populations of barnacles are accessible to scientists at regular intervals. Despite having this unique adult habitat, the barnacle has a lifecycle like most marine animals. Many marine animals have a dispersive larval stage, which was lost during the evolution of terrestrial life because distinct environmental features necessitated a different mode of reproduction (Steele 1985). The rocky intertidal barnacle is a model system for many other benthic marine organisms with the dispersive larval stage.

One of the greatest contributions to the field of marine ecology was the ability for barnacle ecologists to distinguish between settlers and post-metamorphic individuals (Connell 1985). Features that can be measured of settlers, such as their abundance are more closely representative of the dynamics during the larval period of the barnacle lifecycle, such as the supply of larvae. The precise definition of settlement is the first record of when an individual has attached to the benthic habitat. By this definition, after the first record of an individual settling, this individual is not considered a settler in 
subsequent visits to the rocky intertidal, even if it is recorded once again in its earliest cyprid stage. Therefore, settlement at a given period of time carries specific information about the transition from the larval to the benthic phases in the marine animal lifecycle. In other recruitment systems, settlement cannot be measured as frequently or as reliably. The earliest stages recorded in other recruitment systems are generally post-metamorphic stages, which often are not considered settlers at all, but recruits due to their advanced stage of development.

I monitored settlement and survival of the barnacle, Semibalanus balanoides, at an intertidal site in Woods Hole called Gardiner beach. Barnacle recruitment at this site has been intensely monitored several years preceding my first field season including a preliminary study comparing this site to another one nearby in Woods Hole (Pineda, Riebensahm and Medeiros-Bergen, 2002), and a preliminary analysis of settlement and survival patterns on a daily frequency (Pineda, Starczak and Stueckle 2006). I heavily depended on the knowledge gained from these previous studies to create the spatial and temporal scales for my measurements. I sampled settlement at a daily frequency, because important variability in barnacle settlement occurs on this scale (Pineda 2000). I monitored rectangular surfaces 1.5 by $2 \mathrm{~cm}$, because this was the minimum area that would have at least one recruit and could also be easily photographed using the macro setting of the digital camera that I used. There have been several occasions where people have recorded recruitment at these highly resolved scales, but the number of examples is growing larger (e.g. Wethey 1984; Raimondi 1990; Pineda, Starczak and Stueckle 2006) because this research is still yielding novel and sometimes astonishing results that are 
changing our foundational concepts about connections between pelagic larval and benthic adult life stages of marine animals. An important recent advance was the unique information that settlement date provides about the survival of juveniles to the adult stage. My advisor and his co-authors defined a new concept for recruitment research, the recruitment window (Pineda, Starczak and Stueckle 2006). I collected data to resolve the recruitment window in three consecutive years; 2006, 2007 and 2008; and the analysis of the recruitment window has been the primary focus of my thesis. In chapter 2, a descriptive study of the 2006 recruitment window correlated variability in the recruitment window between quadrats at a site with patterns of settlement and recruit abundance. In chapter 4, I average among quadrats to describe whole site trends in the 2007 and 2008 recruitment windows.

Studies using post-settlement measures of intertidal barnacles reveal a rich set of both pre- and post- settlement factors influencing the recruitment of marine animals, and in particular they have focused on the transition during metamorphosis from the pelagic to the benthic stages. Raimondi (1991) tested a hierarchy of nested hypotheses, each carefully conceived to narrow the number of possible factors controlling the distribution of the rocky intertidal barnacle, Chthamalus anisopoma. Using measurements collected after settlement, he inferred that behaviors before and during settlement would explain the distribution of barnacles. In addition, he postulated a hypothesis on which behavioral mechanisms would produce linear and non-linear trends in the distribution of setters with increasing settler density. Jarrett and Pechenik (1997) measured the energy content of settlers through time. Though these measurements were made post-settlement, they 
indicated sources of recruitment variability related to larval feeding conditions and larval duration in the competent cyprid stage. This variability in energy content described some degree of the juvenile growth in the adult habitat, indicating these pelagic experiences had lasting consequences in the benthic stages of the barnacle lifecycle. Miron, Boudreau and Bourget (1999) conducted a hybrid of these two approaches by inferring settlement behaviors that may be influenced by the energy content of settling larvae. Once again, these measurements were conducted only on post-settlement stages, though they relate to pre-settlement processes. The ability to measure settlement patterns with high fidelity allows inferences about which factors are most critical for affecting recruitment during the transition from the pelagic to the benthic stages.

There has been a historical and ongoing pursuit to reach backwards in the lifecycle of the intertidal barnacle before the stages of settlement to larval phases in the nearshore environment to explain the patterns of settlement that are observed. Hawkins and Hartnoll (1982) compared the settler abundance measured over four consecutive years, relating variability in settlement to factors such as variation in the spring diatom bloom and variability in wind conditions that would transport pelagic larvae onshore where they can touchdown on the adult habitat. Bertness et al. (1992) sought to make a link between measurements of larval abundances in the nearshore pelagic habitat with the measures of settlement in the rocky intertidal. Following up on this study Bertness, Gaines and Wahle (1996) linked settlement patterns in the rocky intertidal with larval abundances and wind induced transport in the pelagic environment. Attempts to make links between settlement patterns and pelagic based measurements continue to this day 
(e.g. Jenkins 2003). Yet, planktonic measurements of barnacle larvae were not an objective of my graduate research. I found settlement measurements to impart enough information to study recruitment patterns and barnacle population dynamics.

The scope of this thesis encompasses findings that range over different timescales during the benthic phase of the barnacle lifecycle. At one extreme, the measurements reported in chapter 3 describe how high frequency physical forcing from wind is a source settlement variability. Though the link between wind and wave energy is well established (e.g. Tucker 1991), the fact that stochastic physical forcing may drive daily variability in settlement highlights how unpredictable recruitment patterns are on very short timescales. Chapter 4 investigates trends in temperature and this source of variability on recruitment. While high frequency variability also occurs in environmental temperature, the dominant period of variability is on timescales of a year with distinct periods of cold and warm conditions characterized by seasons that compose this cycle. I compare the recruitment patterns among years to assess how yearly differences in seasonal temperature can account for the recruitment patterns. Further, I employ an experimental approach to assess the role of seasonal changes in temperature on the periods of time when settlers can survive to adulthood. Despite the highly unpredictable nature of the physical forces like wind and temperature that affect recruitment of barnacles, the spatial variability in recruitment abundance may be quite predictable, as is demonstrated in chapter 2 . Therefore, the findings of this thesis may help address an applied question in marine ecological research. Quotas for marine fisheries are calculated on a year to year basis to manage natural stocks of marine animals at 
sustainable levels. The findings of this thesis indicate that standard measurements of marine animal settlement and the physical factors that drive recruitment can be useful in predicting the cohort's recruitment strength for the upcoming year. Since recruitment is an important factor in the fisheries assessments of sustainable yield, these predictions may allow enhanced fisheries management practices.

\subsection{References}

Bertness, M. D., S. D. Gaines, E. G. Stephens, and P. O. Yund. 1992. Components of recruitment in populations of the acorn barnacle Semibalanus balanoides (Linnaeus). Journal of Experimental Marine Biology and Ecology 156:199-215.

Bertness, M. D., S. D. Gaines, and R. A. Wahle. 1996. Wind-driven settlement patterns in the acorn barnacle Semibalanus balanoides. Marine Ecology Progress Series 137:103-110.

Connell, J. H. 1985. The consequences of variation in initial settlement vs. postsettlement mortality in rocky intertidal communities. Journal of Experimental Marine Biology and Ecology 93:11-45.

Crisp, D. J. and P. S. Meadows. 1962. The chemical basis of gregariousness in cirripedes. Proceedings of the Royal Society of London. Series B, Biological Sciences 156:500-520.

Crisp, D. J. and P. S. Meadows. 1963. Adsorbed layers: the stimulus to settlement in barnacles. Proceedings of the Royal Society of London. Series B, Biological Sciences 158:364-387.

Hawkins, S. J. and R. G. Hartnoll. 1982. Settlement patterns of Semibalanus balanoides (L.) in the Isle of Man (1977-1981). Journal of Experimental Marine Biology and Ecology 62:271-283.

Hentschel, B. T. and R. B. Emlet. 2000. Metamorphosis of barnacle nauplii: effects of food variability and a comparison with amphibian models. Ecology 81:34953508.

Jarrett, J. N. and J. A. Pechenik. 1997. Temporal variation in cyprid quality and juvenile growth capacity for an intertideal barnacle. Ecology 78:1262-1265.

Jenkins, S. R. 2005. Larval habitat selection, not larval supply, determines settlement patterns and adult distribution in two chthamalid barnacles. Journal of Animal Ecology 74:893-904.

Menge, B. A. 1991. Relative importance of recruitment and other causes of variation in rocky intertidal community structure. Journal of Experimental Marine Biology and Ecology 146:69-100.

Miron, G., B. Boudreau, and E. Bourget. 1999. Intertidal barnacle distribution: a case study using multiple working hypotheses. Marine Ecology Progress Series 189:205-219. 
Mullineaux, L. S. and C. A. Butman. 1991. Initial contact, exploration and attachment of barnacle (Balanus amphitrite) cyprids settling in flow. Marine Biology 110:93103.

O'Connor, M. I., J. F. Bruno, S. D. Gaines, B. S. Halpern, S. E. Lester, B. P. Kinlan, and J. M. Weiss. 2007. Temperature control of larval dispersal and the implications for marine ecology, evolutiona and conservation. Proceedings of the National Academy of Sciences 104:1266-1271.

Pineda, J. 2000. Linking larval settlement to larval transport: assumptions, potentials and pitfalls. Oceanography of the Eastern Pacific 1:84-105.

Pineda, J. and H. Caswell. 1997. Dependence of settlement rate on suitable substrate area. Marine Biology 129:541-548.

Pineda, J., C. DiBacco, and V. Starczak. 2005. Barnacle larvae in ice: survival, reproduction, and time to postsettlement metamorphosis. Limnology and Oceanography 50:1520-1528.

Pineda, J., D. Riebensahm, and D. Medeiros-Bergen. 2002. Semibalanus balanoides in winter and spring: larval concentration, settlement, and substrate occupancy. Marine Biology 140:789-800.

Pineda, J., V. Starczak, and T. A. Stueckle. 2006. Timing of successful settlement: demonstration of a recruitment window in the barnacle Semibalanus balanoides. Marine Ecology Progress Series 320:233-237.

Raimondi, P. T. 1990. Patterns, mechanisms, consequences of variability in settlement and recruitment of an intertidal barnacle. Ecological Monographs 60:283-309.

Raimondi, P. T. 1991. Settlement behavior of Chthamalus anisopoma larvae largely determines the adult distribution. Oecologia 85:349-360.

Steele, J.H. 1985. A comparison of terrestrial and marine ecological systems. Nature 313:355-358.

Tucker, M. J. 1991. Waves in Ocean Engineering. 1st edition. Ellis Horwood, New York.

Wethey, D. S. 1984. Spatial pattern in barnacle settlement: day to day changes during the settlement season. Journal of the Marine Biological Association of the United Kingdom 64:687-698. 


\section{Chapter 2}

\section{Preemptive competition and the time that recruits settle in the intertidal barnacle Semibalanus balanoides}

\subsection{Summary}

1. Marine animal recruitment can be limited by the supply of larvae or postsettlement processes that affect the survival of propagules that have dispersed. A third source of variability that may contribute to recruitment limitation involves larval choices that are expressed when larvae make the transition to the adult habitat. This transition is most pronounced for sessile invertebrates that cannot move after settlement. Tracking individuals is necessary to evaluate larval choices since the fitness consequences of these choices may not be apparent until long after the metamorphosis to the juvenile stage of the lifecycle. This was accomplished by tracking the survival of settlers of the rocky intertidal barnacle, Semibalanus balanoides (L.).

2. Settlers were tracked using digital photographic monitoring of the benthic habitat to identify individuals that survived to adulthood. The times when adults settled were resolved at a daily interval during the settlement season. The summary of these settlement times from among several quadrats at Gardiner beach, MA identifies the recruitment window for this location.

3. A novel statistical analysis is conducted using these measurements of settler survival to assess whether adults settled early. This analysis was conducted for 12 replicate quadrats scattered across the rocky intertidal, representing the full diversity of habitat at this site. Quadrats were stratified for intertidal height and along shore position. 
4. Quadrats had distinct recruitment windows, which along with adult conspecific abundance at the time of settlement and first day of settlement could predict the abundance of adults that survived to the reproductive portion of the following recruitment season.

5. Settlement choices are inferred from time-series of barnacle settlement. Larvae apparently lost selectivity for habitat with high adult conspecific abundance and for habitat features of natural rock surfaces as opposed to PVC settlement plate surfaces. The degree to which selectivity patterns may coincide with preemption is examined.

\subsection{Introduction}

Predicting recruitment in marine sessile animals with larval dispersal is of great practical importance for management of natural resources. This has proven difficult in the past in part because larval dispersal occurs at large scales, decoupling adult stock from recruitment (Caley et al. 1996). A great deal of the variability in recruitment may be determined once larvae have already dispersed (Connell 1985), and scientists often focus on local sources of variability in recruitment, like larval supply, larval choice, or post settlement mortality (Jenkins 2005). If certain processes such as post settlement mortality limit the abundance of recruits, then much of the variability in recruitment can already be predicted by addressing the sources of propagule mortality that may exist in the habitat of interest. Another type of local processes important for barnacles is a form of passive exclusion called preemption, which involves the alteration of the benthic habitat by the arrival of early propagules that inhibits the recruitment of larvae that subsequently arrive to that location (Hawkins \& Hartnoll 1982; Connell 1985; Raimondi 
1990). Studies that supported the preemption hypothesis tracked sub-cohorts of settlers to assess their relative contributions to the recruit population at some arbitrary date after settlement. From a fisheries perspective, that arbitrary date for recruitment should be the adult stage (Pineda, Starczak \& Stueckle 2006), since this allows identification of periods of time during the settlement season when animals settle and can add value to the coastal resource. In addition, this definition of recruitment ensures the identification of those individuals that potentially contribute to future generations.

Since settlement timing plays a central role in the preemption dynamics, a review of different stages of the barnacle lifecycle that affect the timing of barnacle settlement is necessary to adequately understand the preemption dynamics among barnacles in a settlement cohort. Many of the processes that affect settlement timing occur in the earliest stages of a barnacle's lifecycle in environments far removed from the habitat that barnacles ultimately recruit in. Not all larvae begin developing in the plankton at the same time, since there can be a large degree of geographic variability in the date of larval release in a barnacle population, for example in Semibalanus balanoides (Pineda et al. unpublished). Once in the plankton, the rate of larval development depends on food quantity and quality (Desai \& Anil 2004). The onset of metamorphosis from the planktonic to the benthic life history (Walley \& Rees 1969) depends largely on the food resources encountered during the plankton feeding stages (Hentschel \& Emlet 2000). Resource managers who wish to predict recruitment must account for these sources of recruitment variability, but this poses a problem since these processes occur in environments that are often far removed from the location that is being managed. 
Certain aspects of settlement patterns are determined locally, and could be a focus of locally based measurements to predict the abundance of the recruitment cohort. For example, local measurements of settler density have been one basis to predict recruit density (Connell 1985). Larval barnacles that have dispersed to a location and are competent to settle wait to encounter certain cues before selecting a benthic habitat, a characteristic of settlement that may keep propagules from being lost in benthic habitats that are unsuitable for juvenile growth and survival to adulthood (Hui \& Moyse 1987). We hypothesize that larvae have strategies to optimize settlement choices. Analyses of settlement time-series and possible response of larvae to cues present in the settlement environment indicate that information on settlement choices of barnacles and the progression of the preemption dynamic within a recruitment cohort may reveal timing of recruitment processes and may be a new basis to predict recruit abundances.

\subsection{Methods}

\subsubsection{Site and quadrat selection}

Recruitment of the barnacle Semibalanus balanoides was monitored at Gardiner beach, a stony beach on the Buzzards Bay coast in Woods Hole, Massachusetts. A man made granite boulder wall borders a beach that has a mix of sand, pebbles and melon sized stones. Solitary boulders ranging in size from a cubic meter to several cubic meters are scattered over a range of beach elevations, from - 60 to $20 \mathrm{~cm}$ Mean Lower Low Water (MLLW). Further description of the site is available in a recent study on barnacle recruitment (Pineda et al. 2006). 
The site was visited in the fall of 2005 when 24 surfaces on boulders were identified, which were occupied by adult barnacles and flat enough to lay a $12 \mathrm{~cm}$ diameter disk flush with the surface. Beyond these criteria, these surfaces were stratified across a range of intertidal heights, orientations to the azimuth and zenith, and positions in the long and cross shore directions. Four evenly spaced holes were drilled and filled with green screw anchors to mark the quadrat along a diagonal $12 \mathrm{~cm}$ axis. Quadrats were numbered and evenly assigned to two treatments by random permutation. The first treatment is a natural substrate for recruitment, where the second was a PVC surface to monitor settlement.

\subsubsection{Photographic monitoring of settlement and survival in quadrats}

Half of the quadrats were assigned to the PVC settlement plate treatment. Twelve identical settlement plates were created from the gray PVC sheet. The sheet was cut into $3.5 \times 4 \mathrm{~cm}$ rectangles. Five wells were milled into the surface along the short axis, $3 \mathrm{~mm}$ wide and between 1-2 mm deep. Wells add texture elements that simulate crevices that barnacles prefer to settle in on natural rocky surfaces. The wells covered the center of the rectangle over an area approximately 1.5 by $2 \mathrm{~cm}$, and plates were machined identically to control for the amount of surface available for settlement. Holes were drilled into the two corners corresponding to the position of the middle screw anchors, and the plate was held in place flush with the quadrat surface using two stainless steel machine screws. The plates were deployed in the field a month before the beginning of the settlement season for seasoning. 
Half of the quadrats were assigned to a natural substrate treatment. One month before the seasons' first settlement was recorded, a 1.5 by $2 \mathrm{~cm}$ plastic template was centered between the center two screw anchors of each quadrat. A red felt pen was used to trace the border of the template onto the boulder's rocky surface. The rock surface inside the marked border was scraped clean with a flat head stainless steel screwdriver to remove adult barnacles, algae, and other macroscopic inhabitants. The remainder of the quadrat surface was left undisturbed except for placement of the four diagonal markers.

Settlement was measured by comparing a photograph of a quadrat from one day with that of the following day, and by identifying new cyprids that had attached in the intervening time. Settlement plates were photographed daily for 150 days in winter and spring 2006 to monitor barnacle settlement. Daily photographs of the natural substrate quadrats were collected to identify new cyprids that settled during the first 34 days of settlement corresponding to the first recruitment window (see below). Settlement between days 1 and 11 was recorded for any new settler individuals on any portions of the photographs including areas outside the scraped surface that had a standard surface area. Standardized settlement measurements were conducted after day 11 through day 34. The standard area encompassed the surface that had been scraped between the two markers. First settlement day and first settlement resulting in recruitment were variables measured for recruitment analyses. The arbitrary area defined by the standard surface could alter the measure of the first settlement day if cyprids settled just outside the borders of the standard surface area. After the first 11 days, settlement occurred at a high enough rate that these arbitrary cropped boarders did not substantially alter the settlement 
measurements, but provided an enhanced ability for comparison between quadrats because it provided a better standardized area for density estimation. The measurements of settlement were carried out through day 34 , because this was the last day of the winter recruitment window (see below).

Photographs were also used for identifying the settlement day of individuals that survived to recruitment. Recruitment was defined when an individual from the 2006 settler cohort survived to December, when Semibalanus balanoides typically completes its lifecycle on Cape Cod and releases propagules that settle in the following year's cohort (Pineda et al. 2006). While daily photographs of settlement during the winter and spring provided a precise measurement of settlement day for any of the 2006 cohort of recruits, daily monitoring of the settlement quadrat also allowed determination of important events such as juvenile death and replacement by a second individual. Low frequency monitoring, like on a weekly basis, could introduce error in the settlement date measurements if such replacements went undetected. After the end of the settlement season, the $1 /$ day frequency for sampling barnacle habitat was no longer necessary to reduce this source of error in the measures of settler survival. Afterwards photographing resumed on a monthly basis. Then, once the recruits were photographed in December, it was possible to track all the survivors back in time to identify their settlement date. Tracking a survivor back in time was more efficient compared to tracking a settler forward in time in the unlikely event that it survived. In nearly all quadrats, at least one recruit did not settle within the standard settlement area, but grew into the standard settlement area as it grew in size. In order to identify the date of settlement for these 
individuals, it was necessary to use photographs encompassing larger areas including portions of substrate surrounding the standard surface. The settlement day of recruits defines the recruitment window for the 2006 cohort (Pineda et al. 2006). Dates of settlement were standardized to units of days starting with day one on the first day of settlement, and the last date in December was day 350. Total recruitment was measured as the number of individuals that settled in 2006 and survived until day 350 .

Adult abundance on the first day of settlement was measured for analysis of habitat selection in barnacle settlers. This included any conspecific adults in larger macro photographs that included the outermost diagonal quadrat markers. The adults in this larger area were monitored at weekly to monthly intervals throughout the year. Only one adult of the 491 individuals that were monitored died during the first 34 days of settlement, corresponding to the winter recruitment window (see results). Therefore, the adults present on day one were used for the analysis of habitat selectivity of settlers during the winter recruitment window, since this number remained relatively unchanged during this period.

\subsubsection{Analysis of settlement and recruitment data}

The quadrat average, defined herein, is a useful variable to detect preemption in recruitment patterns. All settlers have a rank determined by the order in which they arrived on a quadrat. The quadrat average is the average rank of arrival among all the recruits in a quadrat during a recruitment window. While recruitment is recorded several months after settlement when barnacles develop into adults that are capable of reproduction, settlers are recorded from daily records of new cyprids that attach to the 
quadrat. The quadrat average is a summary of both the short time-scale settlement pattern and the long-term recruitment pattern.

If preemption is acting in settlement dynamics, the quadrat average should be less than expected by chance, since recruits would settle earlier than the average settler in any given quadrat. The simplest example of this is the case where there is only one recruit and many settlers occurring in a quadrat during a settlement season. The recruitment window for this case is one day long corresponding to the day of settlement for that individual recruit. If the recruit was the first settler, then this would provide the lowest possible order of arrival and a quadrat average value of one. Since more than one settler often occurs between daily intervals of settlement measurements, a recruit's rank can be estimated by finding the median rank among all the individuals settling on that day.

The distribution of possible quadrat average values was computed for each quadrat to test whether the observed quadrat average was significantly smaller than if all the individuals that settled during the recruitment window observed at Gardiner beach had the same chance of recruitment. To facilitate the comparison of the possible values to the observed value, a vector was created with elements indicating the order of arrival for individuals (as above for recruits). Then, subsets of these settlers were selected in quantities equal to the number of observed recruits for the given quadrat, creating a null quadrat average. The total number of possible quadrat average values so calculated is simply the number of combinations of settlers, $n$, that can be selected for a particular recruitment, $\mathrm{k}$. Since the number of recruits always was less than half of the number of settlers, the number of combinations increases monotonically with the number of recruits. 
The power to test the hypothesis and distinguish earlier subsets of recruits among the settlers in the recruitment window depends on there being some minimum number of possible combinations because it is not possible to distinguish patterns of recruitment that support the hypothesis. In addition to the number of recruits, the number of settlers, $n$, also affects the possible number of combinations. Minimizing the types of combinations that would support the hypothesis increased the power of the statistical test. The observed last day of recruitment for each quadrat was several days earlier than the end of the recruitment window for the site as a whole in many cases. Many barnacles settled after the last recruit settled on each quadrat. Assigning the last recruit for the null samples of settlers allowed removal of many individuals settling after the recruitment window in the creation of the null recruit distribution for each quadrat. These were settlers that may not have had any chance of survival anyway, and this substantially decreased the number of possible combinations because it decreased the number, $\mathrm{n}$. Since the end of the recruitment window was also fixed, the number k was reduced by one, retaining the settlement date of the last recruit for each of the quadrats in the null simulations. The desirable affect of reducing $\mathrm{n}$ and $\mathrm{k}$ was to minimize the number of possible combinations and the chances of finding a significantly lower quadrat average when one did not in fact exist, increasing the power of the statistical test. This minimized number of combinations was computed using the nchoosek function in MATLAB. In most cases, there were too many settlers and recruits to derive all the possible combinations analytically. Therefore, a re-sampling algorithm was employed to approximate the theoretical distribution of recruits among settlers. For each quadrat, $10^{6}$ 
random samples of recruits were conducted to calculate a null distribution for the quadrat average. The p-value for the hypothesis test was computed by finding the proportion of the $10^{6}$ realizations that had a value less than or equal to the observed quadrat average.

The relative quadrat average relates the rank of settlers that recruited in a given quadrat relative to the average rank of contemporaneous settlers among all the natural substrate quadrats. The method to compute the relative quadrat average involves finding the mean rank of settlers among all the natural substrate quadrats the day any recruit settled, and subtracting this value from the recruit's rank in the quadrat in which it resided. The relative quadrat average is an average of this relative measure of cumulative settlement among all recruits in each quadrat. If the cumulative settlement in a quadrat is relatively low when a recruit settled, the relative quadrat average will take a negative value reflecting the relatively low cumulative settlement in the quadrat. Positive values reflect higher than average cumulative settlement at points in time when recruits settle.

Stepwise multiple linear regression analyses were conducted to explain variability in the relative quadrat average and total recruitment. The possible explanatory variables included conspecific adult abundance, day of first settlement, day of first recruitment and mean day of recruitment during the first recruitment window. The criteria for including variables in the regression model were based on the significance of each variable's contribution for describing the dependent variable. Both forward and backwards steps were used to arrive at the final regression model. 


\subsection{Results}

There were two apparent periods of time during the 2006 settlement season when cyprids settled and survived to adulthood several months later (Fig. 1). These periods are referred to as the winter and the spring recruitment windows respectively. The recruits had ranks of settlement that were among the first and last settlers in 2006, encompassing the entire settlement season. Therefore, the method of recruitment window modeling that tests for a shorter window of time than expected by chance (Pineda et al. 2006) would not identify the recruitment windows in this case. The majority of recruits settled during the winter in the first 34 days of the settlement season, and the recruits that settled during the spring were a substantial but lesser proportion of the overall recruitment.

The time-series of settlement during the first recruitment window was intensively analyzed. Settlement during the first recruitment window increased with time (Fig. 2A). The percent survival was calculated by summing the number of settlers over two consecutive daily sub-cohorts and finding what percentage of these individuals survived to recruitment. Percent survival was as high as $30 \%$ during the first half of the first recruitment window, and it decreased precipitously around the middle of the recruitment window (Fig. 2B). Variability in the benchmarks of the recruitment window, including the first settler to recruit, the mean day of settlement for recruits in the recruitment window, and the last day that identifies the end of the recruitment window is shown in Fig. 3. Twelve natural substrate quadrats had distinct values for each variable. In some cases, the beginning of the first recruitment window corresponded to the onset of barnacle settlement, and those cases where the first settler that recruited is either the first 
or second settler for that respective quadrat, including all settlers, are identified in Fig. 3 with a star.

Inferences on fitness consequences of settlement choices were based on comparisons of patterns of settlement and survival on the natural substrate quadrats to other concurrent data analyzed for photographs taken in the field. First, a comparison was made with the settlement plate controls. Settlement plates had standardized milled surfaces so that the amount of habitat available for recruitment is constant, through the background habitat in which they are attached to the rocky substrate may vary. The PVC surface should be a less favorable habitat for barnacle settlement than the surrounding natural substrate habitat, though settlement events may be elicited on settlement plates under certain conditions, like when barnacle lose selectivity for a variety of habitat cues that are absent from the man made settlement plates but would be present on natural substrate. Settlement was monitored daily on settlement plates over 140 days during the 2006 settlement season (Fig. 4). The settlement plates had a large degree of variability in cumulative settlement at the end of 140 days, and cumulative settlement was negatively correlated with the day of first settlement (Fig. 5). Despite the variability in the initial settlement day and the rate of settlement between the quadrats, $60 \%$ of settlement occurred at the same time for all the settlement plates, during a narrow pulse on days 33, 34 and 35 (Fig. 4). There was a corresponding rise in the settlement rate on natural substrate on days 33 and 34 (Fig. 2), and this pulse may in part explain the end of the first recruitment window. Recruitment processes, however, cannot be addressed on these 
settlement plate surfaces, since only one settler out of 1038 settlers survived until day 350.

The quadrat average reflects the order of arrival of settlers that recruited in the quadrat within a recruitment window. The observed quadrat averages were smaller than a significant portion of possible quadrat averages computed using the settler re-sampling method for 9 out of 12 cases (Fig. 6). Two of these cases that yielded insignificant results may be rejected as outliers because the number of combinations were very low causing low power to detect a pattern. In-fact, these insignificant outliers are part of a larger trend among the p-values of the hypothesis test, as they have a negative correlation with number of combinations (Fig. 6). The level of confidence with which the null hypothesis is rejected may be limited in large part by the level of statistical power in each case. There was one case where the observed quadrat average was not smaller than a significant proportion of the null quadrat averages. The adequate statistical power afforded by the high number of combinations suggests that the recruits in this quadrat were an exception to the overall trend of early settlement for recruits on natural substrates.

A further analysis of settlement tested for the possible influence of habitat features on the settlement rate of barnacle larvae. The correlation analysis between the $\log$ of settlement and the log of adult abundance for natural substrate quadrats indicated that these variables were correlated over a majority of the first 34 days. The settler abundance was positively correlated with the adult conspecifics until just before day 30 when there appeared to be a switch to a negative correlation (Fig. 7). Another test for 
habitat effects was the percent settlement on settlement plates, which represent an inferior habitat to natural substrates since recruitment was rare on these artificial surfaces. There was a gradual increase in the percent settlement on plates starting on about day 14 (Fig. 8). Settlement patterns with respect to the adult conspecific abundance and the settlement on plates demonstrated a change in larval choice with time indicative of decreasing larval selectivity.

Regression analyses explained variability in the relative quadrat average and recruitment between the twelve natural substrate quadrats. The variables that explained the relative quadrat average, day of the first recruit settled and adult abundance, could account for 95\% of the variance in this metric of cumulative settlement (Fig. 9). Likewise, the variables that explained total recruitment; first day of settlement, first day a recruit settled, mean day of settlement for settlers that recruited, and adult abundance; could account for over $96 \%$ of the variance in the recruit abundance (Fig. 10). The patterns of relative quadrat average and recruitment were predictable using variables determined early on in the settlement season. An analogous trend was observed on settlement plates where the day of first settlement was correlated with the cumulative settlement over the entire season (Fig. 5). The variety of analyses of the settlement and recruitment time-series were used to make inferences about the fitness consequences of various settlement choices that may be contributing to these observed patterns.

\subsection{Discussion}

Fitness consequences of settlement choices can be assessed by tracking individuals from settlement to adulthood. These empirical relationships are either 
directly observed or inferred from the time-series of settlement when compared to other contemporaneous measures. Fitness is conferred to individuals that survive to an age where it is possible to reproduce, which for the barnacle, Semibalanus balanoides, is survival of the young of the year until December when barnacles release larvae on Cape Cod (Pineda et al. unpublished). Recruitment has previously been defined as survival to an arbitrary time after metamorphosis. The convention of recording recruitment when barnacles are ready to reproduce emphasizes the importance of these settlement and recruitment patterns on population dynamics.

The concept of the recruitment window (Pineda et al.2006) can be described as the portion of time during a settlement season when settlers have any chance of survival to adulthood. Multiple processes affect barnacle recruitment, and it is likely that the combinations of processes change with settlement date (Bertness et al. 1992). Recruitment resulted from settlement during two periods of time between January and May of 2006. Barnacles that settle in the winter would have to endure several bouts of freezing since temperatures in the intertidal can drop well below freezing during typical New England winters. Less than $5 \%$ of the 2546 settlers that settled during the winter recruitment window survived to recruitment. However, some of these daily cohorts had up to $30 \%$ survival (Fig. 2B). Winter-time recruitment appears to have been a viable strategy for barnacles in 2006, though this may have been a mild winter (personal observations), which may have lessened winter weather effects on recruitment. Barnacles that delay settlement until the spring may experience a more hospitable benthic habitat conducive to recruitment. Populations from northern portions of Massachusetts 
and Maine, at higher latitudes, do not start to settle until the spring (Wethey 1986), perhaps as an adaptation in avoidance of winter freezing. A significant portion of the recruits settled during the spring. Nonetheless, recruit abundance could be mostly explained by patterns of settlement and recruitment during the winter, suggesting that processes occurring during the first 34 days of settlement reliably predicted quadrat variability that affected recruitment. Settlement data collected during this relatively short period of time were analyzed to assess what processes control the aspects of the first recruitment window.

The data presented here suggest that there is a preemptive dynamic that confers fitness to the larvae that settle early. Evidence for preemption comes from the distribution of percent survival, which is concentrated in the first half of the recruitment window (Fig. 2B). The fact that the first or second settler was the first recruit for many of the quadrats with the earliest recruitment windows (Fig. 3) supports this interpretation further. Finally the observed quadrat averages were significantly smaller than the null quadrat averages in 9 out of 12 cases.

Population connectivity is best defined as a subset of the populations between which larvae disperse, since connectivity also is more meaningful demographically when considering propagules that reach an adult stage (Pineda, Hare \& Sponaugle 2008). The preponderance of preemption effects that are inferred from the time-series could greatly simplify the issue of connectivity; processes that promote early dispersal are likely to result in survival of propagules to adulthood. In this case, the spatial scale of connectivity might be much shorter than predicted by time averaged dispersal kernels. 
For considering populations of Semibalanus balanoides that are connected to the Gardiner beach population studied here, future studies should turn instead to timedependent estimates of dispersal, since early arriving barnacles have a relatively high probability to become adults.

Much research in larval ecology focuses on the features in the adult habitat that provide cues to larvae to guide their settlement choices after they have been transported to the adult habitat. Perhaps the best documented cue for settlement in the barnacle, Semibalanus balanoides, is a chemical extract from adult barnacles (Crisp \& Meadows 1962). Settlement patterns that are positively correlated to adult abundance summed over large quadrats such as are used in this study may be a manifestation of this adult conspecific cue (Kent, Hawkins \& Doncaster 2003). Adult abundance was a significant descriptor of cumulative settlement (Fig. 9) and recruit abundance (Fig. 10). However, the degree to which larvae exhibit selectivity to the adult cue may vary with time (Jarrett 1997). We hypothesize that shifting settlement choices explain when a consistently positive correlation with adult abundance shifted to a negative correlation around day 30 (Fig. 7). Further evidence for the shift comes from the proportion of all settlement occurring in the settlement plates, which gradually increased towards the end of the recruitment window (Fig. 8). The switch is consistent with of a loss of habitat selectivity at the end of the winter recruitment window.

Modeling results suggest that the time for optimal loss of selectivity can be quite complicated, depending on a variety of factors, such as encounter rate with suitable habitat, relative fitness incurred by settling as a result of selective behavior, and energy 
resources gathered during the pelagic stage that may prolong the duration when larvae may remain competent and settle (Stamps, Krishnan \& Reid 2005). The loss of selectivity might be quite sensitive to a variety of factors that can change quickly during a settlement season (Toonen \& Tyre 2007). We propose that the loss of selectivity inferred from the settlement time-series results from the differential expression in time of two different types of preemptive competition. Early in the season, larvae exhibit a high degree of habitat selectivity, because there are substantial fitness benefits to occupying the best habitats that are still available at this time. As settlement progresses, the probability of encountering a suitable habitat decreases, causing a lower expected survival for these individuals. We use the term scramble preemption to describe the strategy of non-selective settlement to maximize fitness. The degree to which each type of competitive strategy is expressed, and the timing of the hypothesized switch from a selective to a non-selective strategy, would be motivated by the degree of accumulation of barnacles from the cohort present at the time a larvae is making its settlement choice. Consistent with this hypothesis, the probability in survival started decreasing after day 15 (Fig. 2B), which is just after when the percent of all settlement began to increase on settlement plates (Fig. 8). The probability of survival for settlers first reaches zero just before day 30 which corresponds to when the settlement distribution first switched from a positive to a negative correlation with adult abundance on natural substrates quadrats (Fig. 7). Finally, most of the settlement on settlement plates occurred in a synchronous pulse on days 33, 34, and 35 (Fig. 4), that did not occur again throughout the remainder of the settlement time-series. Likewise, the settlement rate on natural substrates reaches 
its highest value at the end of the recruitment window on days 33 and 34. During circumstances when larvae maximize their probability of survival by settling as soon as possible, any contact larvae make with habitat would result in settlement. Therefore, settlement rate during this period may be limited by the probability of chance contacts of larvae with rocky intertidal habitat.

Preemption is an important process underlying the settlement of barnacles during the recruitment window that we observed during the winter of 2006 . We argue that preemption was a dominant feature of the first recruitment window. We inferred preemption based on the temporal distribution of survivors among the settlers in each of the quadrats. Preemption may cause survival to be skewed early in a recruitment window (Fig. 2B). Further, scramble preemption (see above) may affect the timing of various settlement events that dictate the end of the recruitment window. A promising avenue is to detect temporal shifts in the settlement choices of barnacles, with regards to the alterations that earlier settlers make to the benthic habitat. These settlement choices may be diagnostic of benchmarks in the recruitment window, which may be valuable information for purposes of predicting the total recruitment in that year's cohort.

\subsection{Acknowledgements}

My advisor, Jesús Pineda is a co-author on this manuscript. We thank D. Rothman and V. Starczak for discussion on statistical analyses and interpretation of the data. Heidi Blythe assisted with photographic analysis of barnacle abundance. Graduate fellowship support was provided to J.N.B. by the American Society for Engineering Education and the Academic Programs Office at the Woods Hole Oceanographic Institution. 


\subsection{Literature Cited}

Bertness, M. D., Gaines, S. D., Stephens, E. G. \& Yund, P. O. (1992) Components of recruitment in populations of the acorn barnacle Semibalanus balanoides (Linnaeus). Journal of Experimental Marine Biology and Ecology, 156, 199-215.

Caley, M. J., Carr, M. H., Hixon, M. A., Hughes, T. P., Jones, G. P. \& Menge, B. A. (1996) Recruitment and the local dynamics of open marine populations. Annual Review of Ecology and Systematics, 27, 477-500.

Connell, J. H. (1985) The consequences of variation in initial settlement vs. postsettlement mortality in rocky intertidal communities. Journal of Experimental Marine Biology and Ecology, 93, 11-45.

Crisp, D. J. \& Meadows, P. S. (1962) The chemical basis of gregariousness in cirripedes. Proceedings of the Royal Society of London. Series B, Biological Sciences, 156, $500-520$.

Crisp, D. J. \& Meadows, P. S. (1963) Adsorbed layers: the stimulus to settlement in barnacles. Proceedings of the Royal Society of London. Series B, Biological Sciences, 158, 364-387.

Desai, D., V. \& Anil, A. C. (2004) The impact of food type, temperature and starvation on larval development of Balanus amphitrite Darwin (Cirripedia: Thoracica). Journal of Experimental Marine Biology and Ecology, 306, 113-137.

Hawkins, S. J. \& Hartnoll, R. G. (1982) Settlement patterns of Semibalanus balanoides (L.) in the Isle of Man (1977-1981). Journal of Experimental Marine Biology and Ecology, 62, 271-283.

Hentschel, B. T. \& Emlet, R. B. (2000) Metamorphosis of barnacle nauplii: effects of food variability and a comparison with amphibian models. Ecology, 81, 34953508.

Hui, E. \& Moyse, J. (1987) Settlement patterns and competition for space. Barnacle biology (ed A. J. Southward), pp. 363-376. Balkeman, Rotterdam.

Jarrett, J. N. \& Pechenik, J. A. (1997) Temporal variation in cyprid quality and juvenile growth capacity for an intertideal barnacle. Ecology, 78, 1262-1265.

Jenkins, S. R. (2005) Larval habitat selection, not larval supply, determines settlement patterns and adult distribution in two chthamalid barnacles. Journal of Animal Ecology, 74, 893-904.

Kent, A., Hawkins, S. J. \& Doncaster, C. P. (2003) Popualtion consequences of mutual attraction between settling and adult barnacles. Journal of Animal Ecology, 72, 941-952.

Pineda, J., Hare, J. A. \& Sponaugle, S. (2008) Larval transport and dispersal in the coastal ocean and consequences for population connectivity. Oceanography, 20, 22-39.

Pineda, J., Starczak, V. \& Stueckle, T. A. (2006) Timing of successful settlement: demonstration of a recruitment window in the barnacle Semibalanus balanoides. Marine Ecology Progress Series, 320, 233-237.

Raimondi, P. T. (1990) Patterns, mechanisms, consequences of variability in settlement and recruitment of an intertidal barnacle. Ecological Monographs, 60, 283-309.

Stamps, J. A., Krishnan, V. V. \& Reid, M., L. (2005) Search costs and habitat selection 
by dispersers. Ecology, 86, 510-518.

Toonen, R. J. \& Tyre, A. J. (2007) If larvae were smart: a simple model for optimal settlement behavior of competent larvae. Marine Ecology Progress Series, 349, 43-61. 


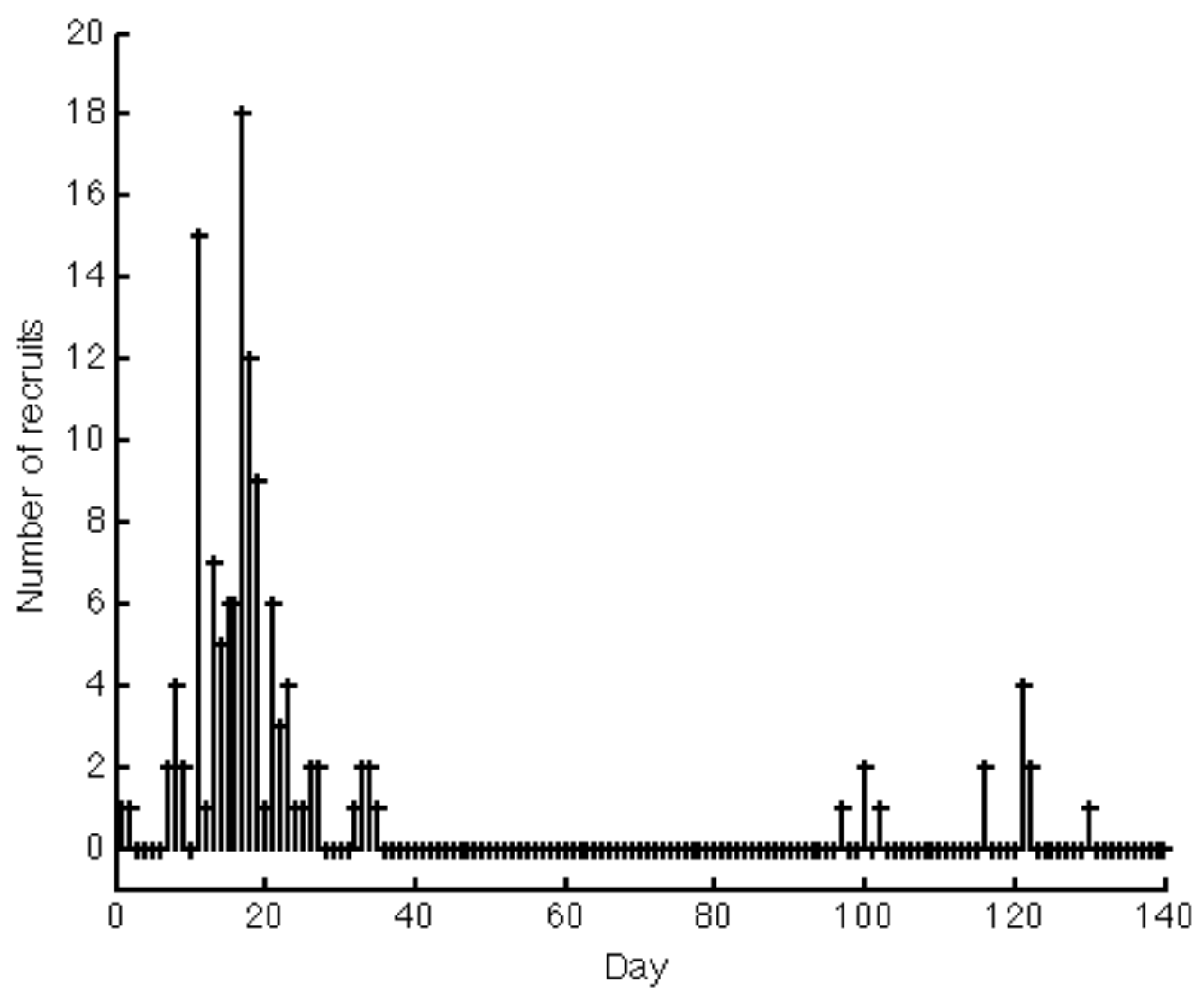

Fig. 1. Distribution of settlement dates of recruits in the 2006 cohort that settled on natural substrate quadrats. Recruits are defined as individuals surviving from settlement to adulthood on day 350, where day 1 was the first day with settlement. The heights of the stems in the stem-plot represent the total number of recruits that settled on a given day. 

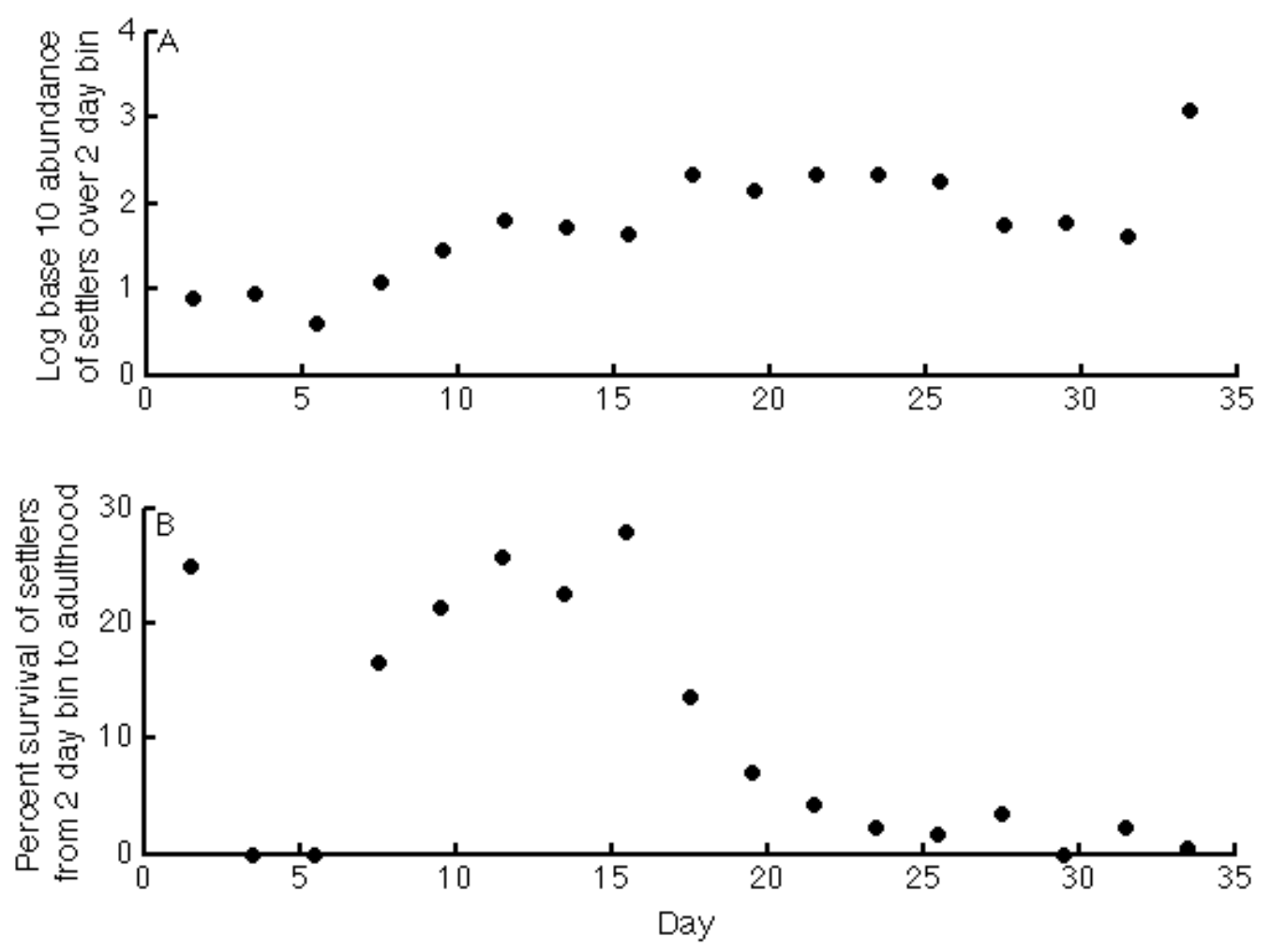

Fig. 2. Settlement and survival during the first recruitment window. The number of new settlers was measured daily among 12 natural substrate quadrats. The abundance was summed over the quadrats at intervals of 2 days (Fig. 2A.). The percent survival of those settlers until day 350 is summarized for each 2-day settlement bin (Fig. 2B.). 


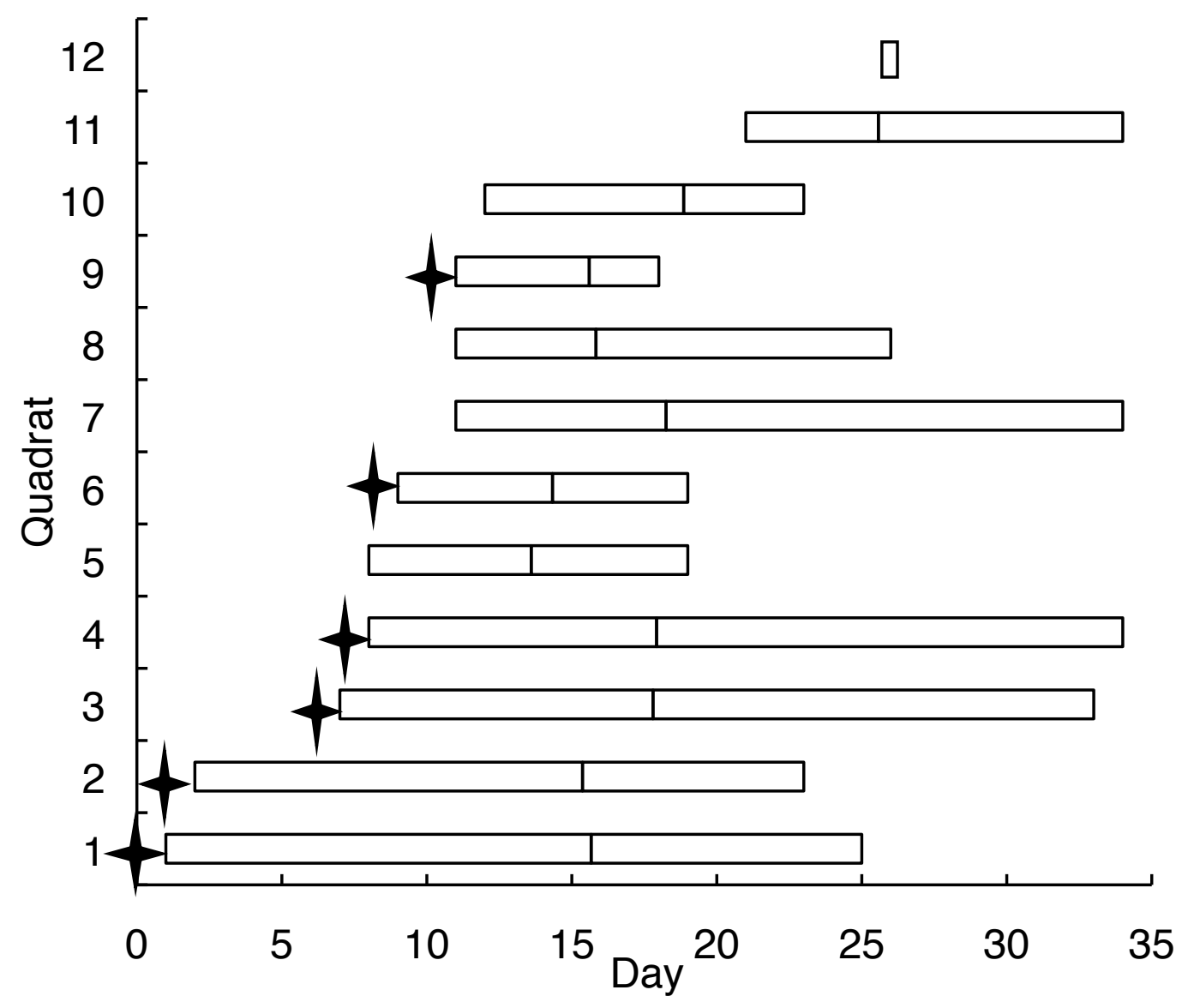

Fig. 3. First, mean and last day that recruits settled for each of the twelve natural substrate quadrats. The stars indicate cases when the first recruit is also the first or second settler. 


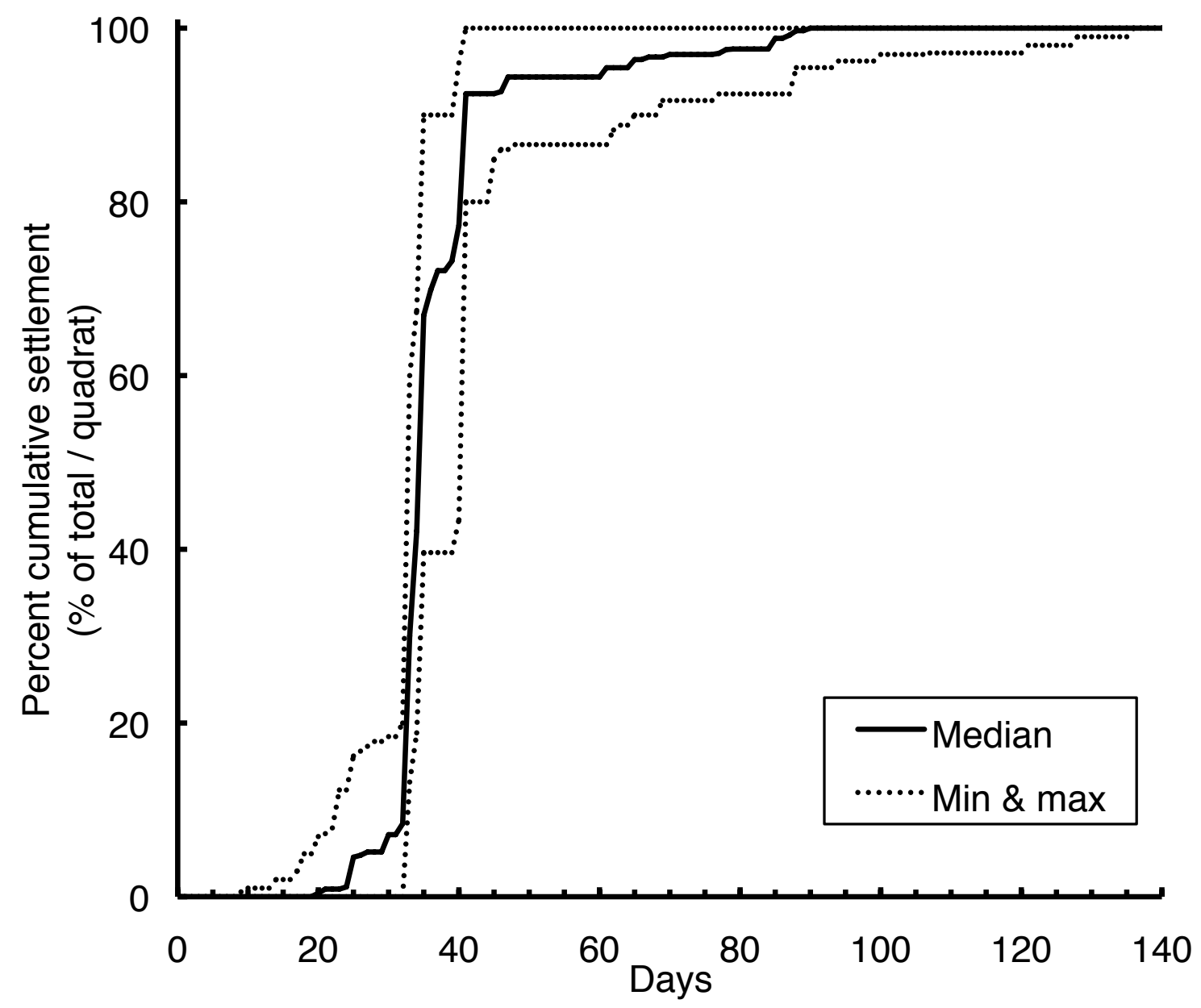

Fig. 4. Time-series of average percent cumulative settlement on settlement plates until day 140 in daily intervals. The minimum and maximum lines represent the limits of observed percentage cumulative settlement on any day in the time-series from among the 12 settlement plate quadrats. 


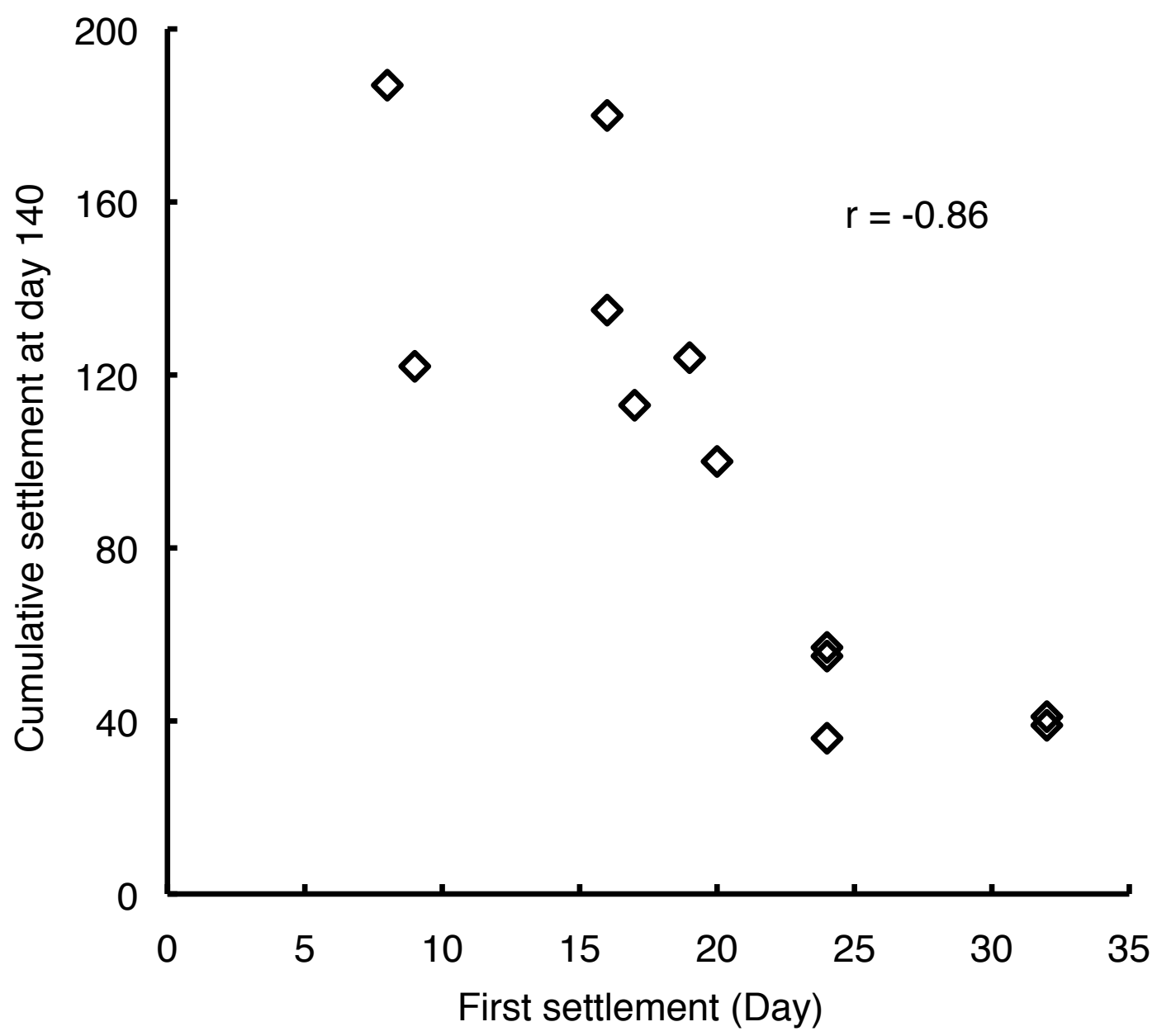

Fig. 5. Correlation between the cumulative settlement at the end of the settlement season with the day of first settlement among 12 settlement plates. Cumulative settlement was the sum of all settlers occupying the settlement plate between days 1 140. First settlement on plates ranged between days $9-33$. 


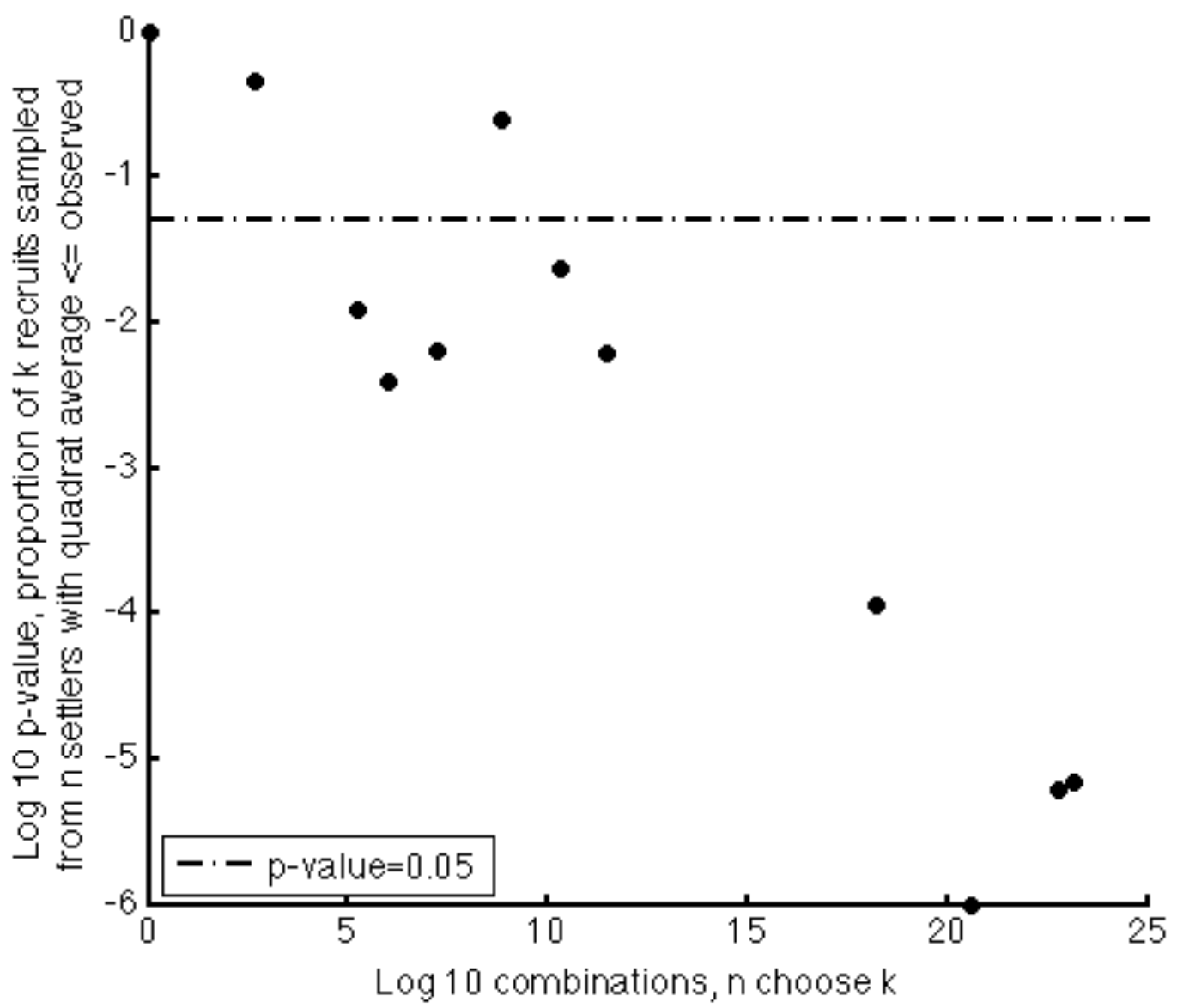

Fig. 6. Inference on preemption is limited by the number of null combinations of recruits among settlers. The p-value is the proportion of realizations for the theoretical recruit distribution that are smaller than or equal to the observed quadrat average. The $\mathrm{p}$-value is negatively correlated with the number of combinations from the theoretical distribution. This reflects the increasing power of the statistical test with the number of possible combinations. Therefore non-significant values may be explained by the low power of the test in cases where the number of recruits is too low or the number of combinations are insufficient to detect divergent patterns. 


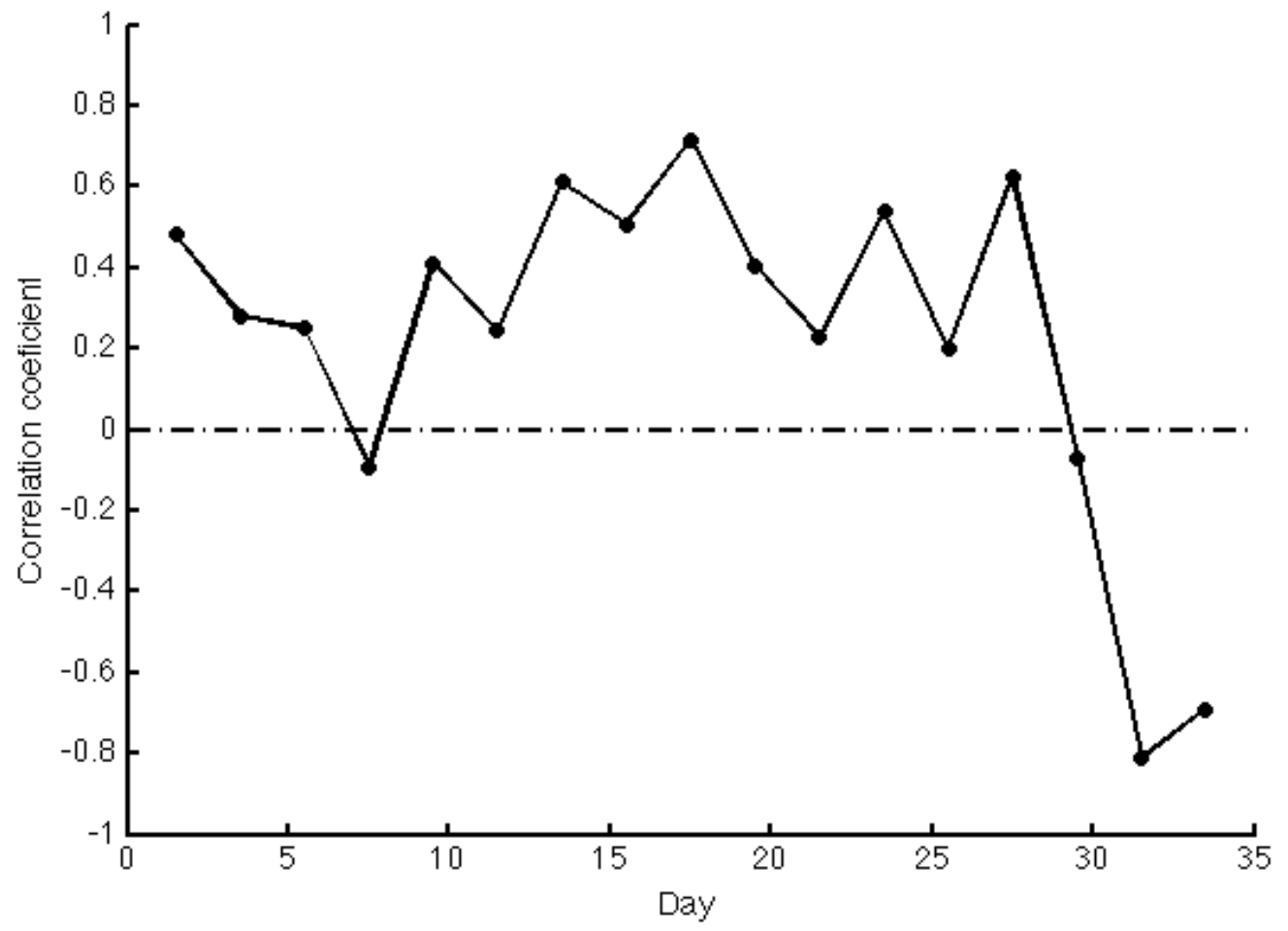

Fig. 7. Correlation between the log of the adult abundance in each quadrat with the log amount of settlement in each 2-day bin among the 12 natural substrate quadrats. 


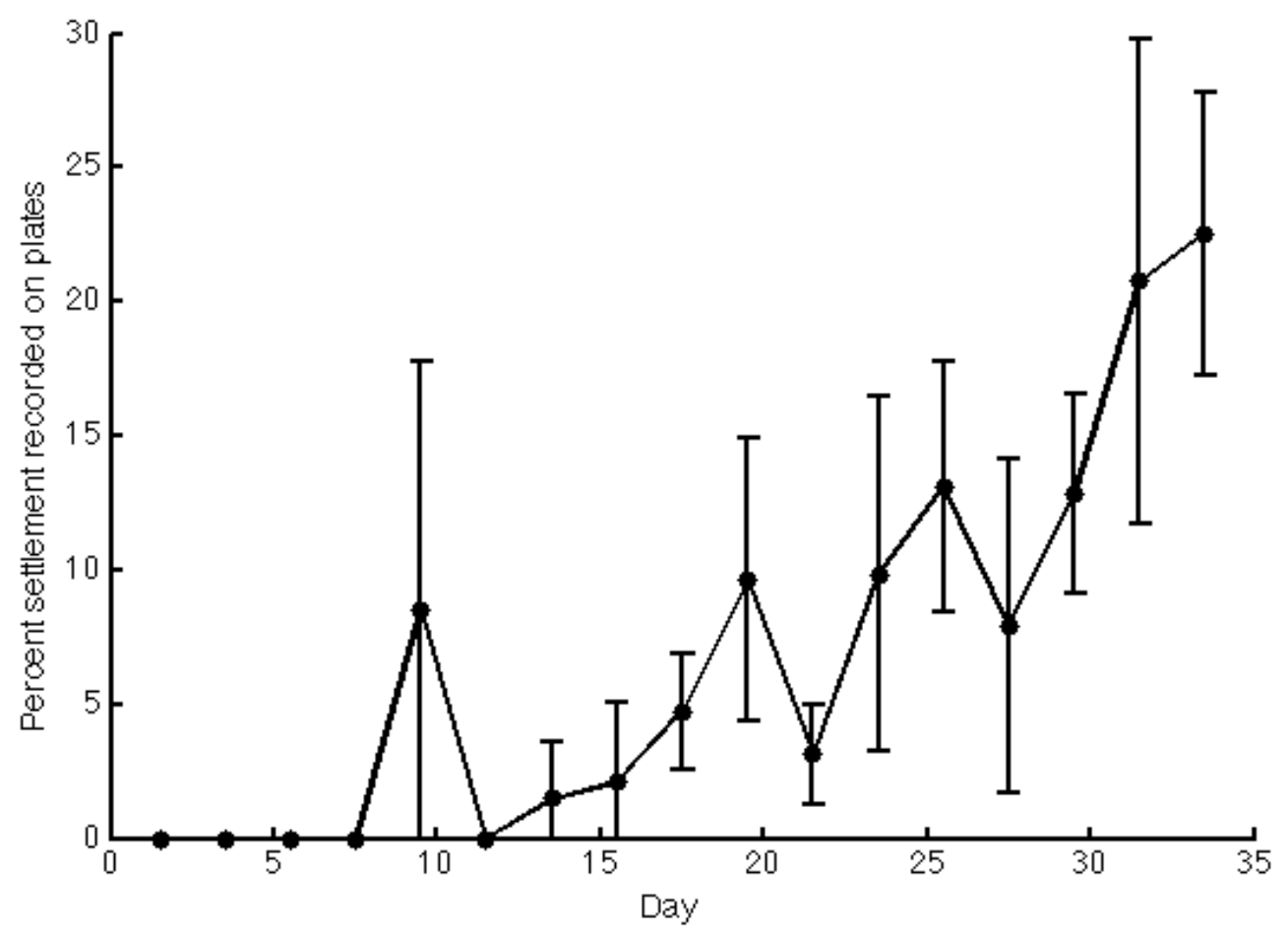

Fig. 8. More of the daily settlement occurred on settlement plates as time progresses during the first recruitment window. The proportion of settlement on plates gradually increases starting before day 14 through the end of the winter recruitment window. Error bars indicate the standard error $(n=12)$ of this settlement measure calculated from among the twelve settlement plates at two-day intervals. 


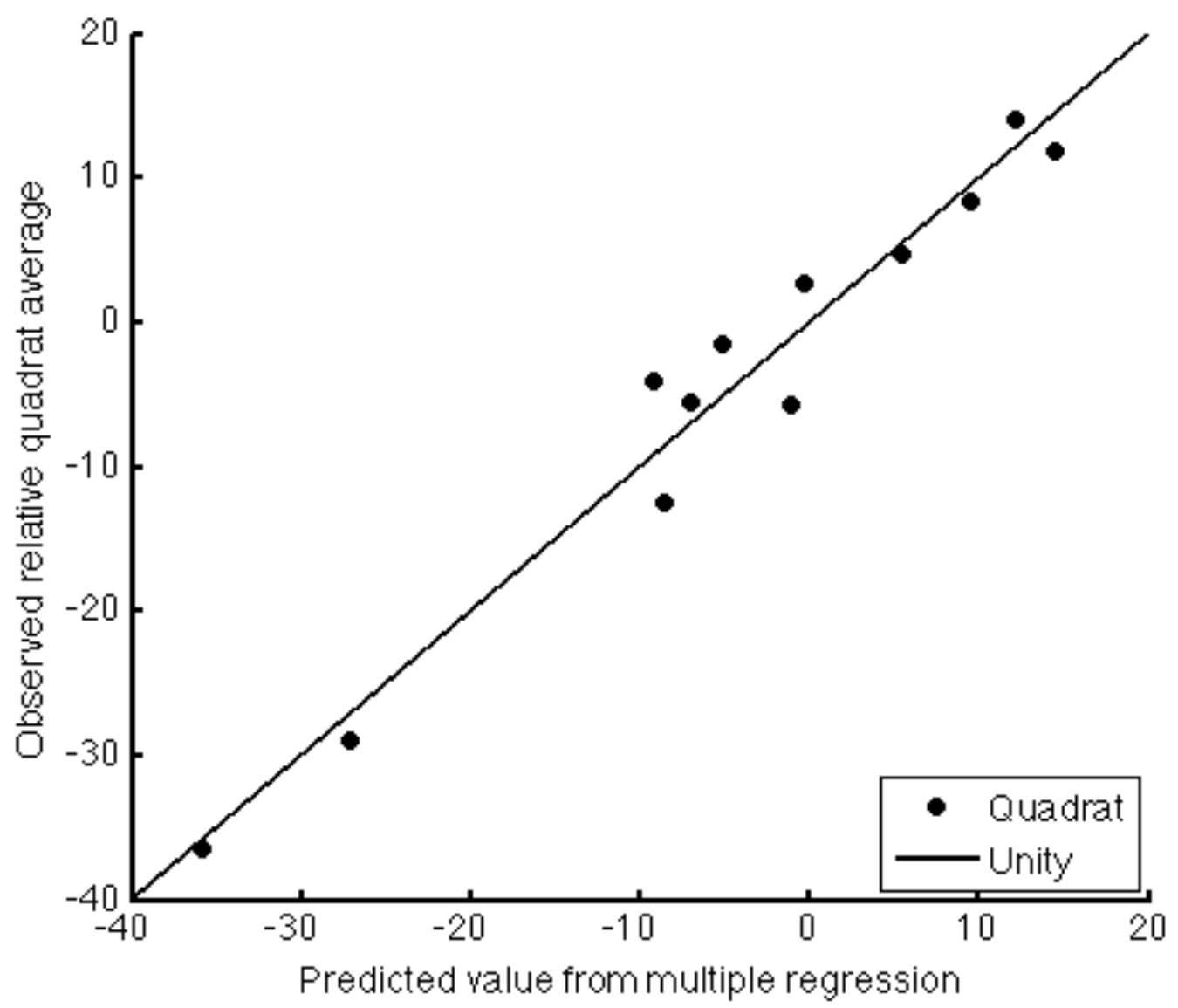

Fig. 9. Multiple regression explaining the relative quadrat average with adult density and the first day a recruit settled. The adjusted r-squared value was 0.95 . The f ratio was 107 and was significant with a p-value 5E-7. The intercept was not significantly different from zero, but the adult coefficient was estimated at 0.22 and significant with a p-value 1E-3. The coefficient for the first settlement date with recruitment was estimated at -1.7 with a p-value less than $5 \mathrm{E}-6$. 


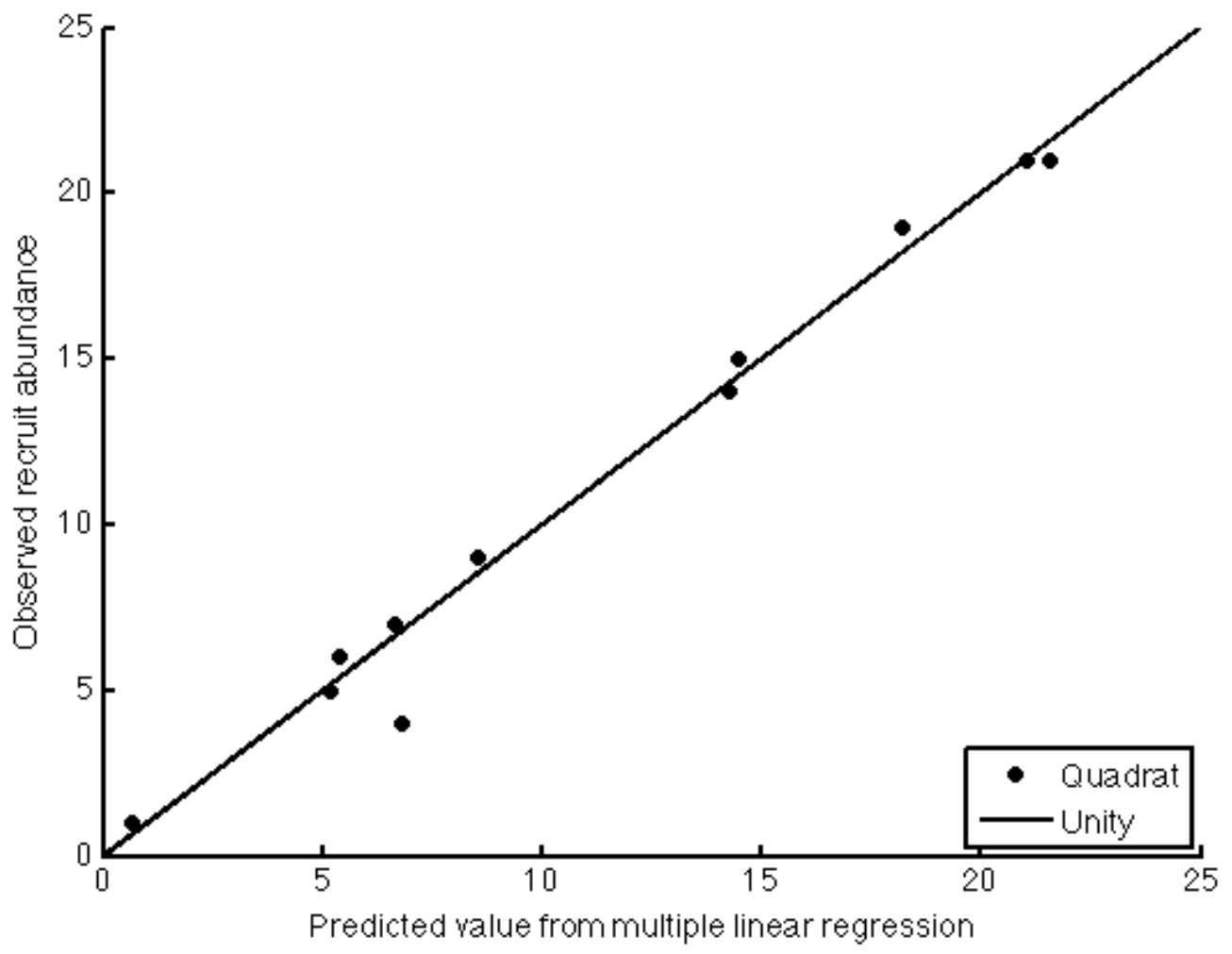

Fig. 10. Multiple regression explaining the number of recruits measured on day 350 after the start of the settlement season. The adjusted r-squared value was 0.967 . The $\mathrm{f}$ ratio was 88 and was significant with a p-value less than 5E-6. The intercept was -15.4 significantly different from zero. The adult abundance coefficient was estimated at 0.12 and significant with a p-value of 0.0002 . The coefficient for the day with first settlement was 1.1 and was significant with a p-value less than 0.001 . The coefficient for the day with first recruitment was -1.9 and was significant with a p-value less than $1 \mathrm{E}-4$. The coefficient for the mean day of recruitment was 2.0 and was significant with a pvalue less than 0.0001 . 


\section{Chapter 3}

\section{Wave energy drives settlement in the intertidal barnacle, Semibalanus balanoides}

\subsection{Abstract}

We observe a correlation between wave energy and barnacle settlement in a natural rocky intertidal site. The components of wave energy, namely swell and wind chop, are clearly distinguishable in the observations and can be related to different sources. The swell component originates from oceanic storms and regional winds, while the wind chop is locally generated on short time scales. The total wave energy is serially correlated with barnacle settlement over five tidal cycles, suggesting that the cyprids behaved much like passive particles and attached to the substrate in proportion to the wave energy. Passive behavior may have been caused by the freezing and thawing of seawater that preceded the period with settlement, and the use of such periods is suggested to be a novel approach in assessing the role of wave action and boundary layer processes on settlement.

\subsection{Introduction}

Wind stress produces waves that propagate to the near-shore environment. The energy that these waves bring to the intertidal habitat can affect the settlement rate of barnacle larvae by increasing the turbulence in the boundary layer and enhancing the transport of larvae to the substratum. It is possible that the amount of turbulence is a limiting environmental variable to the settlement rate of marine organisms (Denny and Shibata 1989). Therefore, wave energy has consequences for settlement and thus, recruitment of marine organisms, a topic of general interest to marine ecologists and of 
great importance to segments of our society dependent on benthic marine invertebrate resources.

The prevailing paradigm in larval ecology is that boundary layers at sub meter length scales control the transport of larvae to the benthos (Nowell and Jumars 1984; Abelson and Denny 1997). This hypothesis has been supported in the laboratory setting where the settlement of marine larvae was measured in pipes that have well characterized boundary layer properties. An enhanced settlement rate occurred with increasing amounts of turbulence in the experimental boundary layers (Eckman and Duggins 1998). The hypothesis was also supported in the field using sticky plates that keep cyprids from exhibiting substrate rejection behavior, therefore approximating the contact rate of larvae with the substratum (Jonsson et al. 2004).

Mechanisms of marine invertebrate settlement are complicated, because of the influence of multiple factors. For example, boundary layers may serve as a cue for settlement (Mullineaux and Butman 1991) as much as the mechanism of transport itself. Disentangling sources of settlement variability often requires ingenious experimental tests. One study compared settler attraction to adults versus plaster replicas that would create a similar boundary layer disturbance (Miron et al. 1996). The authors assessed the mechanism of gregarious settlement by conspecifics cues, and found that it was most likely of chemical origin and not physical in origin. Experimental tests such as these demonstrate how larval behavior modifies the distribution of settlers despite the role of boundary layers on the transport of larvae to the benthic habitat. By contrast, the approach that we take assesses how settlement patterns are influenced by variability in 
the boundary layer, which for the rocky intertidal primarily originates from variability in wave action. Wave action is a physical process like few others since it can affect larval transport in close proximity to the rocky intertidal. Yet, wave energy varies at spatial scales that are larger than what is typically considered in studies that focus directly on boundary layer dynamics. This provides a top down perspective on the cascading effects of environmental variability on settlement process.

Wave energy can be studied at distinct frequencies. The benefit of this approach is that different frequencies are associated with distinct sources in the marine environment, and we can start to disentangle the contributions to wave energy in the rocky intertidal environment. The swell signal in wave time-series can represent waves produced far from the shoreline due to the ability of this frequency of wave to propagate long distances. However, part of the swell signal also results from wind forcing nearby. Identifying wind conditions that create the sea state at a location can greatly enhance our ability to predict this contribution to swell energy. Finally, wind produces high frequency waves, also known as wind chop, in the near-shore environment. The kinds of waves that propagate to a shoreline combine to generate the wave energy realized at the shore that affects the settlement of marine invertebrates. Since these waves are produced at different characteristic time and length scales, by analogy it should be possible to consider the possible time and length scales at which marine invertebrate settlement will vary. 


\subsection{Methods}

We deployed a Triton Acoustic Doppler Velocimeter equipped with a pressure sensor (SonTek Triton, San Diego, CA USA) in the intertidal zone at Gardiner beach, Woods Hole (Figure 1). It collected a burst of 52 wave-series samples every twelve hours starting at 18:00 hours on 16 February 2007 (day 47 for reference to later discussion). Samples were composed of $2 \mathrm{~Hz}$ pressure records that were 512 seconds long. We designed this sampling scheme to maximize coverage of high tides during a spring tide series occurring over the ten-day deployment. At low tide, the instrument was completely exposed, as the elevation of the pressure sensor was $70 \mathrm{~cm}$ above Mean Low Low Water (MLLW) as determined by surveying. When the duration of the burst overlapped with periods of time when the pressure sensor was exposed, these samples from the burst were not usable for wave series analysis. The best coverage occurred during the middle of the deployment when we collected four hours or more of quality controlled wave-series data at each tide (Elgar et al. 2001; Elgar et al. 2005). Figure 2 graphically depicts the timing of samples in each burst, and the samples that were selected for analysis because they were recorded at a period of time when the pressure sensor was continually submersed in seawater. We could detect when the pressure sensor was not completely submersed because the wave troughs appeared to be truncated in the raw pressure record.

There was a 40 second pause between each wave series sample, which is when the sensor recorded temperature and some other routine measurements. We subsampled periods of time when we knew the instrument was completely submersed to analyze the 
seawater temperature from the instrument's thermometer (Figure 2). We confirmed the presence of ice on the surface of the water when we visited the site during the low tide while we were taking settlement photographs. There were recurring bouts of seawater freezing for the first half of the deployment. Frozen seawater most likely caused the pressure sensor to malfunction for an entire tidal period at the end of day 51 . We have quality controlled wave series data from all the other tides during the deployment.

Level loggers (Onset corporation, Bourne, MA) were deployed at Gardiner beach, attached to the same boulder as the ADV from the winter of 2007 . We collected a wave record for every tide starting on March $28^{\text {th }}$ through April $30^{\text {th }}, 2008$. The loggers were set to record 5120 pressure measurements at $1 \mathrm{~Hz}$ timed to correspond with the peak of each high tide.

We analyzed sea surface elevation from pressure measurements. Due to the relatively low frequency of these measurements, sea surface elevation was taken to be a direct function of the mass of seawater and the acceleration due to gravity. For the ADV data, we removed the mean and detrended the data, then cut each burst of data into 512second Hanning windows with $75 \%$ overlap (Emery and Thomson 2004). For the level logger data, we first subtracted the sea surface elevation pressure measured at the Otis Airforce Base to find the sea surface elevation, and then removed the mean, detrended, and cut the record into Hanning windows with $75 \%$ overlap as for the AVD data, except each tide had 5 windows that were 1024 seconds long. The Hanning windows were Fast Fourier Transformed (FFT), we merged three adjacent frequency bands to improve the spectral estimates while still maintaining high frequency resolution, and we calculated 
the average spectral estimates for each frequency band among all the Hanning windows in a burst. The degrees of freedom for the winter 2007 ADV measurements ranged between 30 and 210 , because it is related to the total duration of the timeseries, which varied between tides due to exposure of the pressure sensor during low tides. For the level loggers, all measurements had 30 degrees of freedom. It is possible to integrate the spectral bands over a range of frequencies to identify variance from particular components of interest (Emery and Thomson 2004), and we identified the frequency ranges $f a$ and $f b$ that capture the peaks in the Swell and Chop signal variance by visually inspecting the power spectra (Equation 1). We observed a distinct swell signal between periods 5 to 20 seconds. Therefore, we used frequency range limits of $\mathrm{e}^{-1.5}$ and $\mathrm{e}^{-3} \mathrm{~Hz}$. A Chop signal was observed between the periods 1 and 5 seconds, and the corresponding frequency range was between $\mathrm{e}^{0}$ and $\mathrm{e}^{-1.5} \mathrm{~Hz}$. In addition, we calculated the total variance between periods 1 and 20 seconds corresponding to a frequency range between $\mathrm{e}^{0}$ and $\mathrm{e}^{-3} \mathrm{~Hz}$ for the adv measures. Level logger measuremnts of waves corresponded to periods between 2 and 20 seconds due to the distinct sampling interval, corresponding to a frequency range between $\mathrm{e}^{0} / 2$ and $\mathrm{e}^{-3} \mathrm{~Hz}$.

$\sigma^{2}\left(f_{\text {Swell,Chop }, \text { Total }}\right)=\int_{f_{a}}^{f_{b}} f \times S_{y y}(f) d[\log f]$

Wave Energy $=.5 \times \rho \times g \times \sigma^{2}$

Significant wave height (Hsig) was also calculated for Swell and Chop. It is a more intuitive measure of wave action, as it has the same units as sea surface elevation. Using the estimate of wave energy from Equation 1, we calculated Hsig (Equation 3). 
$H \operatorname{sig}($ Swell,Chop $)=4 \times \sigma\left(f_{\text {Swell,Chop }}\right)$

We compared environmental records, including wind conditions and oceanic swell, to describe the sources of swell energy measured at Gardiner Beach. Significant swell height estimates were obtained from the Martha's Vineyard Coastal Observatory (MVCO) for the period of time overlapping with our pressure sensor deployments. MVCO wave data were collected at a 12-meter deep underwater station off the south shore of Martha's Vineyard (Figure 1). These data were reported at twenty-minute intervals. We identified the significant swell height estimate from the MVCO data that was closest in time to the mean time of each tidal pressure measurement. Wind data were obtained from the Otis Air Force Weather Station located at the far end of Buzzards Bay (Figure 1). Wind speed and direction measurements were available in one hour or better increments for the duration of the pressure sensor deployments. The wind data was decomposed into a 240-degree positive component corresponding to the arrow in Figure 1. Wind in this direction would contribute most to Buzzards Bay swell production since it has the longest fetch. The duration between subsequent reported wind values served as an increment to conduct a weighted averaged of the wind speed. We calculated the average wind speed for a range of averaging intervals between one hour and eighty hours corresponding to a variable period of time prior to the Gardiner beach significant swell height estimate. Then we found the correlation of each average of wind speed with the significant swell height, and compared the regression statistic to find the averaging interval with the highest correlation. A multiple regression model was computed to examine whether Gardiner beach significant swell height could be 
explained by oceanic Significant Swell Height measured at MVCO and the time averaged wind component. The coefficients of the linear regression were then used to predict the expected swell wave height given the oceanic swell and local wind measurements concurrent with the month long level logger deployment in the spring of 2008.

We collected barnacle settlement data to measure how settlement changes with patterns of wave energy. Quadrats were located on boulder surfaces and marked with screw anchors that were driven into holes drilled three months prior. The screw anchors were positioned to mark the bottom left and top right corner of each quadrat, defining a 3.5 by $4 \mathrm{~cm}$ surface that barnacles could settle on. Quadrats were strategically located at an elevation of $40 \mathrm{~cm}$ above MLLW to control for tidal inundation, and we stratified quadrats onto most boulders distributed along a 20 meter shoreline at Gardiner beach (see chapter 4 for more information on the sampling areas). We covered all surfaces of the boulders evenly with quadrats, without respect to orientation of the normal angle of the bolder surface from the alongshore axis or the zenith. Prior to the deployment we selected 10 quadrats at random from a pool of 60 to create the first set of natural substrate settlement surfaces. In the afternoon of day 50 we selected another 10 quadrats at random from the remaining 50 quadrats for a distinct set of natural substrate settlement surfaces. The day before settlement measurements were to commence in each set of ten quadrats, each quadrat was scraped creating a 1.5 by $2 \mathrm{~cm}$ clearing in the center of the rock surface using a flat head screwdriver. We took digital photos of the quadrats at all of the low tides throughout the pressure sensor deployment starting on 
day 50, which provided only one settlement measure for the first set of ten quadrats. We counted the total number of cyprids settling on the 3.5 by $4 \mathrm{~cm}$ surface as determined by visual comparison of sequential digital photographs. A total settlement count for each tide was calculated by summing the number of individual settlers observed over all 10 quadrats during each prior tidal cycle. We were unable to photograph quadrats after tides on days 55 and 56 because a strong NW wind picked up and boulder surfaces remained splashed with seawater throughout these low tides. Since settlement monitoring was disrupted during this period, the settlement quantity was determined by comparing photos from the evening of day 54 with the evening of day 56 .

For the spring of 2008 deployment, all 60 quadrat surfaces were cleared as before, and settlement was recorded using photographs collected on three consecutive tides between day 98 and 99 of 2008 . The settlement rate was standardized on a 10 quadrat area basis covering $140 \mathrm{~cm}^{2}$ in order to compare these settlement rate measures with those collected on 10 quadrats in the winter of 2007.

\subsection{Results}

There were two freezing events during the winter 2007 deployment that are worth noting here (Figure 2). The seawater temperature record suggested freezing conditions on the morning of day 49 . We observed sea ice floating on the seawater surface during low tide, and much frozen seawater lay stranded on the shore as well. The seawater warmed, and no sea ice was present during the low tide on day 50. A second freezing event occurred on day 51 and sea ice was visible on the morning and afternoon low tides. The seawater warmed again on day 52 , and we observed that most 
of the sea ice melted and was absent from the seawater surface for the remainder of the deployment through day 57.

Significant wave height for the swell component of our pressure wave-series was most highly correlated with a 37 hour running average of the 240-degree wind component. This average of wind and the oceanic swell both contributed to the swell recorded at Gardiner beach, as indicated by the significance of the parameters for the wind and MVCO swell variables in the multiple linear regression and the good fit of the regression model to the observed swell (Table 1, Figure 3). The linear regression coeficients were then applied to predict the wave energy measured in the spring of 2008. We found that this swell wave model could explain $50 \%$ of the variability in the spring 2008 month long record of swell, and there was a significant regression between the predicted and observed swell wave height values (Rsq: 0.51, Fratio: 60.35, P-value < 2E-10).

We recorded a serial correlation between settlement and wave energy (Figure 4) corresponding to a series of five tidal cycles starting with the second tide on day 52 and continuing until the beginning of day 55. We were unable to record settlement on day 55 after the fifth tidal cycle because of the high wave action that was caused by a strong NW wind that picked up almost synchronously with the end of day 54 . We did record settlement on the evening of day 56 when the NW wind subsided, and, given the absence of settlement during other periods in the record when the chop wave heights were so elevated, we suggest that the settlement that we recorded on the evening of day 56 corresponds to settlement that occurred on the last tide of the five tidal cycle series at 
the end of day 54. Settlement could have been inhibited between day 55 and the morning of day 57, and the times when barnacles did settle seems to have corresponded with tides when the chop waves had relatively low energy, in the same range of wave heights as the swell waves (Figure 3). One explanation is that when chop waves had elevated wave heights during this deployment, they were an order of magnitude higher than the swell, and the overall wave action could have inhibited barnacle settlement. Evidence for settlement inhibition comes from the settlement rate measurements from the spring of 2008 occurring during two days with onshore winds and intermediate wave chop height values. On the first tide, chop values were in the range of those zero settlement days recorded during the winter of 2007, and there seemed to be an inhibition of settlement compared to the settlement rate on the following tide. On the second tide, the settlement rate increased substantially, and the difference in settlement from the previous tide may be due to a threshold physical limit to barnacle settlement from high chop wave energy (Fig. 5). Unlike open ocean rocky intertidal habitat, Gardiner beach is located in a low wave energy environment (Jackson et al. 2002), and swell wave energy can not reach the same level of energy as the chop waves. Chop wave energy was highly dynamic and may be an important physical feature for settler inhibition at this site.

We fit a linear regression model to the serially correlated wave energy and settlement data during low chop wave energy days from the winter deployment in 2007 (Figure 5). Since we took repeated measures of settlement on subsequent tides and used the same ten quadrats, the linear regression is pseudo replicated, limiting the inference 
of the relationship between these two variables. We used the settlement value recorded on day 50 as an independent data point to test this linear model, because it was recorded well before the five tide series using a different set of randomly selected quadrats. The observed settlement on day 50 was within a range of plausible values provided by the $90 \%$ prediction interval of the settlement count given the measured wave energy on day 50 (Figure 5).

We calculated the wave power spectra and observed distinct chop and swell signals for each of the tides during the winter of 2007 with settlement, where each spectral estimate had better than 160 degrees of freedom (Figure 6). Though wind chop was relatively calm during these tides, a visual inspection of the wave power spectra, taking the area under the curve, indicates that wind chop still contributed more energy on some of the tides (Figure 6, C and F) and contributed an equal amount of energy on other tides (Figure 6, D and E). There were only two tides where most of the wave energy was contributed from the swell component (Figure 6, A and B). These data indicate that the bulk quantity of wave energy during tides with settlement resulted from varying combinations of oceanic swell, wind generated sea state in Buzzards Bay and an across shore wind component that creates chop waves.

\subsection{Discussion}

We have measured three sources of wave energy that contribute to turbulent mixing and contact of cyprid larvae with a substrate in the rocky intertidal. First, ocean swell travels a long distance and originates from a variety of sources at regional to whole ocean basin scales. This oceanic signal was recorded by the MVCO wave sensor 
at a station 20 kilometers south of Buzzards Bay. The high correlation with Buzzards Bay swell indicates that swell energy varies little at this scale. None the less, the significant swell height was recorded at levels two orders of magnitude less at Gardiner beach, most likely due to an depth limited maximum wave height typical of shallow water depths (Tucker 1991).

A running average of the along bay wind component provides an indication of the scales at which wind variability contributes to Buzzards Bay swell. The maximum correlation with measured swell occurs at a thirty-seven hour period. Variability is easily noticeable from the time series at this period, but wind is also highly variable at higher frequencies. This time average acts as a low pass filter emphasizing low frequency variability in the wind data, reflecting weather systems that move into and out of the Buzzards Bay region. Therefore, the sea state that is generated by wind over Buzzards Bay is not entirely different from oceanic swell produced by the same weather systems in the Atlantic Ocean. Buzzards Bay is distinct, however, in terms of the wind directions that contribute to the sea state, since the direction of maximum fetch lies along its main axis corresponding to the 240 degrees wind component. By contrast, a wider range of wind conditions in the Atlantic could produce swell that propagates to Buzzards Bay. The fact that the 240 degrees wind component is a significant descriptor of significant swell height in Buzzards Bay suggests that this is an important source of wave energy at our rocky intertidal site.

Finally, an important source of wave energy is locally produced wind chop. Wind chop was present at our intertidal site during the deployment, and it was most 
pronounced on days 50 and 51 and days 55 through 58. Chop waves were also the predominant waves contributing to wave energy during two tides where we recorded barnacle settlement during the spring of 2008. During these periods a strong wind picked up from offshore, and wave heights were an order of magnitude higher than during the settlement periods of the winter of 2007 (Figure 3). Tides with settlement during the winter of 2007 had chop waves that were relatively low, but it was still an important component of the wave energy (Fig. 6).

We believe that there is a simple explanation for these data. The oceanic swell and wind in the Buzzards Bay area created wave energy at our rocky intertidal site. The wave energy enhanced the turbulence in the boundary layer. Since larvae were present in the water column, this turbulence transported them to the rock surfaces where they could attach to quadrats and settle. This could explain why the wave energy was highly correlated with settlement rates above zero that we observed in the winter of 2007. Previous field work with another barnacle has demonstrated this link (Jonsson et al. 2004). The settlement rate appeared to increase linearly with the wave energy forcing for tides with low wave energy values, while the settlement rate appeared to be inhibited during high wave energy tides. Chop waves seemed to have played a particularly important role in settler inhibition, since this was the primary source of wave energy during high wave energy days. This is the first field study for the barnacle, Semibalanus balanoides, that attempts to address the role of wave energy on the settlement rate. These results indicate that the chop component of the physical forcing plays a unique role in settlement inhibition. Low to intermediate chop wave energy contributes to 
enhancing settlement rate. Swell wave energy is a longer time and spatial scale source of physical forcing that drives the swell wave energy, which also contributes to enhancement of the settlement rate.

Barnacle settlement rate is controlled by a variety of physical and biological processes. We have observed that settler competition drives the timing and location of barnacle settlers through behavioral choices (Chapter 2). Further, habitat choice affects the spatial distribution of settlement (Wethey 1984; Bertness et al. 1992). However, it is plausible that barnacles that settled during the winter deployment acted like passive particles. The apparent lack of cyprid behavior might relate to the freezing periods on day 49 and day 51 (Figure 2). It has been observed that when barnacle larvae freeze and then thaw, they lose their propensity to discriminate between settlement substrates (Pineda et al.2005). If barnacles were frozen on days 49 and 51 and thawed on the following days, they would be able to resume settlement as we observed on day 50 and the afternoon tide of day 52. Since the offshore winds that produced high wave chop also caused sea ice to accumulate on the shoreline, we think it is plausible that the barnacles that settled following these freezing periods at Gardiner beach were caught in the sea ice and possibly rafted to the shoreline while still frozen. To reproduce this observation, it would be necessary to record wave action and settlement after a distinct bout of freezing and warming. This prescription is a new tool in addressing the importance of boundary layer process in the recruitment of marine invertebrates. In addition, the results presented here represent an important supporting observation for the role of wave action in barnacle settlement. 


\subsection{Acknowledgements}

Jim Thomson was a Joint Program student when we first proposed this research, and he is now a faculty member at the Applied Physics Lab, at the University of Washington. He along with my advisor, Jesús Pineda are co-author of this chapter. We thank Britt Raubenheimer and Steve Elgar for loaning us the Sontek Triton and Peter Schultz and Levi Gorrell for calibrating, programming, deploying and recovering the data from the instruments. Peter Schultz was invaluable in helping design the stand to deploy the Sontek Triton. We recognize Martha's Vineyard Coastal Observatory for significant wave height data. Support for this research was provided by the Coastal Ocean Institute at the Woods Hole Oceanographic Institution. We are grateful to Heidi Blythe for field assistance and lending her expertise with GIS.

\subsection{References}

Abelson, A., and M. Denny. 1997. Settlement of marine organisms in flow. Annual Review of Ecology and Systematics 28: 317-339.

Bertness, M. D., S. Gaines, E. G. Stephens, and P. O. Yund. 1992. Compoonents of recruitment in populations of the acorn barnacle Semibalanus balanoides (Linnaeus). Journal of Experimental Marine Biology and Ecology 156: 199-215.

Denny, M. W., and M. F. Shibata. 1989. Consequences of surf-zone turbulence for settlement and external fertilization. American Naturalist 134.

Eckman, J. E., and D. O. Duggins. 1998. Larval settlement in turbulent pipe flows. Journal of Marine Research 56: 1285-1312.

Elgar, S., B. Raubenheimer, and R. T. Guza. 2001. Current meter performance in the surfzone. Journal of Atmospheric and Oceanic Technology 18: 1735-1746.

---. 2005. Quality control of acoustic Doppler velocimeter data in the surfzone. Measurement Science and Technology 16: 1889-1893.

Emery, W. J., and R. E. Thomson. 2004. Data Analysis Methods in Physical Oceanography. Elsevier.

Jackson, N.L., K.F. Nordstrom, I. Eliot, G. Masselink. 2002. 'Low energy' sandy beaches in marine and estuary environments: a review. Geomorphology 48: 147162.

Jonsson, P. R., K. M. Berntsson, and A. I. Larsson. 2004. Linking larval supply to recruitment: flow-mediated control of initial adhesion of barnacle larvae. Ecology 85: 2850-2859.

Miron, G., E. Bourget, and P. Archambault. 1996. Scale of observation and distribution of adult conspecifics: their influence in assessing passive and active settlement mechanisms in the barnacle Balanus crenatus (Brugiere). Journal of Experimental Marine Biology and Ecology 201: 137-158.

Mullineaux, L. S., and C. A. Butman. 1991. Initial contact, exploration and attachment of barnacle (Balanus amphitrite) cyprids settling in flow. Marine Biology 110: 93-103.

Nowell, A. R. M., and P. A. Jumars. 1984. Flow environments of aquatic benthos. Annual Review of Ecology and Systematics 15: 303-328. 
Pineda, J., C. DiBacco, and V. Starczak. 2005. Barnacle larvae in ice: survival, reproduction, and time to postsettlement metamorphosis. Limnology and Oceanography 50: 1520-1528.

Tucker, M. J. 1991. Waves in Ocean Engineering, 1st ed. Ellis Horwood.

Wethey, D. S. 1984. Spatial pattern in barnacle settlement: day to day changes during the settlement season. Journal of the Marine Biological Association of the United Kingdom 64: 687-698. 
Table 1. The Buzzards Bay swell model regression parameters fit to the winter 2007 ADV data. Both the local wind and the oceanic swell parameters are significant at a 95\% level of confidence.

\begin{tabular}{|l|c|c|}
\hline & Parameter & $95 \% \mathrm{CI}$ \\
\hline Y intercept & 0.88 & $-2.68,4.44$ \\
\hline Wind Speed, $\mathrm{m} / \mathrm{s}$ & 2.1 & $1.1,3.0$ \\
\hline Hsig Swell MVCO, cm & 0.051 & $0.009,0.093$ \\
\hline
\end{tabular}




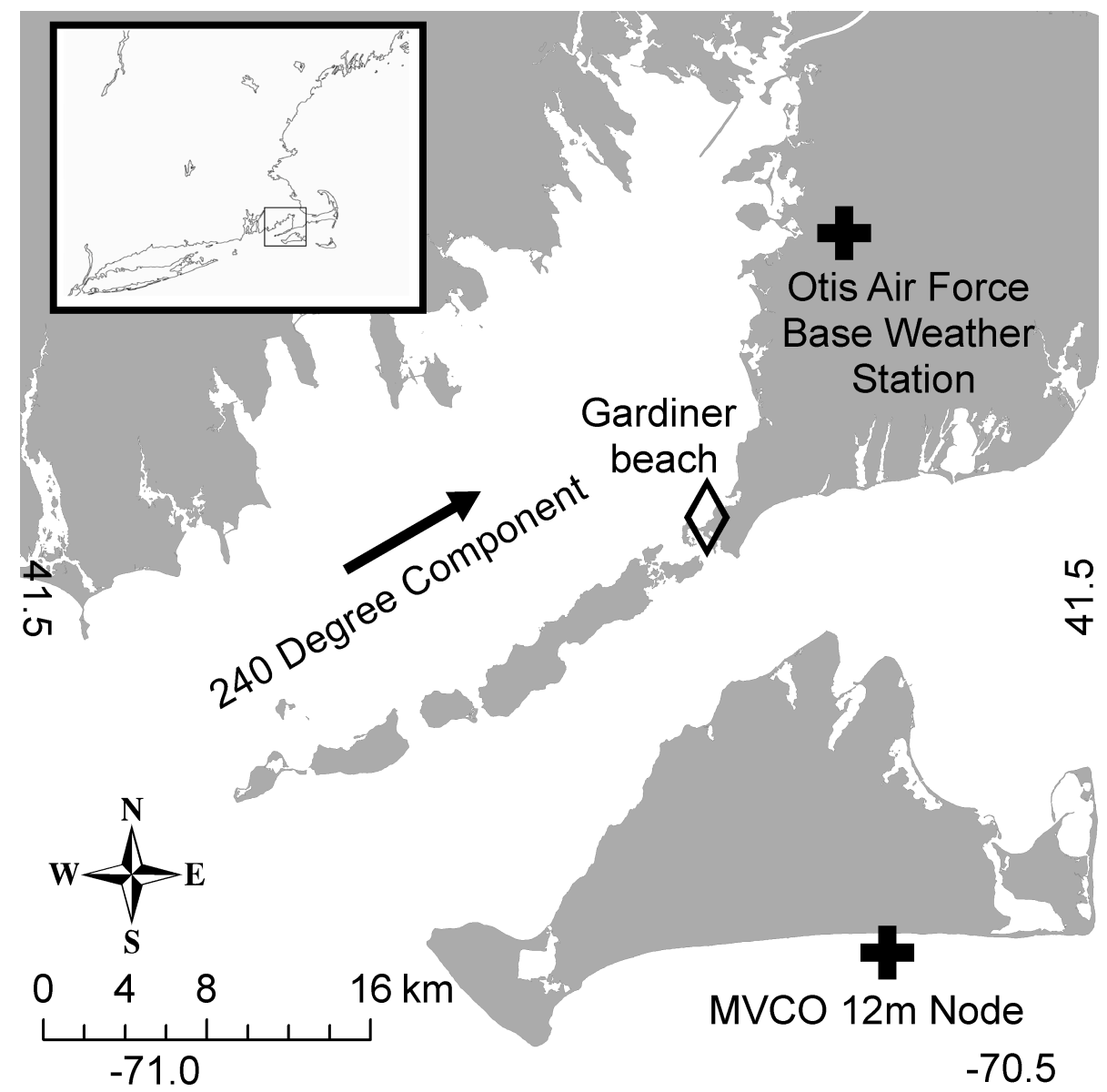

Fig 1. Study area. We deployed a Sontek Triton ADV and later an Onset level logger at Gardiner beach. The Martha's Vineyard Coastal Observatory (MVCO) 12 meter node is where the oceanic swell data were collected. Otis Air force Base weather station is located at the lee side of Buzzards Bay, in a prime location to record the strength of the wind in the 240-degree component that we analyzed to describe the production of swell waves in Buzzards Bay. 

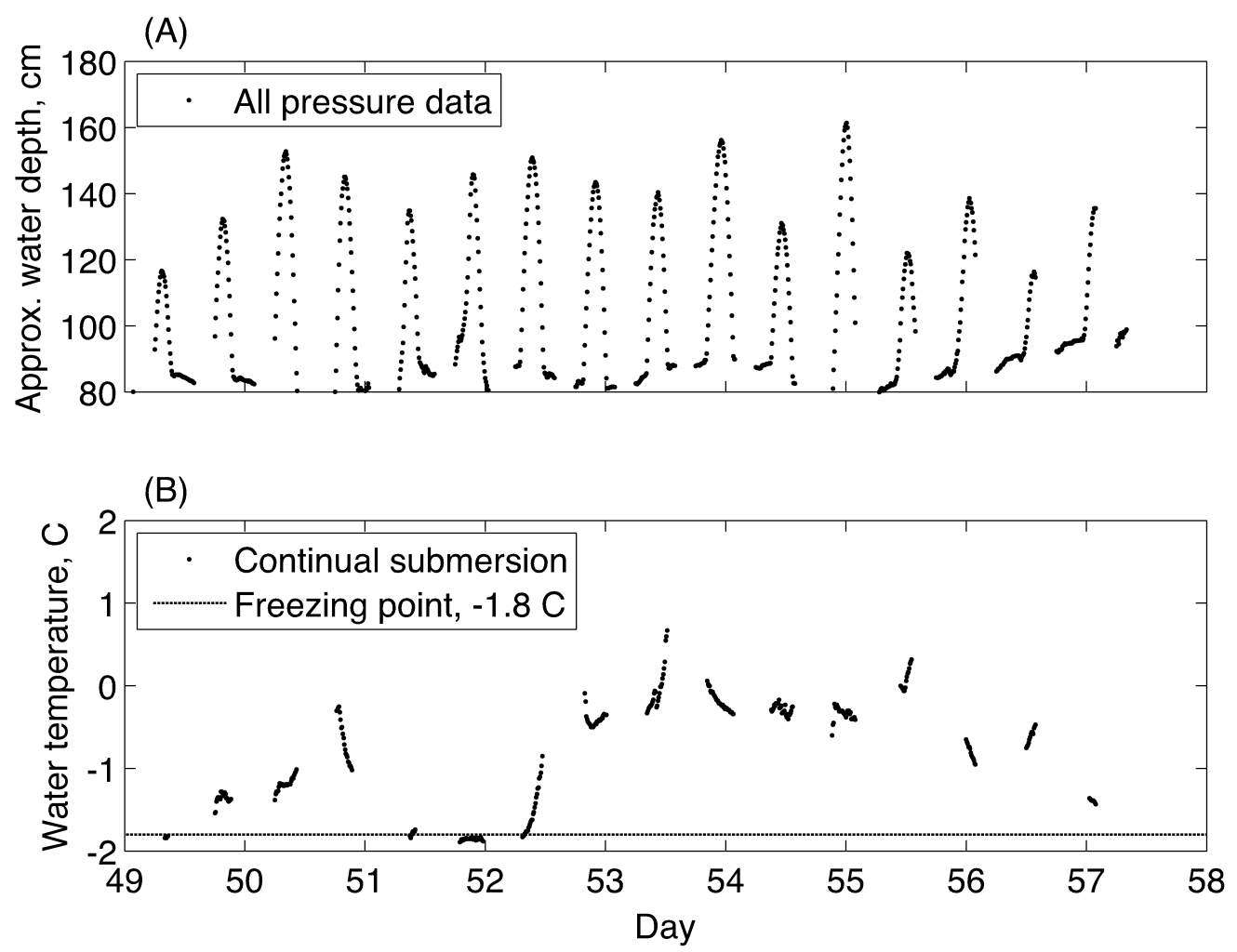

Fig 2. (A) Mean water depth recorded by the pressure sensor at each of the sample intervals during the deployment. (B) The water temperature recorded during each of the sample intervals when the pressure sensor was completely submersed. This figure depicts when the seawater was below freezing temperature. 

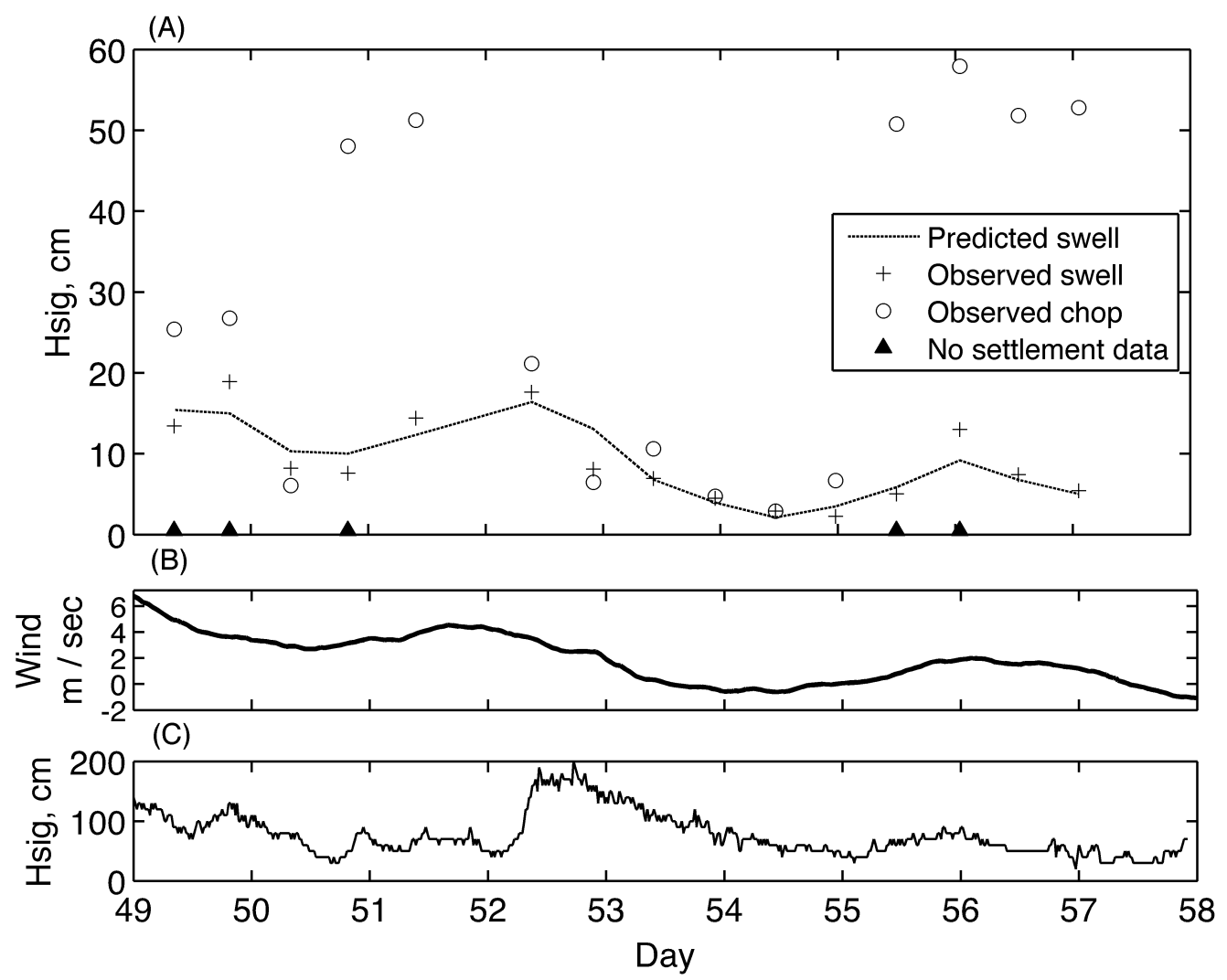

Fig 3. (A) Predicted swell and observed swell and chop Hsig data calculated for each of the tidal submersions of the deployed pressure sensor at Gardiner beach. (B) The 37 average of wind in the along Buzzards Bay component. (C) Martha's Vineyard Coastal Observatory Hsig for swell. 


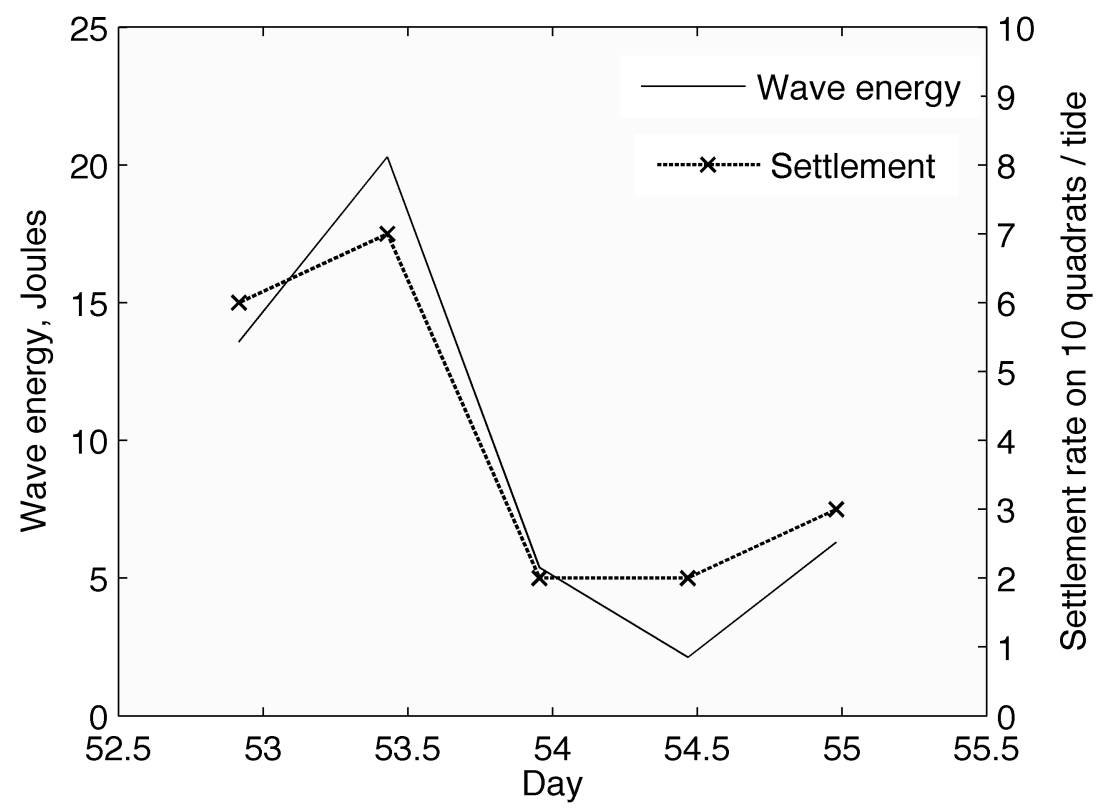

Fig 4. Total wave energy and settlement over five consecutive tides from winter 2007. 


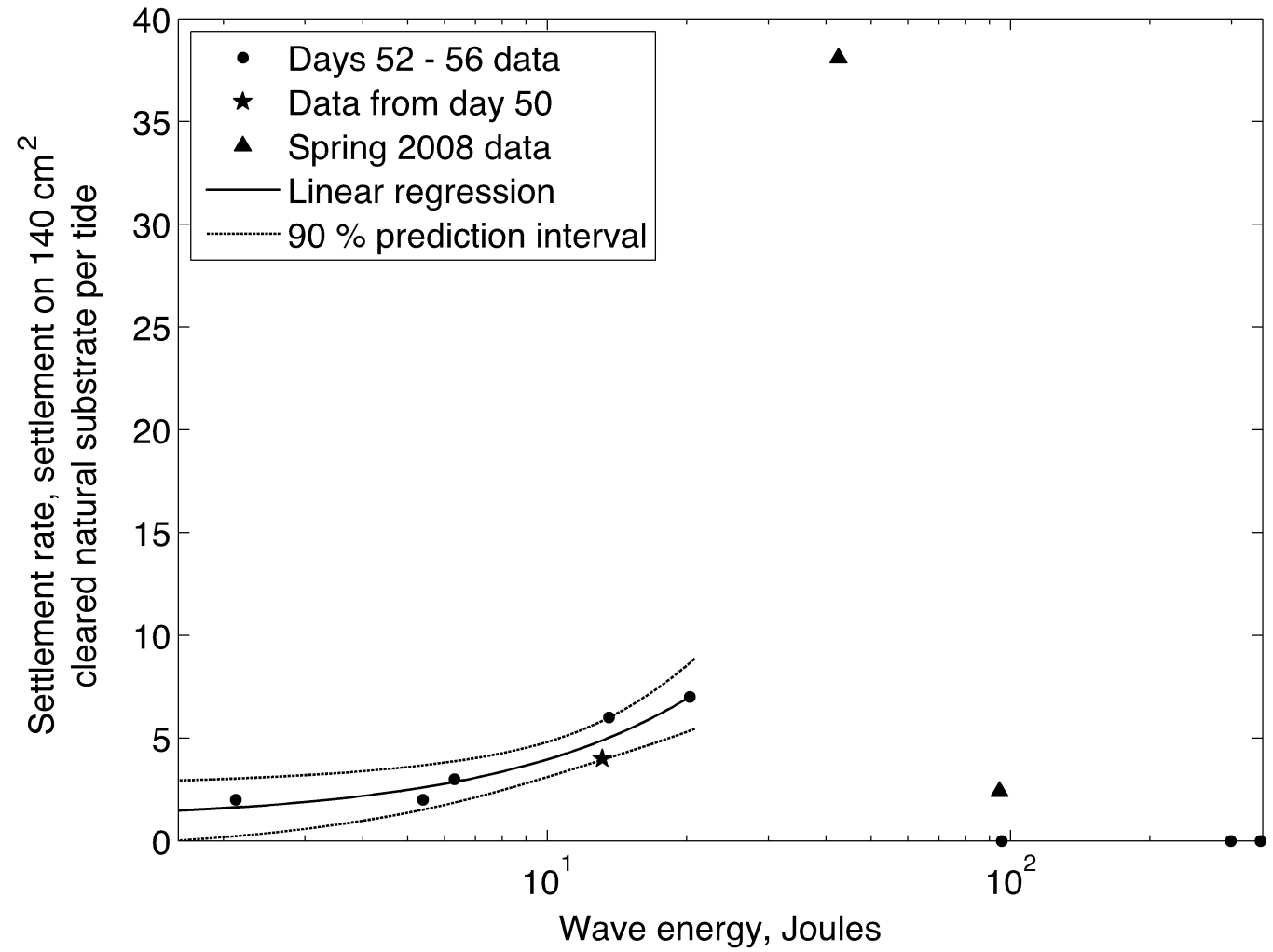

Fig 5. Regression of wave energy with settlement for the five consecutive tides and the plausible predictive range for settlement given the wave energy at a future time. The observed settlement on Day 50 is within this plausible range. The zero settlement with high wave energy were not included in the linear regression because at high wave energy values, settlement rate could reach a physical limit. The spring 2008 wave energy and settlement data fill in the gap between high and low wave energy tides from the winter deployment, since it has one intermediate wave energy value with uninhibited settlement preceded by an slightly higher wave energy tide with settlement rates that are appear relatively inhibited. Wave energy is plotted on a log scale because these data cover such a broad range of values, which also highlights the dynamic scale of wave energy at Gardiner beach. 


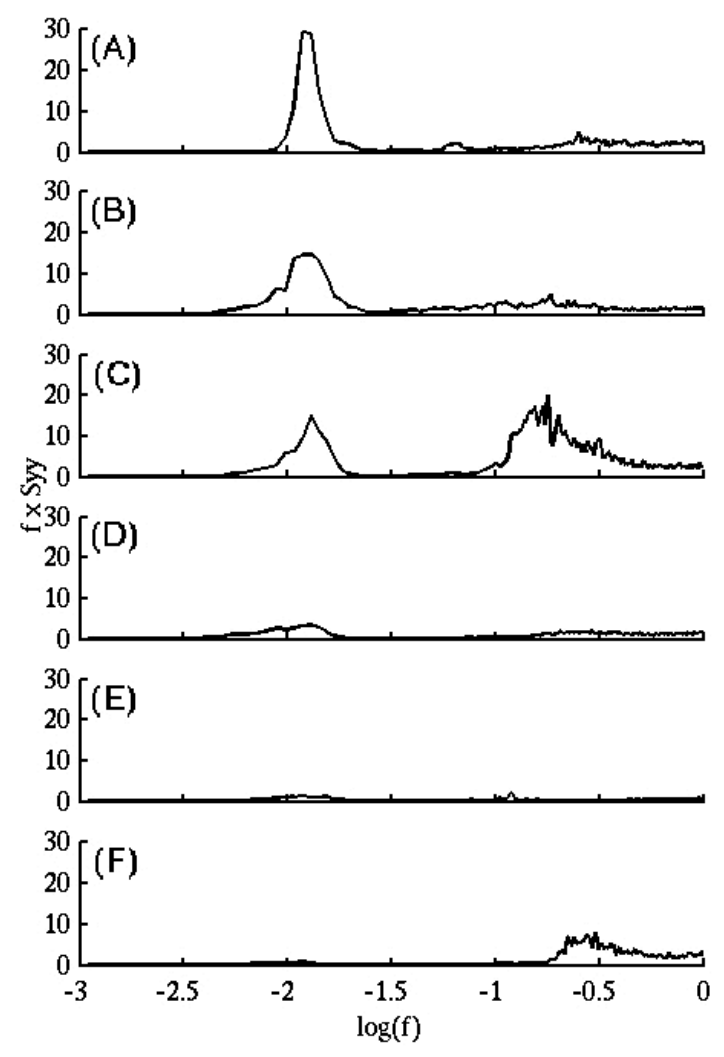

Fig 6. Power spectra for each of the tides when settlement occurred on (A) day 50, and (B - F) days 52-55 of the winter 2007 ADV deployment. The range of swell frequencies is -3 to $-1.5 \log$ (f) and the range of chop frequencies is -.15 to $0 \log (\mathrm{f})$, which divide the $\mathrm{x}$ axis in half. The area under the curve in each of these quadrats equals the wave energy for the swell and chop component respectively. 


\section{Chapter 4}

\section{The Recruitment Window, a novel tool to address the role of seasonally changing influences in benthic marine invertebrate recruitment}

\subsection{Abstract}

Settlement and recruitment of the intertidal barnacle, Semibalanus balanoides, were recorded at Gardiner beach on Cape Cod over two consecutive years. These two years had distinct patterns of recruitment as marked by the settlement date of recruits, which defines the recruitment window. Factors that were found to be important to the recruitment dynamic were seasonal temperature and the availability of recruitment substrate, two factors that varied distinctly between these two years. Field experiments were conducted to examine the role of each of these factors on recruit timing and abundance. By clearing substrate previously settled by juveniles from the year's settler cohort, it was possible to induce high levels of recruitment that did not concurrently occur on natural substrates. Cold stress due to temperature of the intertidal habitat during low tides following settlement may explain altered physiology of metamorphs, which may have lasting consequence for juvenile survival. Enduring periods of cold stress post metamorphosis may additionally explain lower survival for winter settlers. The results presented here highlight the value of considering seasonal dynamics for predicting recruit abundance and for demographic applications such as fisheries management. Though this study is based on describing trends in recruitment with the change in seasons, attempts are also made to address recruitment processes. Remotely measured seasonal trends in temperature coupled with this process-oriented knowledge 
may eventually replace painstaking and often costly field based measures of recruit abundance for fisheries stock assessments.

\subsection{Introduction}

In recruitment studies of marine organisms, scientists usually study changes in the density of marine animals in time, and often the focus is on a distinct cohort of the animal that is just arriving, after the metamorphosis from the planktonic life stage to the benthic life stage. For recruitment systems with seasonal periodicity, defining the cohort is simple enough, because it relates to all those individuals that arrive during one period of recruitment. Then it is usually the case that changes in the cohort of recruits is related to biotic or abiotic factors in the marine environment. One complication is that for most seasonal systems, the biotic and abiotic factors that may explain changes in density also change with the season. Patterns of seasonal recruitment are correlated with environmental changes, requiring methods to control for multiple factors that vary with season, but do not directly affect recruitment.

In general relating individual traits to population level dynamics that ecologists are used to working with is not a trivial matter. Population level summaries of physiology are rarely conducted in the field where the environmental source of variability is complex, and causal links to, for example survival of recruits (Brawley and Johnson, 1991), may only hold over micro scales over which environmental gradients can be characterized. Scaling up may involve extrapolating small scale trends with environmental factors to larger scales according to the power law relationship of how the environment varies with spatial scale (1/f noise relationship described for intertidal 
systems by (Denny et al., 2004)). Scaling up is also possible in theory for biotic variables like the predation of fish on coral reefs (Steele and Forrester, 2005). The key to scaling up in many cases is to find aggregate variables that can be adequately summarized at the larger scale of interest, an aspect that ecologists are quite proficient at, since variability is dealt with at the level of aggregate variables instead of the most reduced components (Michell, 2005). An example are the aggregate variables size and shape of mussel shells that are derived from width and height length measurements of the shell (Blythe and Lea, 2008). Generally, aggregate variables that are meaningful at an individual level but also describe patterns at the population level are the ones that are useful for scaling. Periodic features of the environment where aggregates of variables change on characteristic scales can be a starting point for addressing physiological correlates to population variability. For recruitment systems where cohorts are defined seasonally, changes in seasons are an ideal aggregate variable to compare and contrast possible processes that affect recruitment.

Planktonic stages in the lifecycle of marine animals also respond to seasonal changes, and the rates of change measured during recruitment studies may not entirely be related to the biotic and abiotic factors experienced by marine animals in the benthic habitat. For example, the organic content of barnacle larvae had a significant trend with time over the transition from late winter to spring (Jarrett, 2003). Furthermore, phenotypically plastic traits of larvae that change in response to environmental conditions in the plankton may carry over after metamorphosis and mediate the survival of juveniles in the benthic habitat (Gimenez, 2004). For example barnacle larval 
condition is correlated with post-settlement performance (Pineda et al., 2005, Thiyagarajan et al., 2002). Therefore, methods to assess whether the quality of larvae can account for recruitment patterns are necessary, yet assessing the traits and condition of larvae and metamorphs comes at a premium in a scientific discipline for which simple counts of animals can be quite involved (e.g. measures of barnacle settlement taken on a lower than daily frequency can be erroneous (Minchinton and Scheibling, 1993)). Seasonal trends in environmental variables provide an aggregate summary of variability that may be helpful in distinguishing between hypotheses on the sources of recruitment variability.

During a typical New England winter on Cape Cod, air temperature and seawater temperature gradually decrease with the lowest temperature occurring sometime during February (Pineda et al., 2005). The barnacle, Semibalanus balanoides, settles throughout the winter starting in January, and continues to settle through the spring into May. With the onset of spring, the air temperature and water temperature begins to increase, and the barnacles settling during this period of time do not encounter such cold temperatures in the benthic habitat as those that had settled in the winter. Therefore, differences in survival for barnacle settlers from the winter and spring may be in part due to temperature differences that they experience upon settlement, since larvae probably experience a much more narrow temperature range while in the plankton. Barnacles may freeze when they are caught in the neuston or in nearshore pelagic environments where freezing is common in the winter, but this has only been naturally observed to occur for late stage cyprids that are about to settle (Pineda et al. 2005). 
A biotic source of covariance in this recruitment system is the accumulation of juvenile barnacles on the settlement substrate with time. Barnacle accumulation causes competitive exclusion, which is increasingly intense with time. This decreases the survival rate of late $S$. balanoides settlers on natural substrates, and causes an early skewness in the distribution of settlement dates for recruits (Chapter 2). Early settlers have priority for the habitat since they occupy and exclude subsequently settling barnacles. Priority effects have been detected in barnacle settlement by comparing one substrate that has been cleared once at the beginning of the settlement season to a second substrate that is continually cleared throughout the measurement period (Connell, 1985, Hawkins and Hartnoll, 1982, Raimondi, 1990). Enhanced settlement on the continually cleared substrate indicates that the supply of larvae would support higher rates of settlement but that these settlers are inhibited by the presence of barnacles from the same recruit year cohort.

The recruitment window, the temporal distribution of settlement for the subset of individuals that recruit, is a concept that is apt for summarizing population level trends in recruitment that co-vary with seasonal trends in the environment. Two periods, one winter and one spring (Chapter 2), define when barnacles settle and recruit in Woods Hole, MA. Given this pattern, it is possible to ask what the relative probability of survival is for any given settler during the winter and spring recruitment windows. The intertidal barnacle, Semibalanus balanoides, is unique among marine animals because it is possible to track distinct daily cohorts of recruits to compare for example the rate of metamorphosis and growth between cohorts (Jarrett, 2003). Novel techniques are 
employed herein that take advantage of this fact, and address the role of seasonal variability on barnacle recruitment. A manipulative experiment that involves the clearing of substrate is employed to remove preemption effects on barnacle settlement rate and survival. Another manipulation, the smother plate, is described herein, which prevents disturbance to the winter and spring cohorts until a reasonable period of time after their respective settlement dates to facilitate comparisons of the survival probability between settlers from the winter and spring. Finally, physiological and survival probability measurements of laboratory transplanted recruits is a method that has previously been used to remove environmental sources of variability so that these measurements can be compared to patterns in similar field based populations of recruits (Jarrett, 2003), but the application of this technique is new.

Spatial patterns of environmental variability are highly complex in the rocky intertidal (Denny et al. 2004). Temporal patterns are much more amenable for evaluation of recruitment processes since there are typical progressions of recruitment patterns over the change in seasons that have meaningful consequences at the individual level, for example, the cold stress response from a freezing event in the intertidal. However, the application of experimental methods to address the role of temporally changing environmental factors has been limited. The recruitment window is a method to investigate temporal patterns in recruitment at a high resolution, indicating that barnacle settlement timing is informative in addition to the spatial component for recruitment studies. The smother plate experiment provides a vital test for the utility of the recruitment window concept for clarifying variability in recruitment. Mortality had 
consistent patterns in space and variance increased at larger spatial scales. However, the temporal pattern in recruitment informs the overall recruitment pattern for barnacles and does not appear to be confounded by this spatial variability in the mortality of juveniles.

\subsection{Methods}

\subsubsection{Natural substrate monitoring}

Natural substrates at Gardiner beach were selected for monitoring of settlement and recruitment. A survey of the intertidal habitat at Gardiner beach was conducted to measure the spatial location of low tide barnacle habitat between 20 and $40 \mathrm{~cm}$ Mean Lower Low Water (MLLW) and high tide barnacle habitat between 40 and $60 \mathrm{~cm}$ MLLW. A method to select barnacle habitat from among the naturally occurring barnacle habitat was employed. The probability of selecting a surface was equal to the proportion of its area to all the area measured at the site as a whole. Once surfaces were randomly selected, Gardiner beach was visited at low tide and a quadrat was installed in each of these locations, according to two additional criteria. One or more adult barnacles were to be present inside the quadrat surface, and the surface of the quadrat was to be flat enough to lay a $12 \mathrm{~cm}$ compact disc flush with the surface. Fifteen quadrats were selected in each of two consecutive years, 2007 and 2008, using these criteria.

Markers were hammered into evenly spaced holes that were drilled into the quadrats along the diameter of the $12 \mathrm{~cm}$ disk. The surface between the two center markers of each quadrat was cleared one month before the beginning of the settlement 
season. The area $1.5 \times 2 \mathrm{~cm}$ surface was cleared and the remainder of the quadrat, except for during the installment of the quadrat markers, remained undisturbed.

Daily photographs of each quadrat targeted at the area between the two center markers commenced on January $1^{\text {st }}$ in the years 2007 and 2008. For reference, January $1^{\text {st }}$ is day one in both years. Daily measures were conducted until day 151 and 152 respectively, at the end of May. Individuals surviving to the end of May were identified in these photos. The day that recruits settlement was identified by tracking back from the end of May going backwards through the record of the daily photos. These measurements provided a distribution in time when recruits settled, like the recruitment window presented in Chapter 2, except recorded for survival to the end of May instead of December.

\subsubsection{Lipid experiment}

Sixty settlement plates that had been seasoned for two months in a laboratory seawater aquarium were affixed to quadrats at the rock wall at an elevation of $40 \mathrm{~cm}$ MLLW on day 39 before the coldest period of February 2008. A cold spell was forecasted to enter the area later that week, which made for ideal conditions for a natural experiment of the effect of environmental temperature on the physiology early in the benthic stages of barnacle settlers. Half of the barnacles that settled over 24 hours through day 40 were transplanted to the lab before the cold spell arrived. The remainder of the settlement plates remained in the field, where mortality and environmental conditions were monitored on a tide-by-tide basis. Intertidal zone wind was measured by placing a wind sensor at an elevation of $1 \mathrm{~m}$ MLLW atop a stainless steel stand that 
was bolted to a boulder outcropping from the rock wall surface. The wind sensor was located within $10 \mathrm{~m}$ of all the settlement plates, centrally located in the shallower of the two sample areas at the rock wall (Fig. 1). Since the stand would be inundated at high tide, the wind was measured only during periods of low tide when the wind sensor could be temporarily mounted on the stand. Temperature was recorded using two Onset tidbit temperature loggers mounted at $40 \mathrm{~cm}$ MLLW in the intertidal zone, at the same elevation as the settlement plates used in this experiment. When the transplant occurred, one logger was placed in the seawater bath to record the temperature of barnacles in the seawater tables, since they remained submerged for the duration of the experiment.

Direct measures of barnacle temperature were recorded by measuring the temperature of the plastic settlement plates to which settlers were attached using a Fluke 54II thermocouple temperature probe. Four measurements were taken on each plate, except for the second tide when only one measure was taken of each settlement plate. After the cold spell, the settlement plates were recovered at low tide on days 54, 55 and 56, and immediately brought to the lab on ice and processed for lipids. In most cases samples represented either one or a combination of more than one settlement plate with approximately 5 cyprids per sample, but when the number of juveniles on plates exceeded 5, all barnacles from a plate were lumped into one sample. Some barnacles had settled on day 44 after the cold spell, and they were also collected for lipid analysis.

The measurements of barnacle lipids were conducted on 15 samples, 7 of which were samples of one or more settlement plate replicates that remained out in the field throughout the cold period. The lab treatment included four samples that each were 
collected from one or more settlement plates that were transplanted to the lab on day 40 (see later, Fig. 7C). Finally, the settlers from day 43 were collected from distinct settlement plates, or in some cases were sub-sampled from plates that were also sampled for older settlers for the cold treatment in the experiment. In cases where new and older settlers co-occurred on settlement plates, the photos of these settlement plates conducted on each tide helped to distinguish their settlement date.

Lipids were extracted from samples of barnacle settlers using the Bligh and Dyer method (1959). The lipid composition of these samples was analyzed using an High Performance Liquid Chromotgraphy (HPLC) and Mass Spectroscopy technique (Sturt et al. 2004). Lipid components had distinct migration times (Sturt et al. 2004), because lipids migrated on the HPLC according to their head groups. The area under the peak of each lipid fraction was an approximate measure of lipid concentration, and six lipid fractions characterized the lipid composition of barnacles. The peak areas from each of these lipid fractions were summed to estimate the total lipid mass in each sample. The total lipid concentration was divided by the concentration of an internal standard that was dosed at a known concentration prior to lipid extraction. This normalization corrected for variability in total lipid concentration that occurred during extraction and dry down phases of the Bligh and Dyer method. This total lipid concentration was highly correlated with the number of cyprids used in each of the analyses $\left(\mathrm{R}^{2}=0.86\right)$.

The identity of the two of the most abundant lipid fractions were PE, PC, as determined by MS analysis of the head group mass. These peak areas were divided by the total lipid concentration correction factor to get a normalized lipid concentration for 
each of these components. A third lipid that is particularly important in the temperature stress response in eukaryotes, sphingomyelin, was a minor component of the lipids in the barnacle sample. Sphingomyelin was abundant enough to reliably measure its concentration in the samples, and its mass was also normalized by the total lipid concentration correction factor. A canonical factor analysis was conducted on the log of the PE, PC and sphingomyelin lipid concentrations to test the hypothesis that the cold or warm treatments could induce detectable patterns of variability in these lipid components. Another abundant lipid, PS, and two unknown minor component lipids, were not included in the factor analysis because there was no reason to suspect the bulk concentration of these components played any role in the eukaryotic temperature response.

\subsubsection{Smother plate experiment}

A field experiment was conducted during the winter and spring of 2007 . One hundred and twenty quadrats were drilled at an intertidal height of $40 \mathrm{~cm}$ MLLW, thirty at each of the four sampling locations between the rock wall to the west and Gardiner beach to the east (Figure 1). Quadrats had four markers equally spaced along the diameter of a $12 \mathrm{~cm}$ disk, as before. Quadrats from each sampling area (Fig. 1) were divided into six winter and spring treatments (Fig. 2). 25 quadrats were assigned to cleared natural substrate treatments between days 20 and 90 , and five more quadrats for each sampling area remained un-manipulated as a control.

Starting on each of five consecutive settlement periods, five natural substrate quadrats in each sampling area were cleared of juveniles from a rectangular area with a 
height of $1.5 \mathrm{~cm}$ and a width of $2 \mathrm{~cm}$. Photographs were taken of the cleared surface over the following two weeks after the initial clearing, corresponding to the duration of the settlement period. Whenever possible, daily photographs were taken during the spring tides of each series and a lower frequency was taken during the intervening period before the next spring tides (see Fig. 2 for the days when photos were taken). These photos were used to identify settler cohorts. For the first settlement period between day 20 and 32, 10 individual cohorts of settlers were identified. In the last settlement period, between days 79 and 93, 13 cohorts were identified. After each respective settlement period, the natural substrate quadrats that had been cleared and monitored during that interval were covered with a grey PVC plastic sheet measuring 3.5 by $4 \mathrm{~cm}$ that was attached to the substrate with two machine screws at the bottom left and top right corners. Once attached, the smother plates remained covering the quadrats until day 132, except for temporary removals at regular intervals to monitor survival of the settlers. The survival of these cohorts of barnacles was monitored on a two week to a monthly basis corresponding to the interval between settlement periods.

The mortality rate between photograph intervals was calculated by dividing the number of individuals still alive at the end of the interval by the number of individuals at the beginning of the interval, logging this ratio, dividing by the number of days in the interval, and multiplying by negative one, as in (Jenkins et al. 2008). The mortality rate so calculated is well suited to summarize mortality using statistics such as the mean and variance. Another statistic, the mortality rate of settlement cohorts, provided a natural pairing for Gardiner beach and rock wall juveniles, based on the subsets of barnacles 
settled on the same day. The mean difference in mortality rate, where the mortality rate of rock wall cohorts was subtracted from the mortality rate of Gardiner beach cohorts, was calculated from among 10 settler cohorts from the winter and 13 settler cohorts for mid-spring quadrats. This provided a mean and a range of cohort differences characterized by the standard deviation of the difference in the cohort mortality rate.

Once the smother plates were removed from the winter and mid-spring cohorts, photographs were collected at higher frequencies to characterize mortality during the interval of time between days $132-151$. A high mortality might occur when plates were initially removed if they held barnacles in place, so at first, photographs were collected on a tide-by-tide basis about every 12 hours to record whether barnacles died very quickly in the beginning. After several days, the interval increased to a daily and then a two-day interval. The mortality that occurred in each of these intervals was characterized in two distinct manners. First, each quadrat had a number of barnacles that either settled during distinct daily cohorts in either settlement period one or five, but not both, since distinct quadrats were used for each of these settler sampling intervals. The number of individuals that died in each quadrat on each interval was divided by the initial number of live juveniles in the quadrats upon the smother plate removal and also divided by the amount of time in the photograph interval. This provided a measure of the proportion mortality rate in quadrats over all the intervals of measurement. High values for this variable would result from the synchronized mortality of individuals in a given location, due to spatially coherent disturbance events such as the feeding scars left by predators. The mortality data were summarized by a second method that involved 
grouping juveniles by their settlement cohort irrespective of what quadrat in which they settled. The number of individuals from a cohort that had died in an interval was divided by the initial number of live juveniles at the beginning of that interval, and divided by the amount of time in days in that interval. High values of this variable would include mortality that occurred synchronously among distinct quadrats. A comparison was made between the quadrat and the cohort summaries of mortality by plotting the empirical cumulative distribution function of the proportion mortality rates, and finding the proportion mortality rate at which they were maximally distinct. This maximum difference was then tested using a Kolmogorov two-sample test, to see if the two summaries of the data gave distinct proportion mortality distributions.

The probability of survival was calculated from photographs collected on day 151, 19 days after the smother plate removal. The identity of individuals that had settled during periods 1 and 5 and were still alive on day 151 was ascertained by tracking individual barnacles from regular photos that were taken during temporary smother plate removals up until 132 and over the smother plate removal period. The proportion of survival was the number of survivors divided by the total number of settlers from each settlement cohort from settlement periods 1 and 5. In addition to settlers from cohorts from settlement periods 1 and 5, six cohorts from settlement period 4 also had substantial settlement. Their survival to day 151 was also recorded by a distinct technique, using a backward tracking method as in Chapter 2 and that was used for the natural substrate recruitment window measurements. Settlement was low during 
settlement periods 2 and 3 in the winter between days 33 and 70, so the survival of these barnacles was not measured.

Settlement plates were put in the field to collect settlers on similar intervals and equal numbers to the smother plate experiment for comparison with the cleared natural substrates (Fig. 2). They were deployed on quadrats that would be used in the smother plate experiment in the following tidal cycle in order to reduce the number of overall quadrats that were required for this experiment. During the last settlement period, the settlement plates were placed over the un-manipulated substrates, which were then subsequently uncovered on day 93 when these settlement plates were transplanted to the lab. After the settlement period, the settlement plates were recovered and placed in a laboratory flow through seawater table, being attached upright to a plastic egg crate structure so they were separated and not lying flat on the bottom or touching solid surface. Survival of these barnacles from the date of transplant on days $32,45,61,75$, and 93 until day 153 was recorded using digital photography. In addition, a set of 8 settlement plates that were situated between Gardiner beach and the rock wall, and not distributed at random as above, were outplanted before day 1 and recovered on day 18 to collect settlers from this period prior to the smother plate experiment. The probability of survival was the proportion of individuals that had been transplanted on the dates respectively for each treatment and were still alive on day 153 . A $99 \%$ confidence interval was calculated by fitting a binomial distribution to the number of transplanted settlers, $n$, and the number of survivors, $x$. The estimate for the probability has higher 
error in cases where fewer barnacles settled, which is reflected in the $99 \%$ confidence interval for each probability estimate.

\subsection{Results}

The day when barnacles settled and survived until the end of May defined the recruitment window for barnacles settling at Gardiner beach in 2007 and 2008. As in the year 2006 (Chapter 2) there appeared to be two distinct periods of settlement that resulted in recruitment in 2007: those periods define the winter and spring recruitment windows (Fig. 3A). In 2008, there was no discontinuity in the recruitment window (Fig. 4A), though trends in seasonal temperature were different between these two years (Figs. 3B and 4B). Loggers were located at different depths in the two years, so the temperatures are not directly comparable. The temperature may be lower on average in 2008 because the logger was placed at a depth one meter below the location of the logger in the prior year, and may be sampling a denser and colder layer of water in the thermocline. The trend in temperature indicates that after an initially warm start to the settlement season in 2007, there was a sustained cold period before the spring. In 2008, the temperature was initially very cold and except for a freezing event that is part of the cold stress experiment highlighted in Fig. 3b, there was a gradual warming of water temperature throughout the remainder of the winter.

The probability of survival of settlers transplanted to the lab on settlement plates at the end of each of these settlement intervals (Fig. 5) demonstrates that for three of these settlement periods depicted in Fig 3B, there was a higher probability of survival for individuals transplanted to the lab than for barnacles that remained in the field for the 
smother plate experiment (Fig. 3C). The highest survival probability for laboratory transplanted barnacles occurred for individuals settling before the beginning of the smother plate experiment and were transplanted to the lab on day 18. These barnacles settled when the seawater temperature was the warmest (Fig. 3B), and was the period of time when barnacles recruited in highest abundance (Fig 3A). The gap in the recruitment window occurred during the coldest period in the sub-tidal temperature record (Fig. 3B). The settlement rate was quite low during this cold period (Fig. 6), which was also true for the settlement plates. Low settlement makes it difficult assess the survival probability of settlers from these periods (see large confidence intervals, Fig. 5), which is why the analysis of the smother plate results was only conducted on the one winter and two spring periods that are depicted in Fig. 3B.

Environmental conditions that barnacle settlers were exposed to during a pronounced cold spell between days 41 and 43 of 2008 were recorded using a combination of field sensors. The seawater temperatures recorded in the intertidal zone were near freezing, similar to a short interval of freezing temperature discussed in detail in chapter 3, which occurred during one of the winter smother plate experiment intervals. In 2007, freezing conditions occurred when winds came from an offshore direction, which had an additional effect of creating high chop wave energy (Chapter 3). During the freezing period of 2008, the coldest tides occurred when the primary wind direction was from the southwest in the alongshore direction. High wave action that enhanced the sea ice accumulation on the shoreline in 2007 did not occur in the freezing period of 2008. The high wind velocities recorded in the intertidal contributed to the 
cooling of intertidal rocks and the settlement plates on which the barnacles settled (Fig. 7B). Additionally, high wind may contribute to barnacle desiccation. Compared to the barnacles that settled on plates and were exposed to the cold and wind in the field, the barnacles that had settled and were transplanted to the lab had relatively calm and hospitable environmental conditions. The temperature of these barnacles could be roughly approximated by measuring the ambient seawater temperature in the aquarium table in which the settlement plates sat, which was recorded by the temperature logger that was transplanted along with the settlement plates on day 40 . Field barnacles were at minimum 2-3 degrees lower than the lab controls, for example at high tide when they were inundated in the relatively warm seawater. On three consecutive low tides, barnacles reached temperatures between 6 and 10 degrees Celsius cooler during low tide exposures (Tides 2, 3 and 4, Fig. 7A), compared to the temperature recorded from a logger that was transplanted to the laboratory seawater table. A third group of barnacle larvae settled after the three harshest freezing low tides and were first recorded on tide five. Air and water temperature subsequently warmed in the field, so that this third group of settlers was mostly exposed to warmer environmental conditions once attached in the intertidal zone.

An analysis was conducted on the lipid samples collected from barnacles after a cold spell in 2008. The lab control and the new settler control were lumped into the warm sample category to reduce the canonical factor analysis to one dimension. The comparison of warm versus cold treatments was significant at a p-value $<0.02$. The mean and standard deviation for the first canonical variable is plotted for the seven cold 
samples for comparison to the lab control and the new settler samples separately (Fig. 8). The eigenvector for the first canonical variable was -16 for the PE component and 19 and 6 for the PC and sphingomyelin components. These eigenvectors relate the proportions of the log lipid component concentrations that maximally distinguish cold from warm samples. The sign of the log component concentration is particularly informative as the linear combination of these log components are log ratios of PC or sphingomyelin to PE. Log ratios for the first canonical variable that are less than zero are consistent with a cold acclimatization, since sphingomyelin and PC are lipids that tend to increase membrane order, while PE decreases membrane order (Williams, 1998). Barnacles exposed at low tide in the field may have experienced cold stress that would have caused acclimatization of the lipid components.

In addition to cold stress during metamorphosis, barnacles endured cold stress throughout the juvenile period of development, which may have contributed to the relatively lower survival probability of winter settlers compared to the spring cohorts from the smother plate experiment (Fig. 3C). The abundance of recruits resulting from the three settlement cohorts in the smother plate experiment with high settler abundance were compared to test for the effect of an endured winter effect on barnacle recruitment. Spatial and time differences in the settlement rate are covariates that may confound the comparison of survival probabilities. The influence of settlement rate was removed from the recruitment values by regressing the per day recruit abundance of a cohort against the rate of settlement for that cohort (Fig. 9). Due to the increasing variance in recruitment values with high settlement rate values, the settlement rate and the recruit 
densities were log transformed and fit with a linear regression model (Fig. 9). The linear model explained $57 \%$ of the variability in recruit density, and the slope was significantly less than one at a p-value $<0.00005$ indicating that this trend was sub-linear. Residuals from the regression were analyzed using a linear two-way ANOVA with settlement period and site as the two factors. This would test for recruit abundances that were not explained by the model of recruitment based on the settlement rate. The settlement period factor was significant at a p-value $<0.02$, and the site factor was highly significant at $\mathrm{p}$-value $<0.0001$ (Table 1 ). There was no interaction between these factors indicating that combining the two sites into the ANOVA analysis did not result in confounding variability from the settlement periods with variability from the settlement sites. Settlement period and settlement site appeared to independently influence recruitment variability.

A multiple comparison of recruitment resulting from settlement periods 1,4 and 5 indicated that the period 1 settlers recruited in significantly lower abundances than predicted by the trend of recruitment with settlement rate than did period 5 settlers. However, the period 4 settlers had a pattern of recruitment that was not distinct from either of the two other settlement periods. Winter cold stress could present a source of mortality that the spring settlers did not experience. Juveniles that settled during the winter and were living under the smother plate treatment had winter mortality similar to control quadrats, but that were substantially higher than mortality rates of barnacles under smother plates in the spring between days 103 and 122 (Fig. 10). Winter mortality between days 49 - 78 was much lower than spring mortality for the un- 
manipulated plates between days 103 and 122. Higher mortality in the spring could be associated with the seasonal emergence of barnacle predation by crabs in the intertidal zone (Brousseau and Goldberg, 2007); which the smother plates were able to protect juveniles against this much like predatory exclusion cages, although when smother plates were removed, winter and spring barnacles experienced similar high rates of mortality (Fig. 10). Winter settlers did not have a higher mortality rate than spring settlers between days 132 - 151 after smother plate removal (Fig. 10). A comparison of the recruitment residuals for each of the sites indicated that settlers at Gardiner beach had a consistently lower probability of survival than at the rock wall. The spatial comparison of mortality changed with season, as Gardiner beach mortality was higher during the winter (Fig. 11). By contrast, mid-spring barnacles initially had equal mortality rates at Gardiner beach and the rock wall and the site differences in survival were not apparent in these quadrats until the high mortality interval when smother plates were removed (Fig. 11).

High frequency measures of survival between days 132 through 152 after smother plate removal reveal an aggregated mortality dynamic in the days and weeks after barnacles that had been under cover since the winter or mid-spring were first exposed. Few large mortality events described the distribution of mortality on quadrats, in contrast to the cohort summaries that had much more even distributions (Fig. 12). For example, groups of barnacles that were arranged by their settlement date irrespective of their settlement location gave a distribution that was significantly different from the quadrat based summary that grouped barnacles by their settlement location irrespective 
of their settlement date (Kolmogorov two sample test, p-value $=1.166 \mathrm{E}-21)$. Cohort groups that had some spatial distinctions, such as being assigned with respect to the site difference the rock wall versus Gardiner beach also produced a significantly different distribution than the one based on quadrats alone without respect to settlement date (pvalue $=1.151 \mathrm{E}-6)$. Identifying groups of juveniles by settlement date across larger spatial scales averages out spatially aggregated mortality events. The smallest independent spatial groups from this study are the four sample areas (Fig. 1) which when juveniles were grouped by cohorts and sample areas, their mortality distribution was not significantly different from the quadrat based mortality distribution ( $\mathrm{p}$-value $=$ 0.3163). In part this convergence between the cohort and the quadrat summaries at smaller spatial scales is an artifact of having fewer quadrats to average out high mortality events that occur asynchronously among quadrats. However, comparing mortality summaries in each of the sample areas separately, grouping juveniles either by cohorts or quadrats, shows that these distributions of mortality become coherent at the smallest scale (Fig. 13). Null cohort summaries were computed by assembling juveniles by settlement date and four randomly allocated groups of quadrats. Null sample mortality distributions were more distinct from the quadrat mortality distribution for the site as a whole than was the cohort summary grouped by the four actual sampling areas (P-value $<0.001)$. The grouping of quadrats by sample area may reflect habitat features unique to each of these sample areas that influence the survival of juveniles during the high mortality period between days 132 - 151 . 
The spatially aggregated mortality may in part explain why the sites Gardiner beach and rock wall had distinct mortality rates during this interval. Survival patterns also reflected these spatial differences, though the survival index used here is based on cohorts grouped by settlement date rather than densities of settlers occurring in a location. Since aggregated mortality is highly localized at a quadrat level, the cohort summaries of survival can be used to average out aggregated mortality events and serve instead as a spatial average of mortality for individuals settling on a given date. Sites had distinct trends in the log settler rate versus log recruit abundance regression, where for Gardiner beach it explained $74 \%$ of the variance and had a slope significantly less than one at a $\mathrm{P}$-value $<0.001$, and for the rock wall it explained $82 \%$ of the variance, though the slope was not significantly different from one. The distinctly lower slope at Gardiner beach may indicate a sub-linearity in barnacle recruitment at Gardiner beach that may be important to explain site differences in recruitment. After spatially aggregated mortality occurred in a quadrat, barnacles remained at some basal level of abundance in most quadrats that may be reflective of the remaining population of barnacles not susceptible to mortality in this interval. A possible explanation is that once predators or other spatially coherent disturbance events removed the susceptible individuals, the barnacles that remained may have been fairly well suited to survive. The un-manipulated quadrats had barnacles that survived the springtime mortality in the 102 - 122 day interval, but in the following month between days $132-151$ the survivors had a substantially lower rate of mortality (Fig. 10). 


\subsection{Discussion}

The results from the five settlement period experiment provide a basis for comparison to settlement on natural substrates, helping to explain patterns in the 2007 recruitment window. High survival probabilities were calculated for each of the recruits settling during periods 1, 4 and 5 of the experiment (Fig. 3). Unlike the natural substrates, experimental surfaces monitored for settlement were cleared prior to each settlement period. Therefore, preemption may be a sufficient explanation for why barnacles recruited at relatively low abundance during the same periods of time on natural substrates. It has previously been considered that lower larval quality like from low cyprid carbon content (Jarrett 2003) could explain post settlement survival pattern, but this does not seem to be the case when for example the recruit abundance decreased at the end of the first recruitment window. Barnacles settled and recruited in separate winter and spring recruitment windows in 2007 . The discontinuity between these recruitment windows was not simply a sampling or statistical artifact, and likely resulted from settlement and recruitment processes during this gap. Low settlement during periods 2 and 3 , and the early part of period 4 were low, though not zero, and these periods of low settlement on experimentally cleared substrates overlap precisely with the gap in the recruitment window. The gap also occurred during a period of low seawater temperature, which could play a role in recruitment through cold stress of barnacle settlers.

The primary evidence for cold stress effects come from the settlement plate transplants in comparison to barnacles that remain in the field and experienced freezing 
conditions, especially during winter low tides (Figs. 3C and 5). The lipid experiment was conducted the following year, in 2008, to detect differences in barnacle physiology for individuals transplanted to the lab environment compared to individuals from the same cohort that remained in the field during a cold period. Though cold stress and lipid acclimatization seems to have occurred for field barnacles that settled on day 39 and were exposed to a cold spell between days $41-43$ in 2008 (Fig. 8), the cold stress was apparently sub-lethal, since many of these settlers completed metamorphosis by day 45 . In keeping with the comparison of experimental results to recruitment on natural substrates, barnacles that settled on natural substrates at Gardiner beach on the same day as the experimental barnacles, on day 39 of 2008, recruited in quite high abundance (Fig. 4A). Therefore, this cohort seems not to have been adversely affected by the cold spell soon after their settlement that was the focus of the lipid experiment. The temperature stabilized after the experimental cold spell in 2008 so that there were no more freezing events for the remainder of the season (Fig. 4B). The idea that cold stress during metamorphosis could affect patterns of recruitment well afterwards is intriguing, and it reinforces a reoccurring theme in this thesis of the importance of the time and place when a barnacle makes the transition from the pelagic to the benthic stages. However, there is little support from the results and from the literature that freezing conditions during metamorphosis has any negative long-term impacts on barnacles (Pineda et al. 2005).

I hypothesize that freezing conditions need be present in order for cold stressed barnacles to experience mortality. Cold stress appeared to have greatly affected the 
recruitment of the first period settlers from the smother plate experiment, since they settled before a long period of recurring freezing in 2007 (Figure 3b). Mortality rates were higher in the winter than in the spring in 2007 (Fig. 10), and cold stress may explain the additional source of mortality during the winter. The individuals from the first period of settlement that survived the winter had lower rates of mortality during the exposure period of the smother plate experiment between days $132-152$, indicating that cold stress did not have enduring mortality consequences during the spring period. The lower probability of survival for winter settlers may in part result from more mortality hazards that they endure, which not only includes predation during this exposure period but winter associated mortality like from cold stress. The extended duration of the freezing period of 2007 provided many opportunities for winter associated mortality to take their toll on settlers from the first period. Increased amounts of time by itself, or higher mortality during critical developmental stages such as the early juvenile stage, are not sufficient to explain the lower survival probability of period 1 settlers compared to period 5 settlers. In fact, the mortality rate of period 5 settlers between days $103-122$ was much lower than the comparable developmental period for period 1 settlers between days 49 and 78. However, the lower mortality that period 5 settlers experienced during early developmental stages may partially explain why they had higher mortality rates during the exposure period of the smother plate experiment, since fewer of the individuals that were susceptible had experienced mortality before the exposure interval. Also, un-manipulated cohorts experienced high mortality in the month prior to the experimental smother plate removal, and the mortality of the individuals that had 
survived in un-manipulated quadrats was much lower than the mortality rate in the experimental quadrats after the smother plate covers were removed (Fig. 10).

In chapter 2, a high degree of recruit abundance variability was explained by dynamics in settlement during the first 34 days of settlement, though the recruits had settled throughout 140 days of the recruitment window. This may be the case because early settlers occupied habitat that was suitable for recruitment where subsequent settlers occupied sub-optimal habitat, as is suggested by the preemption patterns from chapter 2 . Barnacles that settled early and occupied suitable habitat may die despite their relatively higher probability of survival, and the mortality of these individuals might not impact the overall abundance of the recruit cohort if they are replaced by new settlers. Often, winter cohort juveniles are quickly replaced by spring settlers, sometimes in the very same tide (personal observation). The spring recruitment window may to a large degree be composed of scavenger larvae that benefit from the mortality events of juveniles in order to access settlement habitat of high quality. During periods of high mortality, like the mortality that occurred on un-manipulated quadrats during the interval between days 103 - 122, suitable substrate for recruitment would no longer be limiting if all juveniles die regardless of the quality of the habitat they were occupying. However, if there is a higher probability of survival for some juveniles, because of the higher quality substrate to which they are attached, then a high mortality rate may be apparent from photographic monitoring, such as in the exposure period of the smother plate experiment, though there is not actually a large change in the amount of available suitable habitat. This is perhaps why the recruits from after the high spring mortality, 
after day 122, did not compose a disproportionate amount of the total recruit abundance. By contrast, when substrates were completely cleared for the smother plate experiment, the early winter barnacles that were completely removed from the experimental quadrats are the ones that recruited in very high abundance, though barnacles recruited in similar mean abundances in each of the three settlement periods analyzed for recruitment patterns and the un-manipulated control (unpublished data). If springtime mortality resembled something more like the clearing of substrate utilized in the smother plate experiment, then one would expect spring barnacles to compose a larger proportion of the recruitment windows of 2006 (see chapter 2), 2007 and 2008.

Spatial variability in the mortality of juvenile barnacles was a pronounced recruitment pattern. The pattern of site differences in mortality rates (Fig. 11) demonstrates that the site differences began during the winter for the winter settlers, and did not occur until after the smother plates were removed in the spring settler treatment. Analyzing spatial patterns of mortality at a high temporal resolution during the smother plate removal period in the spring, mortality patterns in space based on the quadrat area unit were similar to the summaries based on the settlement cohort unit when comparing within similar habitat areas (Fig. 13). However, spatial patterns in mortality did not confound temporal recruitment patterns.

In contrast to chapter 2 where the variability in the recruitment window was investigated by looking at a quadrat by quadrat basis, the main focus of this chapter has been to summarize the recruitment window among quadrats to get some sort of site mean recruitment pattern. Summaries based on settler cohorts can average out spatially 
aggregated mortality events since cohorts are distributed among many quadrats and cohort summaries characterize recruitment patterns over sites that may themselves encompass spatial gradients in biotic and abiotic variables that affect recruitment. Sample areas were stratified so that each site had one area with a low beach elevation between -60 and $20 \mathrm{~cm}$ MLLW and one high beach elevation > $20 \mathrm{~cm}$ MLLW (Fig. 1). The average duration of inundation was identical between all quadrats because they were placed on boulder surfaces at $40 \mathrm{~cm}$ MLLW above the beach elevation. Beach elevation can affect environmental features common to a sample area, such as the wave splash between inundation intervals and the composition of other animals and plants in the area that may directly or indirectly affect barnacle survival. For example macroalgae is more common in wave-splashed areas because this reduces desiccation stress of large plants during warm summer months, and large fronds of algae can cause physical disturbance to juvenile barnacles, enhancing their mortality (Leonard, 1999).

The Gardiner beach recruitment windows were measured from substrates selected at random from above and below the $40 \mathrm{~cm}$ MLLW level to encompass a fuller range of habitats including high and low tide, onshore and offshore areas, and boulders between the two sampling areas from the concurrent smother plate experiment of 2007. The approach in recruitment window measurements was to find the maximum extent of variability in the recruitment window by sampling as wide a range of habitats from Gardiner beach. At progressively larger spatial scales, temporal summaries of recruitment may provide information about recruitment that complements variables 
based on area, which have previously been the major focus of studies of recruitment dynamics (e.g. (Gaines and Roughgarden, 1985)).

\subsection{Future directions}

Much more in depth analyses of the photographic timeseries of barnacles during the settlement season may be a necessary future avenue of research in order to best characterize the recruitment window. Take for example the settlement timeseries from one of the 2007 natural substrate quadrats (Fig. 14). Settlement may determine when the beginning and end of the recruitment window occurs, and the shape that it takes in between (e.g. Fig. 14 in comparison to Fig. 3A). Another measurement to be taken from these timeseries is the mortality rates of individuals, perhaps as a function of the juvenile density, or as a function of the individual's settlement date. Patterns in mortality over time may vary from being random during the winter to having spatial aggregation in the spring. It would be possible to compose distinct mortality distributions by season and compare them to get a better grasp on the phenology of mortality processes, especially with respect to the increased mortality of juveniles during the spring. In either of these cases, however, it helps to have a directed hypothesis. For example, one of the possible hypotheses is to make comparisons of settlement on cleared substrate to those on uncleared substrates. A comparison of the settlement rates in Fig. 6 to the settlement counts in Fig. 14 give some indication that these are quite distinct, though this has been observed before (Connell 1985).

The types of data that could be extracted from the photographic timeseries are numerous, and the methods by which they could be extracted can be customized to the 
particular question of interest. In some cases some types of error can creep into counts of events from photographs, such as settlement and mortality, unless precautions are taken to account for this error. Eventually scientists may employ computer algorithms to make these counts of barnacle settlement and mortality, and the error that is introduced from the transfer of information from the raw photograph to the tallies of individuals might be acceptable if in the end it is possible to throughput higher numbers of individuals and assess patterns over larger spatial scales. Computers can be programmed to perform the same complex operations for example to ensure that an object is in fact a cyprid and not a miniscule bulge in the rocky surface, or to use distinct algorithms when the rocky surface is wet from rain or wave splash making the individual barnacles more difficult to identify. However, scientists will probably always need to be hands on, tailoring such algorithms to their particular set of photographs. With the currently available image processing software, tailoring algorithms to measure barnacles in the settlement photographs would probably take longer than actually taking the time to conduct the counts manually and by eye. The next incremental step in the progression may be to implement more fully integrated computer aided visual counts. One example would be to have automatic photographic registration and to use templates that could carry all the necessary information about each individual barnacle. Templates that are a transparent surface over the raw photograph may aid in detecting individuals, or when distinct individuals that only appear to be the same individual occupy the same location on subsequent photos of a timeseries. 
Photographs on lower frequencies, such as were employed between smother plate photo intervals, may miss new barnacles that have time to settle and metamorphose so that they resemble the juveniles that they replaced. Nearly identical juveniles occurred in photographs of smother plates, though later inspection revealed them to be distinct (personal observation). Low frequency photographs introduce error in estimating the settlement rate (Minchinton and Scheibling, 1993), but more importantly can cause error in assigning the date of settlement for recruits, a pivotal measure for the cohort based measures reported here. This presents a potential pitfall for the further use of smother plates since an increased frequency of removing and replacing the smother plates to take photographs and address this concern would introduce additional physical disturbance. Promising avenues of future development include using clear smother plates to monitor individuals without smother plate removal, or employing statistical methods to estimate replacement probabilities in order to add this source of error to the survival probability estimates.

Future work measuring the lipid composition of cyprid and juvenile barnacles to evaluate the cold response of barnacles should focus on characterizing variability across samples collected throughout the settlement season. This avenue of research might especially be viable if the most abundant and easily detectable PC and PE components can be measured reliably at low cost. These records would allow correlations of lipid composition with environmental temperature over time. The highly sensitive statistical method used here only yielded marginally significant differences between warm and cold barnacles, which may have been due to the small temperature difference between 
the treatments. There is a greater ability to interpret results from a natural experiment on temperature even as compared to correlation of trends over time. However, further verification of a cold stress response of barnacles during the final stages of metamorphosis must be conducted before one can be sure of the interpretation of these results. One immediately promising avenue of research may involve comparing timeseries of pelagic cyprid to benthic cyprid lipid composition. Hypothetically the pelagic environment has a narrower temperature range and the cold stress would be more commonly experienced after settlement. However, one would need to distinguish this from normal developmental trends in lipid composition, which may be derived from the same timeseries comparing lipid composition of benthic versus pelagic cyprids during periods of time when the rocky intertidal and the pelagic temperatures are identical.

The concept that not all barnacle settlers have equal probability of survival (Chapter 2) is equivalent to the concept that not all juveniles have the same probability of mortality (this Chapter). Recruitment dynamics may primarily involve how and when suitable habitat is occupied, a hypothesis that creates many new possibilities for the dynamics of barnacle settlement and recruitment that should be the focus of future research. Perhaps barnacles have hardwired strategies that maximize their fitness when they encounter cold temperatures in the nearshore environment and are competent to settle. To understand this better, a concept of the physiological tradeoffs that barnacles experience upon settlement and recruitment is necessary, because it does not appear to be as simple as barnacles avoiding settlement when the water is cold. In monotonically 
warming years like 2008, cold avoidance would come at a fitness cost, since settlement began during the coldest period of the winter in January before day 31 and potentially the best habitats would be unavailable by the time the seawater warmed later on in the season. The first recruits of 2008 had access to all of the best settlement habitats, but this was hypothetically tempered with a physiological trade off, where cold tolerance comes at a cost of compromising a barnacle's ability to discriminate for habitats of highest quality. Then as water warmed, barnacles had better habitat selectivity, and this could explain the humped shape distribution to the recruitment window in 2008. By contrast, in 2007, the water was warmest at the time when the highest quality habitat was available during the first 31 days of settlement in January. With no cold effect, barnacles could hypothetically express high degrees of habitat selectivity, and the exponential decay apparent in the 2007 winter recruitment window (Fig. 3A) could be a result of a single rate of habitat exploitation governing this dynamic. The interplay between individual fitness, as mediated by a physiological trade off, and seasonal patterns in temperature, may to a large degree predict site average trends in the recruitment window.

Other interesting hypotheses about habitat selection and individual fitness emerge from the patterns of recruitment from the smother plate experiment. An apparent feature of the settlement rate and recruitment relationship was the sub-linear trend fit to the settlement rate and recruitment relationship (Fig. 9). Barnacles that settled at a higher rate had a lower per capita probability of survival. One hypothetical explanation for this pattern is that when barnacles settle at high rates, their probability of 
selecting good habitat decreases. When each site's data was fit with a separate trend, the exponent was not significantly smaller than one for the rock wall quadrats, though it was highly significantly smaller than one at Gardiner beach. A positive correlation was observed between the settlement rate and wave energy occurring at Gardiner beach on cleared substrates of the smother plate experiment (see Chapter 3). However, these barnacles settled during a very cold period in the 2007 winter, and the cold tolerance / habitat selectivity trade off in barnacle settlement discussed above may partially explain why the trend in settlement was linearly related to physical forcing, an assertion that is further supported by the fact that this was the only period during the whole year when barnacles regularly settled at a higher rate at the rock wall (Fig. 6) indicating that the linear trend of physical forcing with settlement rate occurred during an anomalous settlement interval. Nevertheless, an analogous physical mechanism may be driving the settlement rate during the high settlement periods 1,4 and 5. The primary manipulation used in the experiment, clearing small patches in surfaces otherwise blanketed by juveniles, may elicit the types of habitat scavenging behaviors that if successful constitute the bulk of the spring recruitment window. The relationship between settlement rate, survival probability and the possible forces driving this dynamic, namely wave energy, should be a focus of further investigation on the factors controlling the spring recruitment window.

\subsection{Acknowledgements}

This research was conducted with support from the Academic Programs office and the Coastal Ocean Institute at the Woods Hole Oceanographic Institution. The lipid extraction and analysis could not have been conducted without the generosity and expertise extended to me by Benjamin van-Mooy and Helen Fredricks. Heidi Blythe and Michelle Reyes assisted with measurements of barnacle mortality during the winter 
of 2007. In addition Heidi Blythe provided help with GIS and photo analysis for a number of other aspects of this research. Discussions with Jesús Pineda and Victoria Starczak were critical for formulation, implementation and analysis of this research.

\subsection{References}

Bligh, E.G. and Dyer, W.J. 1959. A rapid method for total lipid extraction and purification. Canadian Journal of Biochemistry and Physiology. 37: 911-917.

Blythe, J. N. \& Lea, D. W. (2008) Functions of height and width dimensions in the intertidal mussel, Mytilus californianus. Journal of Shellfish Research, 27, $385-$ 392.

Brawley, S. H. \& Johnson, L. E. (1991) Survival of fucoid embryos in the intertidal zone depends upon developmental stage and microhabitat. Journal of Phycology, 27, 179 - 186.

Brousseau, D. J. \& Goldberg, R. (2007) Effect of predation by the invasive crab Hemigrapsus sanguineus on recruiting barnacles Semibalanus balanoides in western Long Island Sound, USA. Marine Ecology Progress Series, 339, 221228.

Connell, J. H. (1985) The consequences of variation in initial settlement vs. postsettlement mortality in rocky intertidal communities. Journal of Experimental Marine Biology and Ecology, 93, 11-45.

Denny, M., Helmuth, B., Leonard, G. H., Harley, C. D. G., Hunt, L., J.H. \& Nelson, E. K. (2004) Quantifying scale in ecology: lessons from a wave-swept shore. Ecological Monographs, 74, 513-532.

Gaines, S. \& Roughgarden, J. (1985) Larval settlementt rate: a leading determinant of structure in an ecological community of the marine intertidal zone. Proceedings of the National Academy of Sciences, 82, 3707-3711.

Gimenez, L. (2004) Marine community ecology: importance of trait-mediated effects propagating through complex life cycles. Marine Ecology Progress Series, 283, 303-310.

Hawkins, S. J. \& Hartnoll, R. G. (1982) Settlement patterns of Semibalanus balanoides (L.) in the Isle of Man (1977-1981). Journal of Experimental Marine Biology and Ecology, 62, 271-283.

Jarrett, J. N. (2003) Seasonal variation in larval condition and postsettlement performance of the barnacle Semibalanus balanoides. Ecology, 84, 384-390.

Leonard, G. H. (1999) Positive and negative effects of intertidal algal canopies on recruitment and survival of barnacles. Marine Ecology Progress Series, 178, 241-249.

Michell, S. C. (2005) How useful is the concept of habitat? - a critique. Oikos, 110, 634638.

Minchinton, T. E. \& Scheibling, R. E. (1993) Variations in sampling procedure and frequency affect estimates of recruitment of barnacles. Marine Ecology Progress Series, 99, 83-88. 
Pineda, J., DiBacco, C. \& Starczak, V. (2005) Barnacle larvae in ice: survival, reproduction, and time to postsettlement metamorphosis. Limnology and Oceanography, 50, 1520-1528.

Raimondi, P. T. (1990) Patterns, mechanisms, consequences of variability in settlement and recruitment of an intertidal barnacle. Ecological Monographs, 60, 283-309.

Steele, J.H. and E.W. Henderson. (1994) Coupling between physics and biological scales. Philosophical Tansactions of the Royal Society of London (B) 343, 5-9.

Steele, M. A. \& Forrester, G. E. (2005) Small-scale field experiemtns accurately scale up to predict density dependence in reef fish populations at large scales. Proceedings of the National Academy of Sciences, 102, 13513-13516.

Sturt, H.F., R. E. Summons, K. Smith, M. Elvert, and Kai-Uwe Hinrichs. 2004. Intact polar membrane lipids in prokaryotes and sediments deciphered by highperformance liquid chromatography/electrospray ionization multistage mass spectrometry - new biomarkers for biogeochemistry and microbial ecology. Rapid Communications in Mass Spectrometry , 18: 617-628.

Thiyagarajan, V., Harder, T. \& Qian, P.-Y. (2002) Effect of the physiological condition of cyprids and laboratory-mimicked seasonal conditions on the metamorphic successes of Balanus amphitrite Darwin (Cirripedia; Thoracica). Journal of Experimental Marine Biology and Ecology, 274, 65-74.

Williams, E. E. (1998) Membranw lipids: what membrane physical properties are conserved during physiochemically-induced membrane restructuring? American Zoologist, 38, 280-290. 
Table 1. Analysis of variance of residual recruitment abundance. The residuals of recruitment were obtained by regressing the log of the settlement rate for cohorts of barnacle settlers against the log of the realized number of recruits from those cohorts divided by the number of days in the settler cohort. The linear regression removed the co-varying settlement rate that had different mean values for the two factors, settlement period and site. Settlement period factor corresponds to the winter and two spring settlement periods for which there were 10,6 and 13 cohorts respectively. The site factor was the two sites, one to the west on a rock wall and one to the right at Gardiner beach (Fig. 1). Each site had ten replicate quadrats randomly distributed between two sample areas, and a different set of quadrats for each settlement period. A linear two way ANOVA was conducted on the regression residuals using MATLAB's anovan function.

\begin{tabular}{llllll} 
Source & Sum Sq. & d.f. & Mean Sq. & F & Prob $>$ F \\
\hline Settlement period & 1.6107 & 2 & 0.80536 & 4.54 & 0.015 \\
Site & 7.6388 & 1 & 7.6388 & 43.02 & $2.5 \mathrm{E}-08$ \\
Settlement period*Site & 0.2186 & 2 & 0.10929 & 0.62 & 0.54 \\
Error & 9.2343 & 52 & 0.17758 & & \\
Total & 20.3925 & 57 & & &
\end{tabular}




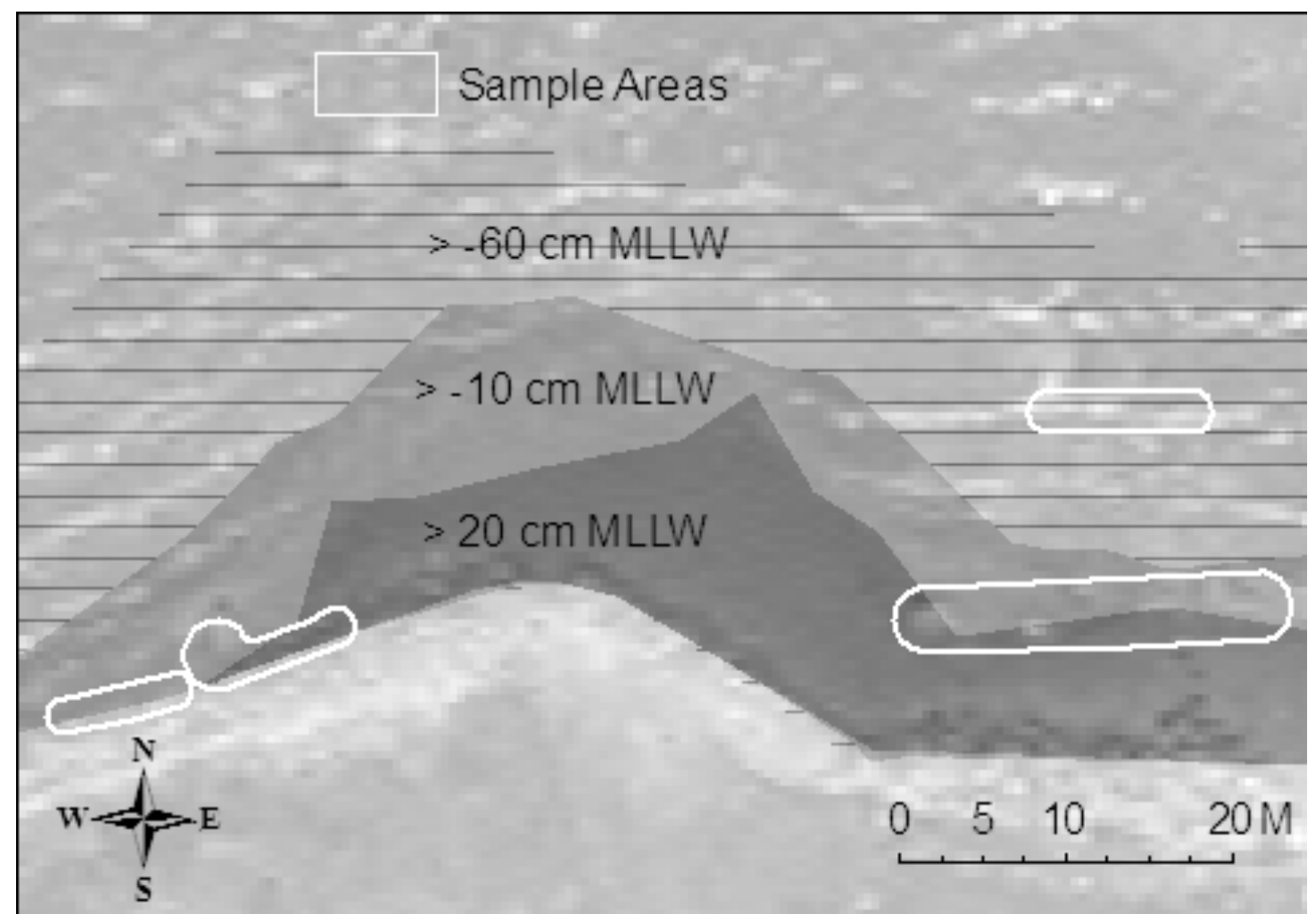

Fig.1. The four sample areas with independent sets of replicates at the rock wall and Gardiner beach. Beach elevations are summarized in elevation intervals like a bathymetric map. The bathymetry at the site monotonically increased from offshore to onshore, where at the bottom of the map is a granite boulder rock wall along the entire perimeter of the intertidal zone. To the left there is a cobble beach where the only barnacle habitat is located on granite boulders that are part of the rock wall. To the right there is a gently sloping sandy beach with large boulders protruding from the beach to elevations in the range of the barnacle zone. Between the left and right is a gradual transition from a sandy to a cobble beach with several large boulders and a rocky intertidal headland that was not sampled in this study except to collect settlers for the initial settlement plate collection on day 18. Sample areas on the left and right are paired shallow beach elevation and deep beach elevation sub-sites to capture a range of environmental variables in this intertidal habitat. The map is plotted overlaying a course grain photographic image of the site to highlight some of the features of the headland that is just to the south of the site, and to indicate the direction of waves that break on the headland, as indicated by the white caps in the offshore regions of the photo. Since the photo was taken at low tide, many of the boulders that are normally inundated at high tide are indicated by light shadows. 


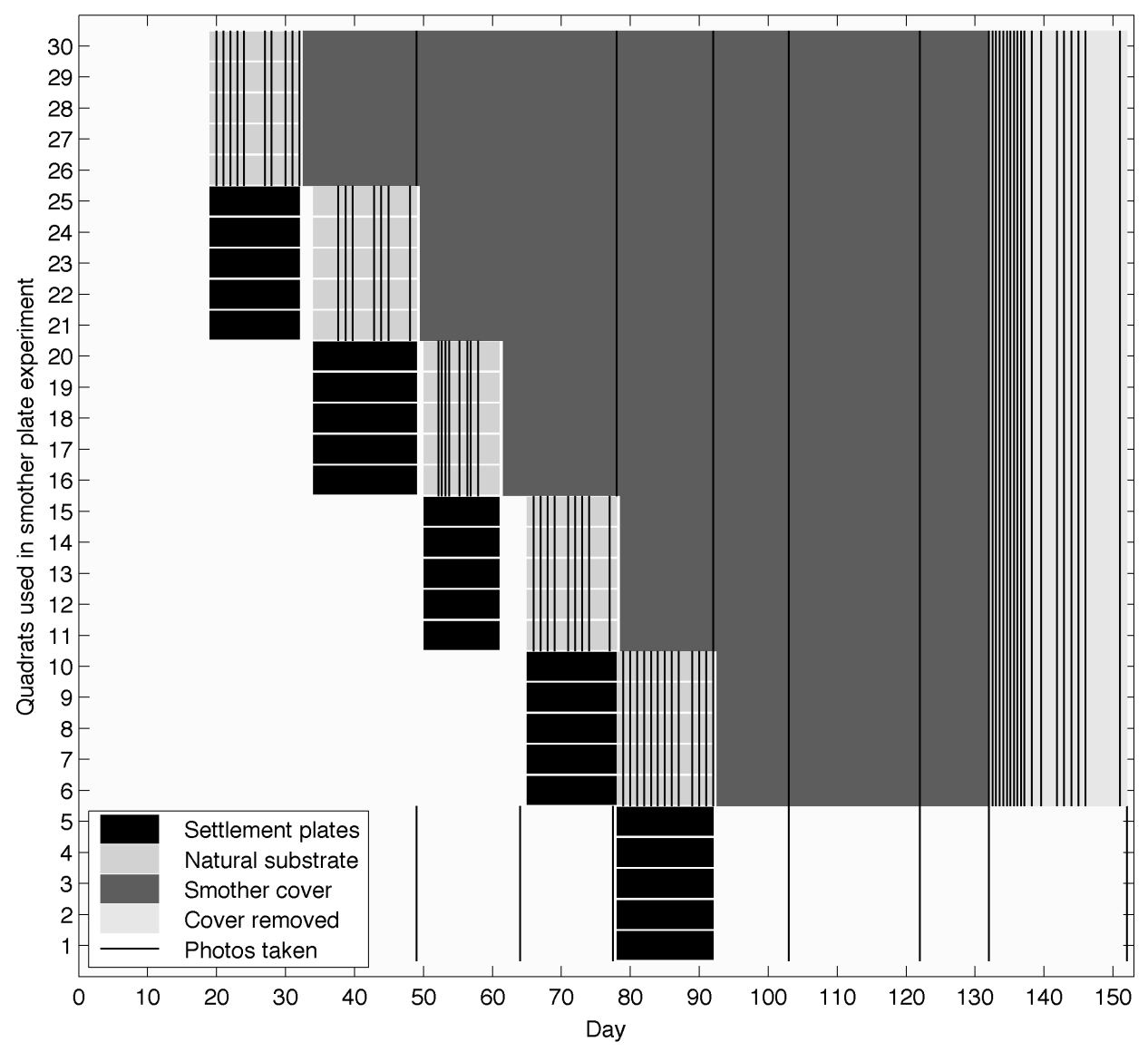

Fig. 2. A schematic to indicate the five settlement periods, smother plate intervals, smother plate removal period and intervals with photographs. Twenty-five quadrats from each of the four sample areas were randomly divided into each of the sample areas, and five additional random quadrats from each sample area were un-manipulated but monitored at regular intervals as a control. Except in the first settlement period, quadrats that were used for settlement plates were later cleared of juveniles and entered into the smother plate experiment. Un-manipulated quadrats had settlement plates covering their surface for two weeks, though they were never cleared nor subsequently covered again. 

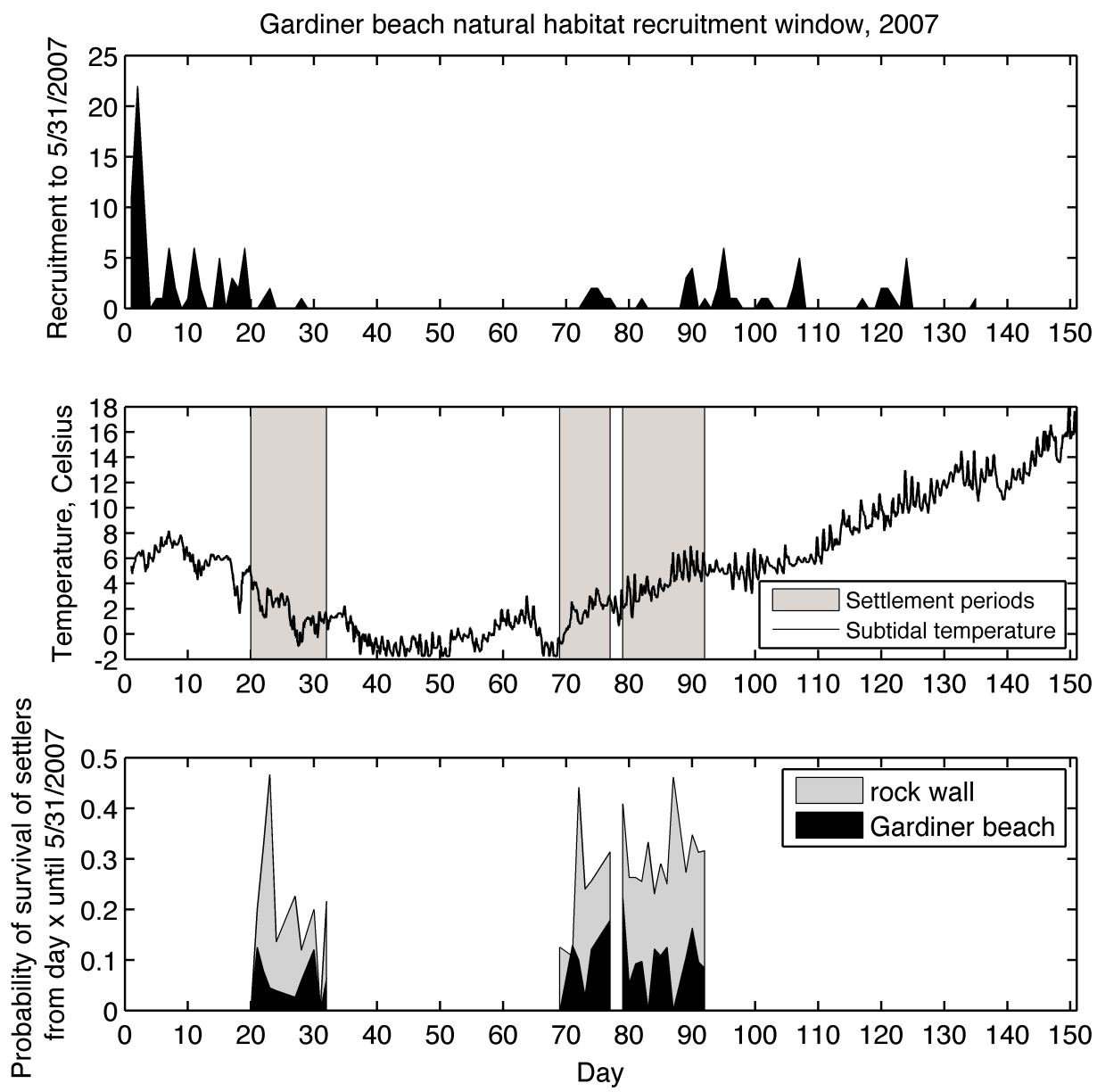

Fig. 3. The 2007 recruitment window, temperature record, and three main sampling periods for recruitment in the smother plate experiment. Fig. 3 A. is the 2007 recruitment window, which has on the $\mathrm{x}$-axis the day in which barnacles settle, and on the $y$-axis the number of the settlers from day $x$ that survived to day $5 / 31 / 07$. The number of recruits is the sum of all individuals recorded from a standard surface area of 15 quadrats. Fig. 3 B. is the sub-tidal temperature record, which has the same X-axis corresponding to the settlement season of 2007, and on the y-axis has the seawater temperature recorded at 1-hour intervals. Gray intervals correspond to the periods of time when barnacles were sampled in the smother plate experiment for survival analysis. Fig. $3 \mathrm{C}$. is the probability of barnacles settling during the respective sampling intervals for the smother plate experiment to 5/31/07. The probability of survival was the fraction of settlers that remained on 10 replicate quadrats for each of the settler cohorts. These are color coded grey for the rock wall and black for Gardiner beach, as a different set of 10 quadrats was monitored for each of the sites and each of the three sample intervals, in all representing 60 quadrats. 

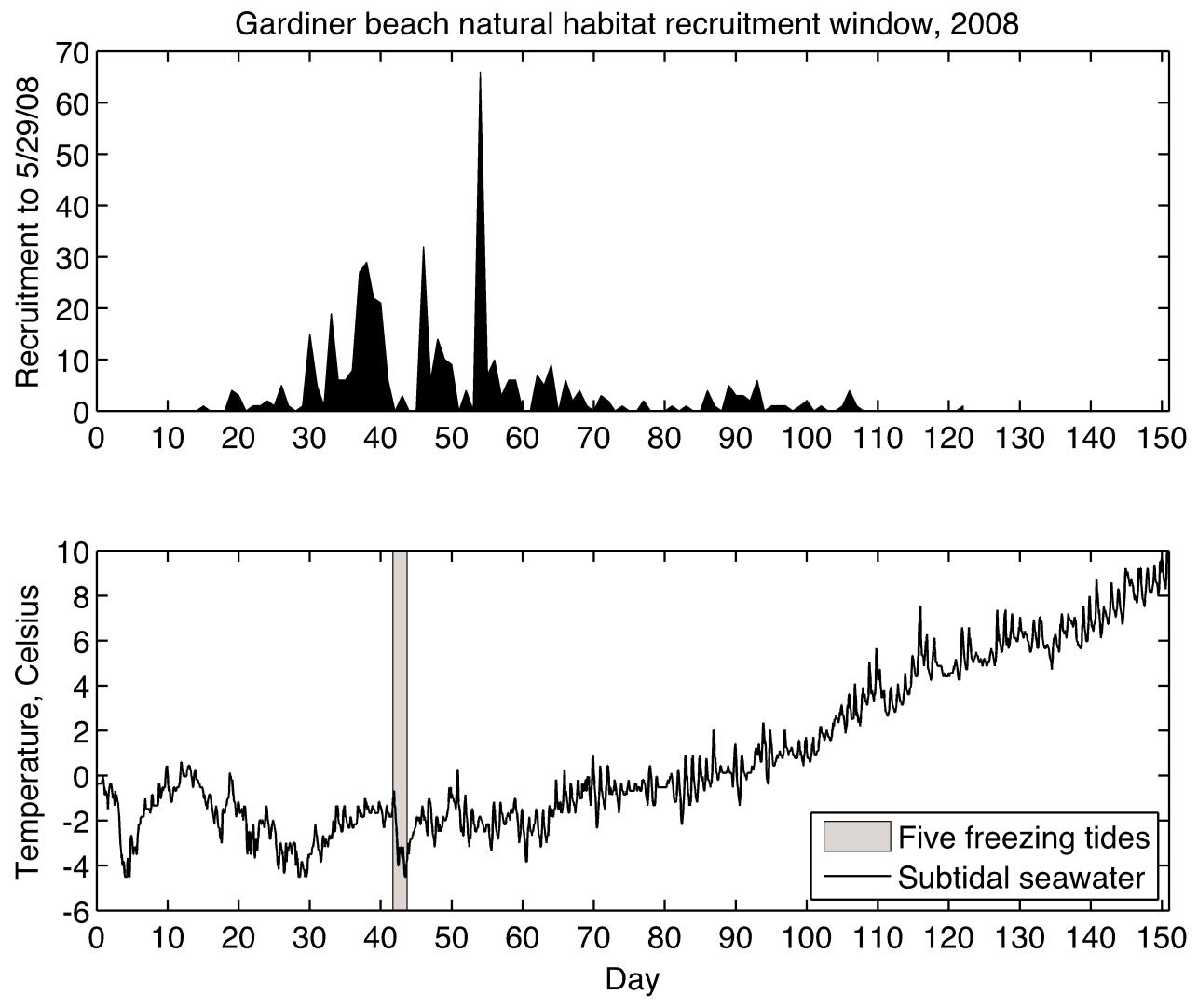

Fig. 4. The 2008 recruitment window and temperature record. Fig. 4 A. is the recruitment window recorded from among 15 natural substrates at Gardiner beach recorded between January $1^{\text {st }}$ and May $29^{\text {th }}$ of 2008. The x-axis is the day during the settlement season when settlers were first recorded on quadrats. The $y$-axis is the number of recruits that were recorded to have settled on day $\mathrm{x}$, summed across all 15 quadrats that were monitored on a daily basis for settlement. Fig. 4 B. The temperature record during the settlement season. The period of time when there were five freezing tides during the cold stress lipid experiment (see Fig. 7) is highlighted for comparison. This subtidal record of temperature is taken at a different depth, about one meter deeper, than the subtidal logger in 2007. 


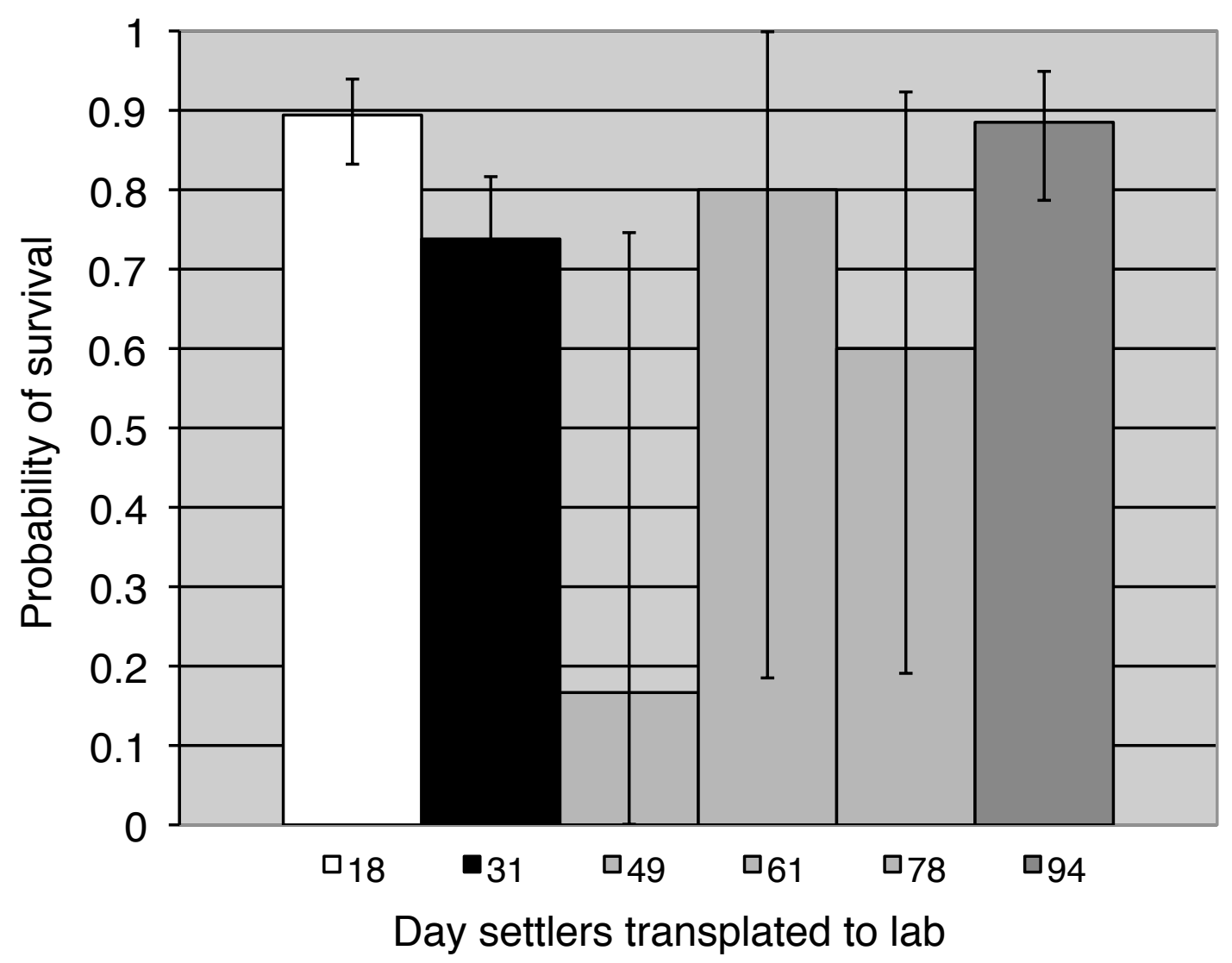

Fig. 5. The probability of survival for settlers transplanted to the lab after six settlement intervals throughout the 2007 settlement season. Six different sets of quadrats were outplanted and recovered at two-week intervals from January to March 2007 corresponding to six settlement periods. Five groups of settlement plates correspond to the five periods of settlement recorded on natural substrate for the smother plate experiment, and these plates were transplanted to a lab seawater aquarium on the day in the label on the x-axis. The first bar corresponds to a set of quadrats that were outplanted on day 1 corresponding to the beginning of the settlement season and before the smother plate experiment began. Those barnacles that survived to day 153 were counted and this number, $\mathrm{x}$, was divided by the total number, $\mathrm{n}$, of individuals that had settled during the respective settlement interval and survived to be transplanted to the lab on the day given in the $\mathrm{x}$ label. The numbers $\mathrm{x}$ and $\mathrm{n}$ were fit to a binomial distribution and the $99 \%$ confidence intervals for the probability of survival so calculated were computed in MATLAB using the binofit function. 


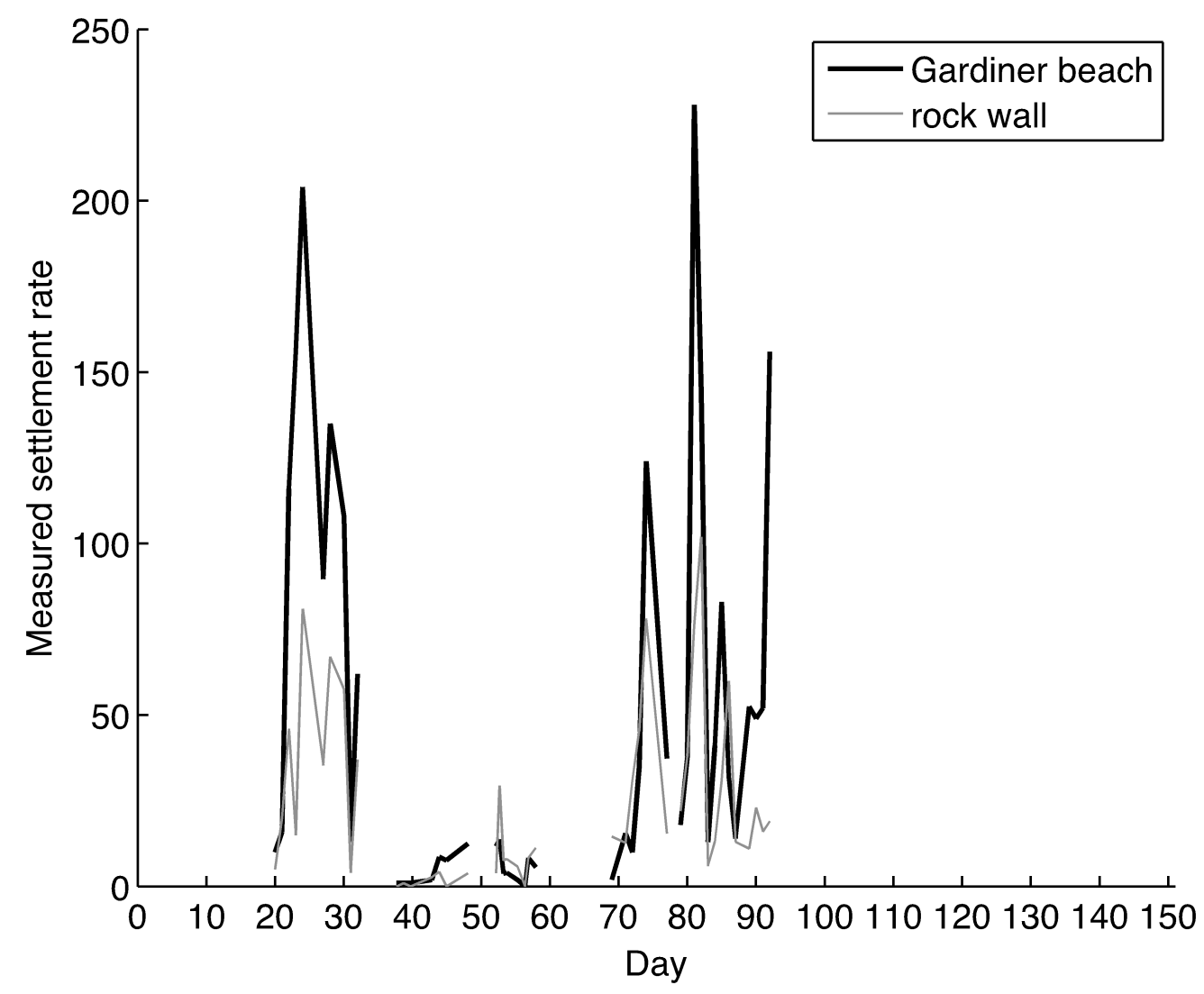

Fig. 6. Settlement rate with time in the five periods where settlement was monitored on cleared substrates for the smother plate experiment. Photographs that were conducted at regular intervals after substrate clearing on independent and replicated sets of quadrats were established at the beginning of each of five settlement intervals. The $\mathrm{x}$-axis reports the day in which settlement was recorded, which in some instances was more than one day before the prior photographs. The y-axis gives the settlement rate that is the number of new settlers recorded ten replicate quadrats divided by the number of days between successive photographs. The legend indicates the color-coding for the line, which indicate the settlement rates recorded at two sites, Gardiner beach and the rock wall. Time between sampled settlement intervals have no values though this does not mean there was zero settlement then. Nor does the first recording from each series of settlement rate measures indicate any number of days over which this datum was calculated, since the first day of settlement was always calculated at a 12 to 24 hour interval after the initial clearing of the settlement substrates, for which there was also a baseline photo to identify new settlers in the initial measurement of settlement rate. 
Fig. 7. Environmental variables, temperature and wind, recorded during the cold stress and lipid experiment conducted in February 2008. The x-axis common to three sub figures are the days, where day 1 is January $1^{\text {st }} 2008$ for comparison. Fig. 7 A. is the temperature recorded using various temperature sensors. Two Onset temperature loggers are initially deployed in the field prior to the experiment, and one of the two was transplanted along with settlement plates to the lab. Measurement intervals for the onset loggers was 5 minutes. The Otis Airforce Base weather station located near the study site (See Fig. 1 in Chapter 3) also had a record for temperature that was recorded on about an hourly basis. Fluctuations in air temperature are cut off from the graph if they greatly exceed the bounds of the temperature loggers below -10 degrees and above 6 degrees Celsius. A thermocouple temperature probe was used to take measurements of barnacle temperature in the field on four of the coldest tides during the cold stress experiment. Barnacle temperature is approximately the temperature of the plastic plate to which the barnacles had adhered upon settlement. The box represents the upper and lower quartiles of these settlement plate temperatures, and the whiskers are the upper and lower extent of the data calculated using MATLAB's boxplot algorithm. Fig. 7 B. Wind speed in meters per second measured at the Otis Airforce Base, and with a weather vein that was deployed in the rock intertidal during the low tides. The width of the boxes indicates the period over which continuous wind data were collected, approximately covering 2 hours per low tide. The top and bottom of the box are the upper and lower quartiles of wind speed and the whiskers and the extent of the data calculated with Matlab's boxplot algorithm. Fig 7 C. A conceptual time plot of three treatments that were collected for lipid extraction on three days at the end of the experiment. Black bars indicate periods of time when replicate settlement plates with barnacle settlers remained in the field. The change from black to a red bar indicates when replicate settlement plates were transplanted to the lab aquarium for a cold stress control. The beginning of the black bars indicate when the barnacle settled, which for one cohort of barnacles, the new settler control, settled after the coldest four low tides and were first recorded on the fifth tide where there were temperature records of settlement plate temperature and wind speed. 


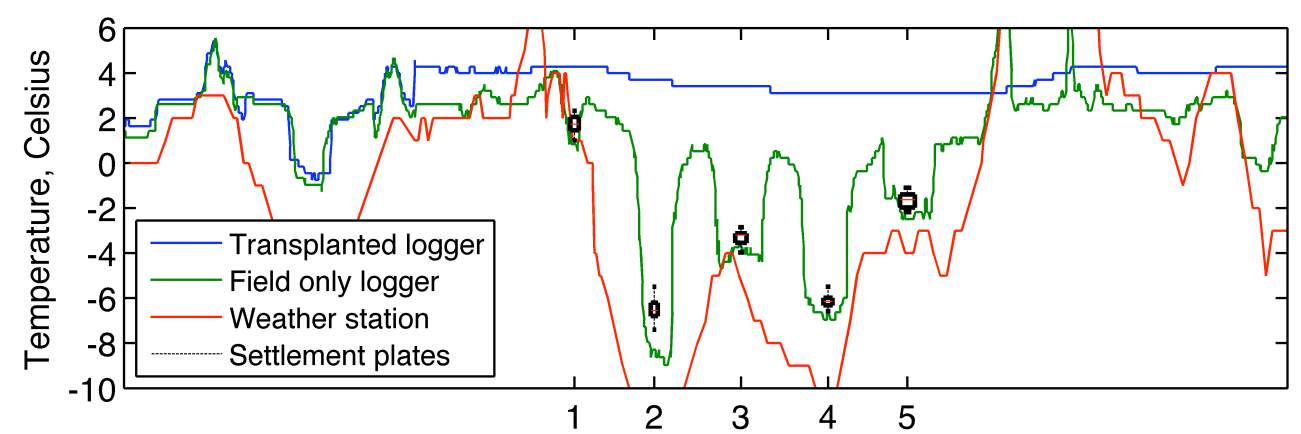

Barnacle temperature sampled during low tides

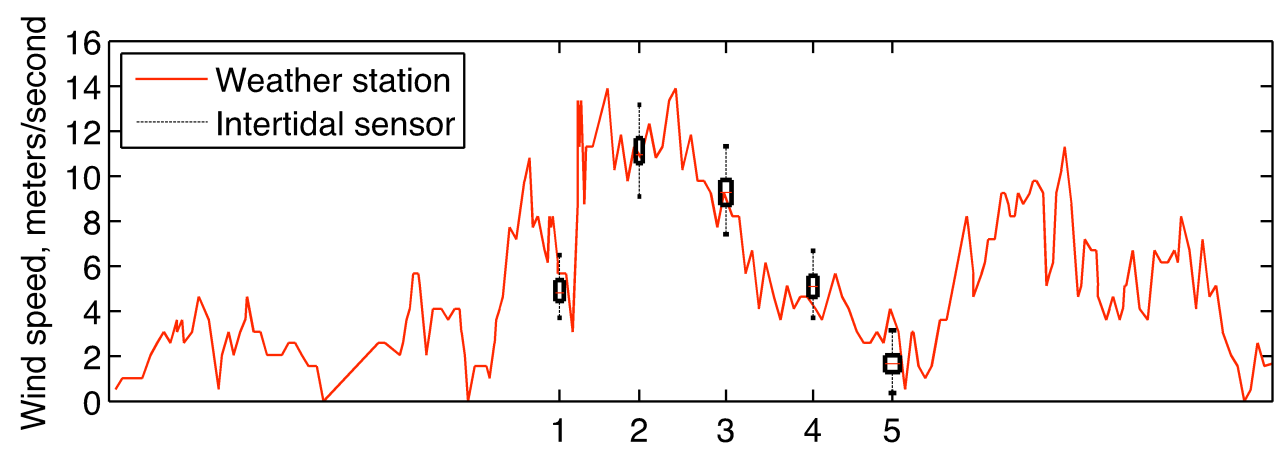

Wind sampled on five low tides

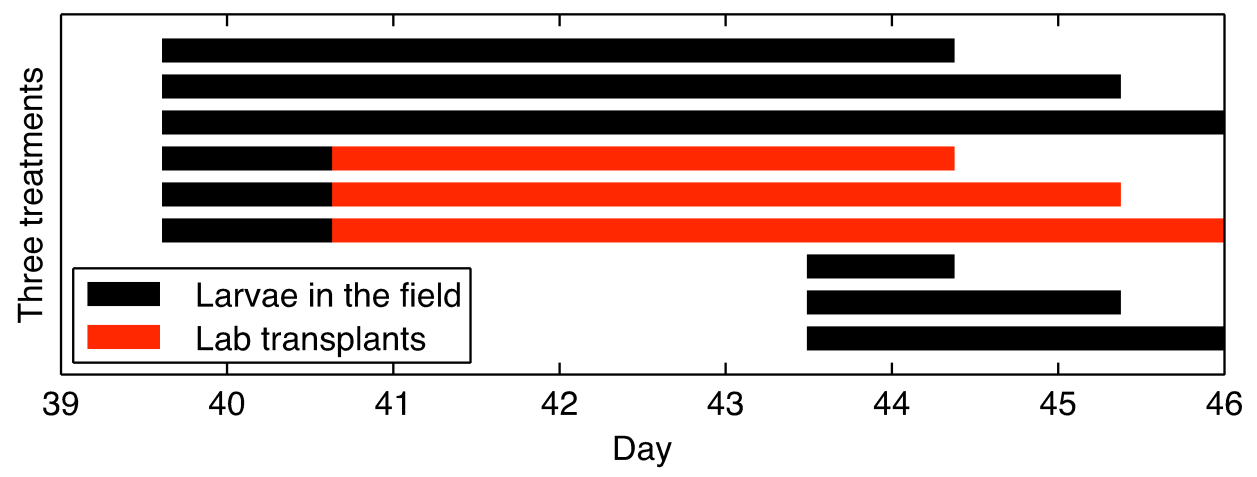

Fig. 7 (see previous page for text) 


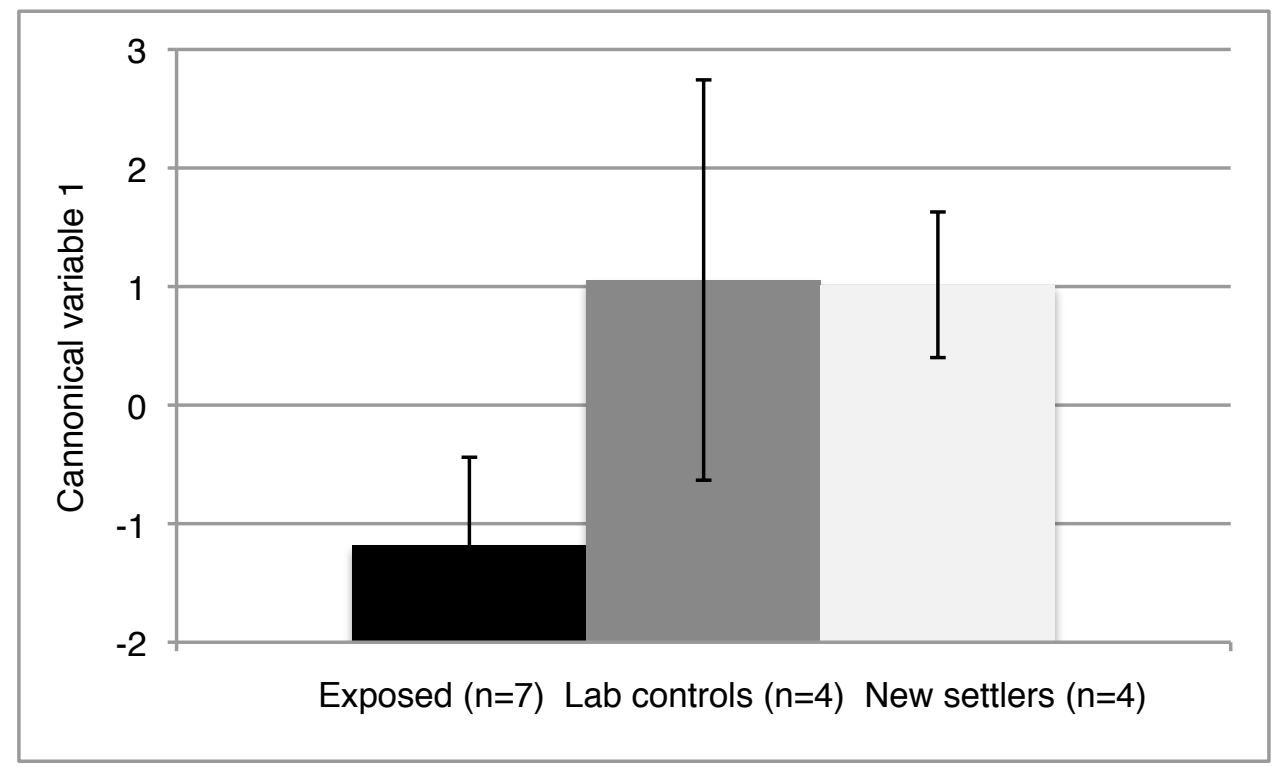

Fig. 8. Canonical factor analysis of lipid samples indicating a cold stress response in cold exposed barnacles. The three treatments are labeled on the $\mathrm{x}$-axis with their respective number of replication. Number of replicates corresponds to settlement plates or groups of settlement plates sampled to collect approximately five individual settlers per lipid sample. The first canonical variable value for each replicate averaged, giving the height of the bars, and the standard deviation was calculated and plotted in the graph with error bars that are 1 standard deviation. 


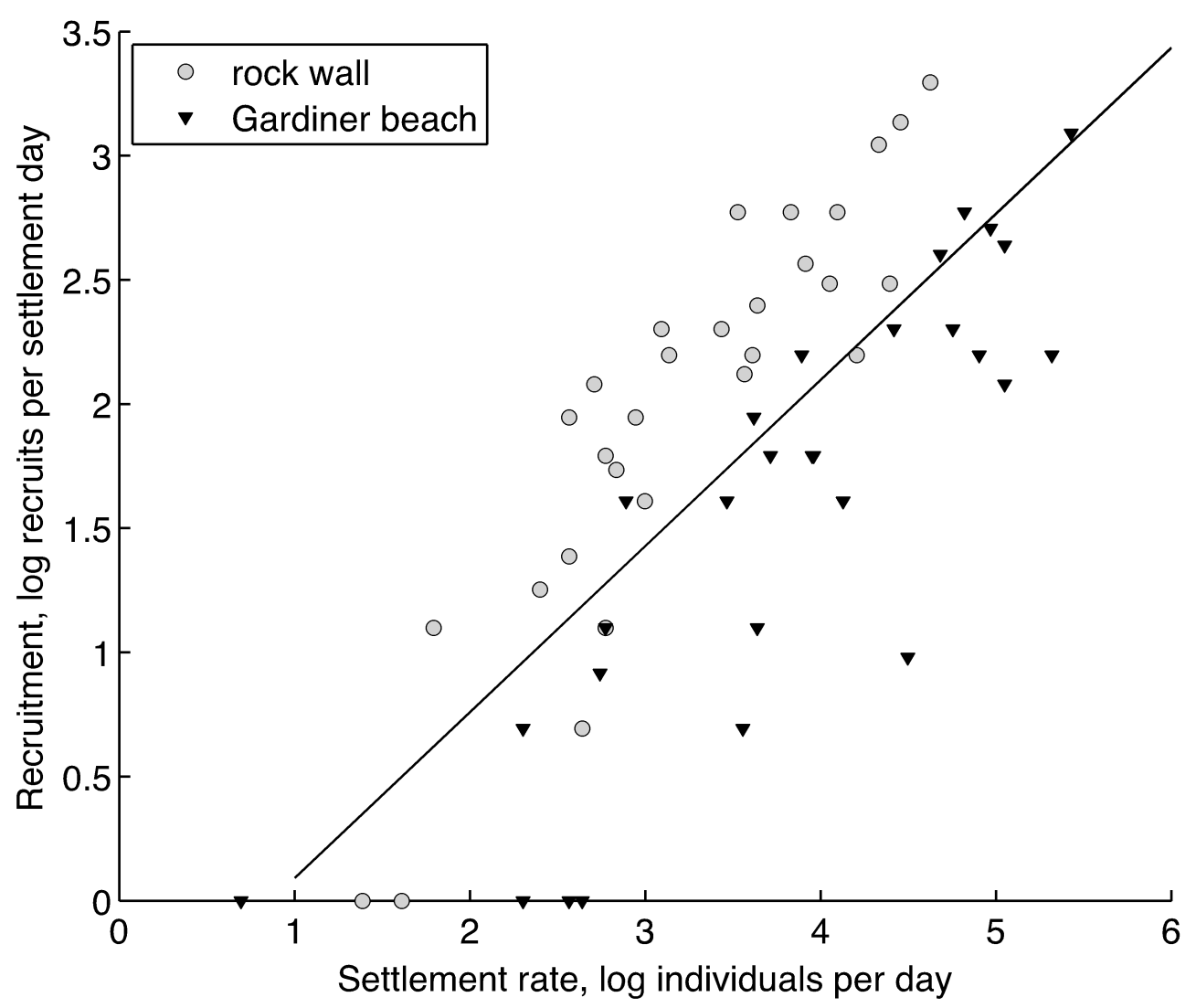

Fig. 9. The recruitment resulting from cohorts with a given settlement rate. The x-axis is the number of settlers measured for each cohort of barnacles divided by the number of days between settlement measures, as in the settlement rate in Fig 6, except only plotted for the three intervals, one in the winter and two in the spring with reasonably high rates of settlement. The y-axis is the number of survivors from each daily cohort divided by the number of days of settlement in each cohort. For regression, the $\mathrm{x}$ and $\mathrm{y}$ variables were $\log$ transformed and fit with a line, which indicates differences in recruitment between Gardiner beach and the rock wall. The site and settlement period factors were assessed using ANOVA of the residuals. Subsequently two lines were fit in the log log space to describe recruitment at each site (See results) but the regression lines are not plotted here. 


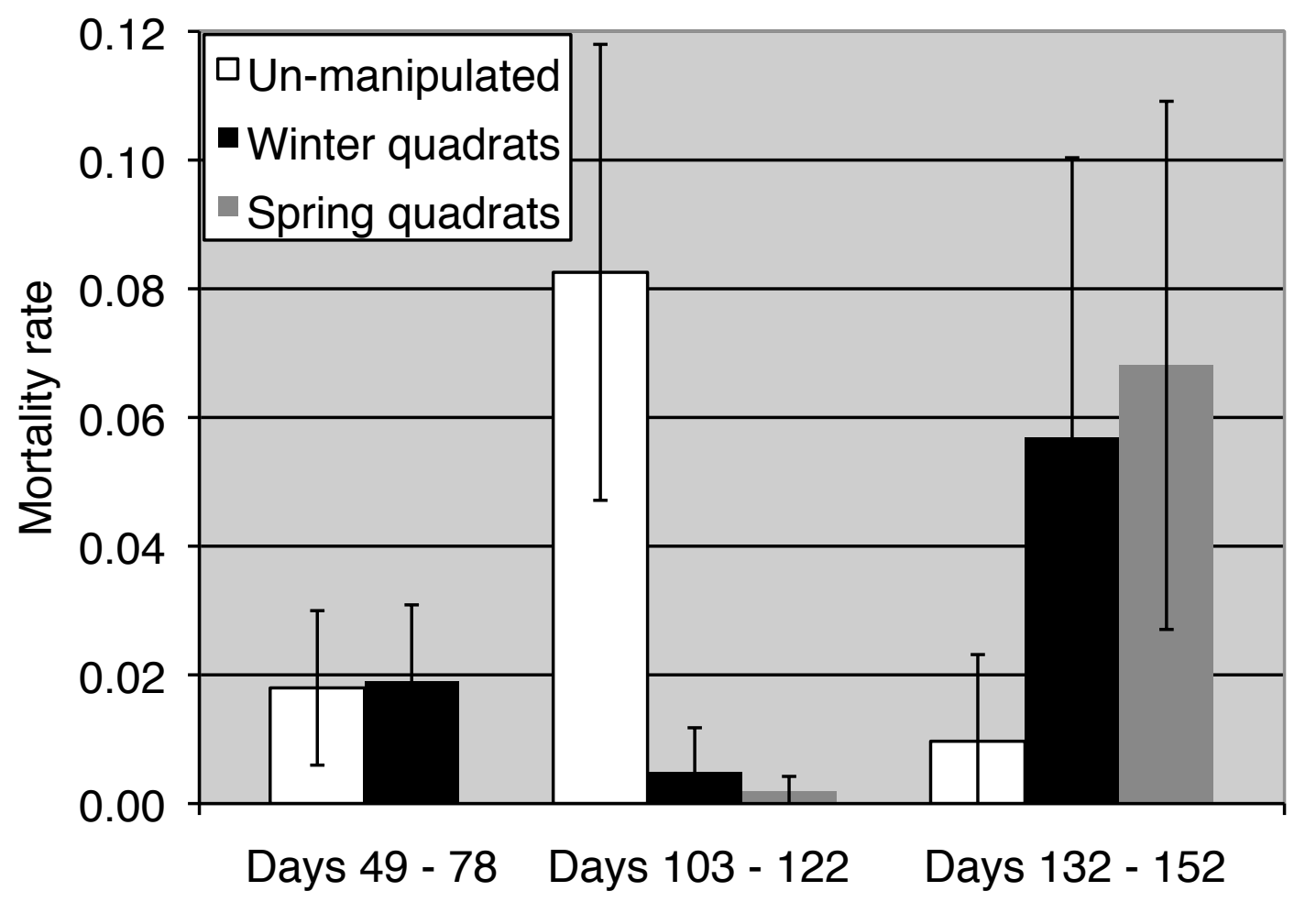

Fig. 10. Mortality rates calculated at three intervals for un-manipulated substrates, wintertime recruits and spring time recruits that had settlement in the mid-spring. The first two sets of bars on the left are mortality rates during the interval days $51-64$ when there are no spring settlers because they have not settled yet. For comparison, the winter recruits have smother plates covering the quadrats while the un-manipulated do not. The middle two sets of bars are the un-manipulated quadrats compared to the winter and spring quadrats with smother plate covers between days $103-122$ when the springtime mortality initially began on natural substrates. The last set of bars represents the mortality rate of these same sets of juveniles one month later, with no change for the unmanipulated quadrats, but with cover removal of the smother plate experiments on day 103. In all cases the error bars are 1 standard deviation in the mortality rate from among twenty replicate quadrats. 


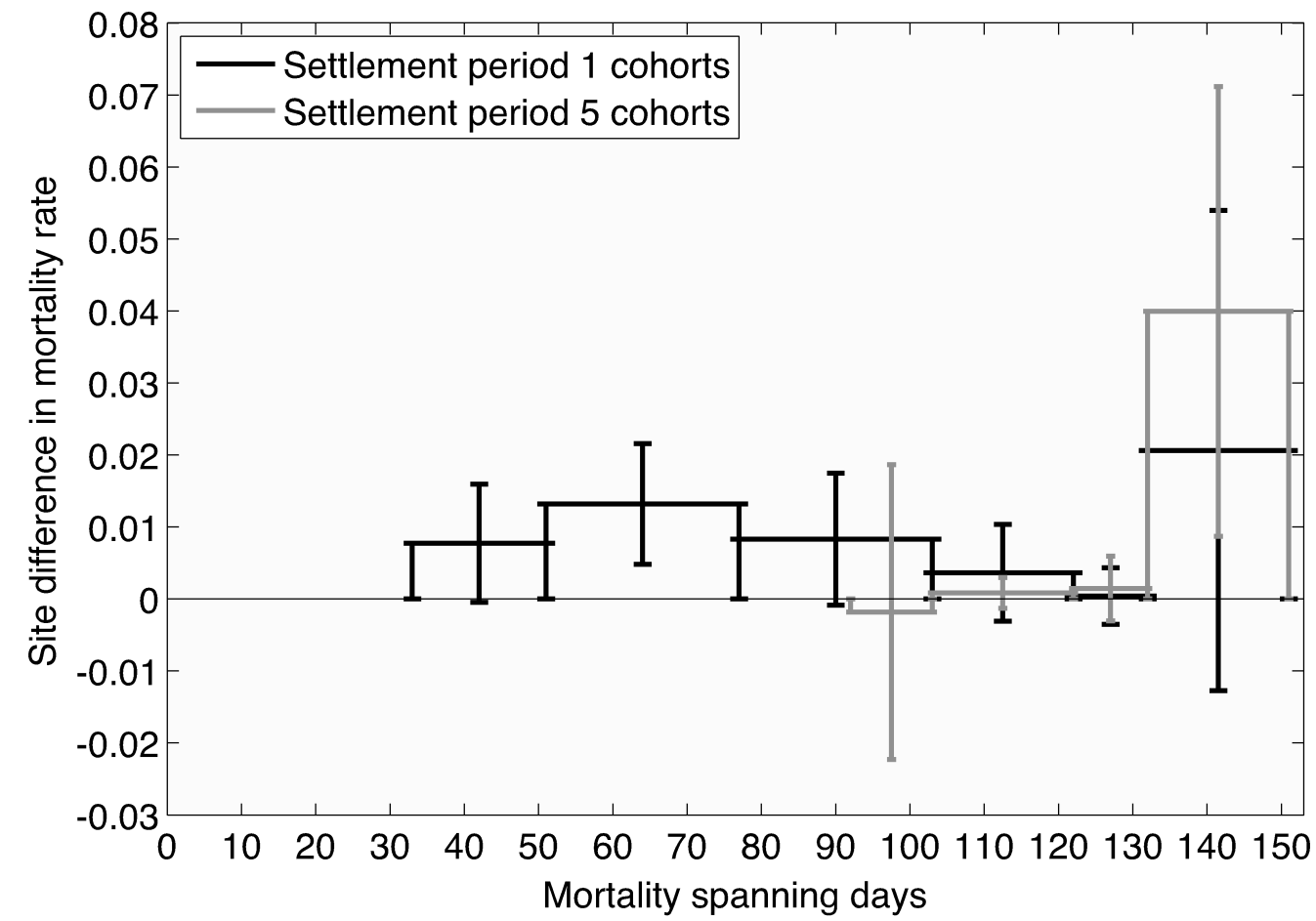

Fig. 11. Site differences in the mortality rate calculated for the winter and mid-spring cohorts. The mortality rate was calculated in consecutive intervals from after settlement through day 151, where the $\mathrm{x}$-axis represents the days of the year, and where the left end of each bar is when the prior photo for reference was taken and the right end of each bar is the final photo for each from which the missing number of juveniles was measured to calculate the mortality rate for this interval. Each bar represents the difference in the mortality rate between the rock wall and Gardiner beach quadrats where a positive value represents higher mortality at Gardiner beach. The calculation for this mortality rate difference is calculated by finding the mortality rate for each settler cohort, which for the winter quadrats has ten cohorts and for the mid spring quadrats has 13 cohorts. The mean of the difference between site cohorts mortality rate and the standard deviation of the difference is plotted in the graph. 


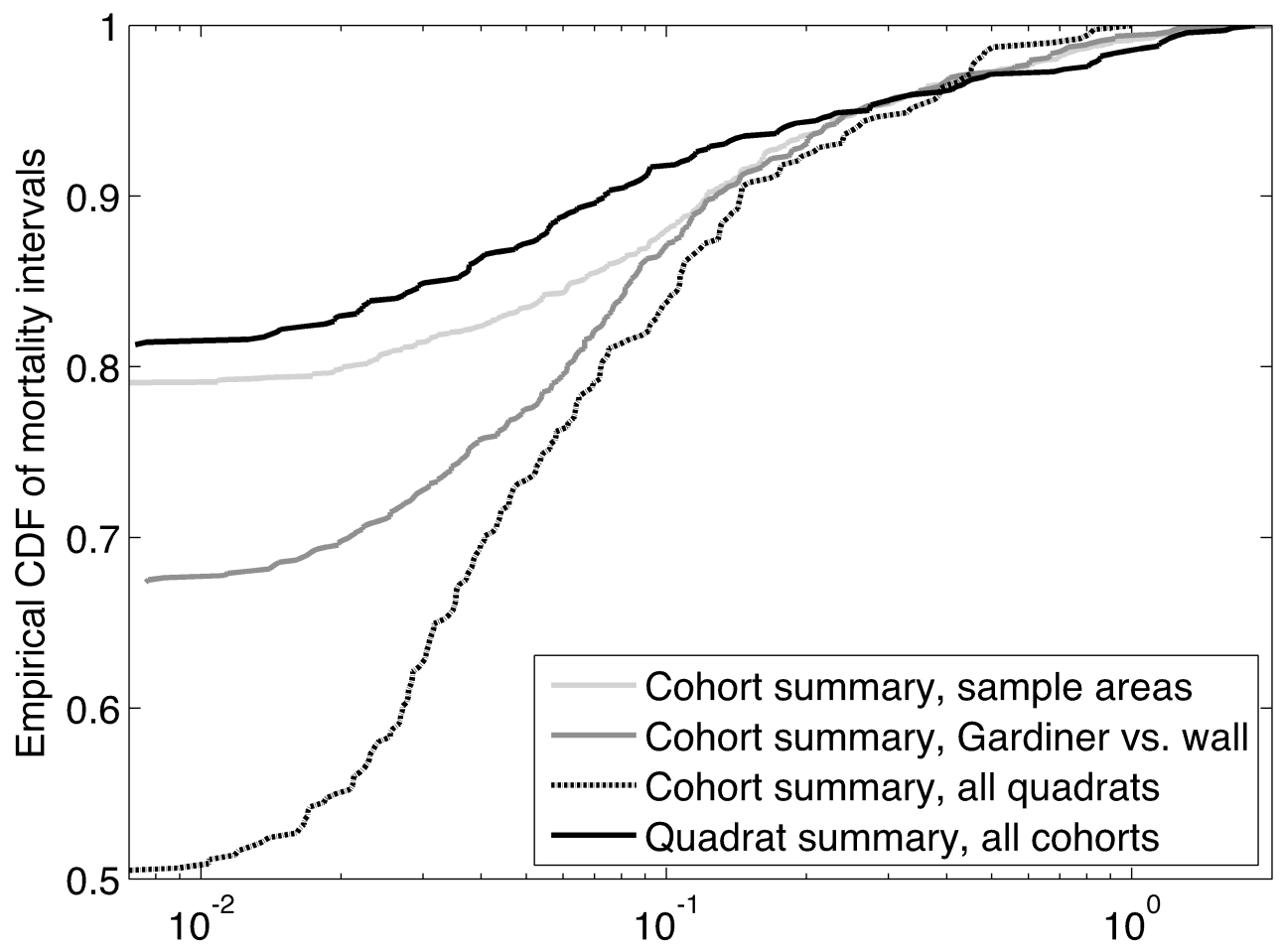

Proportion of pre-cover removal juveniles dead / time in intervals

Fig. 12. The proportion mortality rate distribution in high frequency photograph intervals after the removal of the smother plates from experimental winter and midspring quadrats. Mortality that was monitored on a high frequency after removal of the smother plates is summarized by calculating the proportion of the number of juveniles under the smother plate upon removal dies in each of the photograph intervals, divided by the amount of time in days between these intervals. The $\mathrm{x}$-axis is the proportion mortality rate in a log scale to emphasize differences in the cumulative distribution function at low proportion mortality rates. The y-axis is the proportion of the intervals with a proportion mortality rate less than or equal to the corresponding $\mathrm{x}$ value. Four distributions are plotted with corresponding colors, three of which summarize mortality by settlement date, thus called cohort summaries. The final plot is the quadrat summary described which are the intervals of mortality summarized by the spatial location of juveniles in quadrats. 

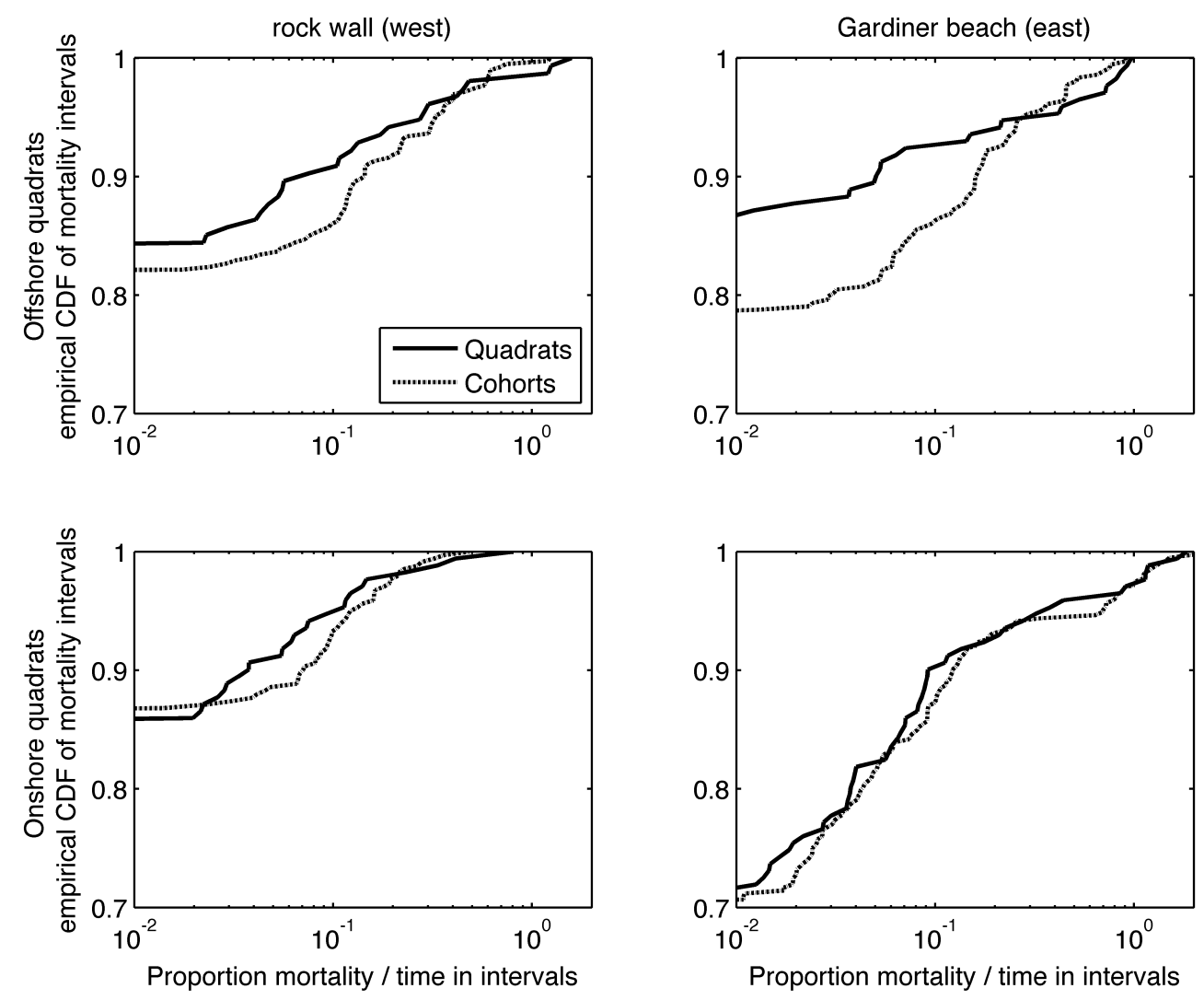

Fig. 13. Cumulative distribution functions for the proportion mortality rates at four sample areas indicate a convergence of quadrat and cohort based summaries at this smallest spatial scale. The $\mathrm{x}$-axis in each subplot it the log of the proportion mortality rate as in Fig. 12. The y-axis in each subplot is the proportion of mortality intervals with a proportion mortality rate less than or equal to the corresponding $\mathrm{x}$-axis value. Two lines in each plot correspond to quadrat and cohort summaries or proportion mortality intervals respectively. The four plots correspond to the four sample areas in Fig. 1 with the offshore quadrats corresponding to the sample areas located in areas with a lower beach elevation. The bottom two subplots correspond to onshore sample areas located in areas with the highest beach elevation. 


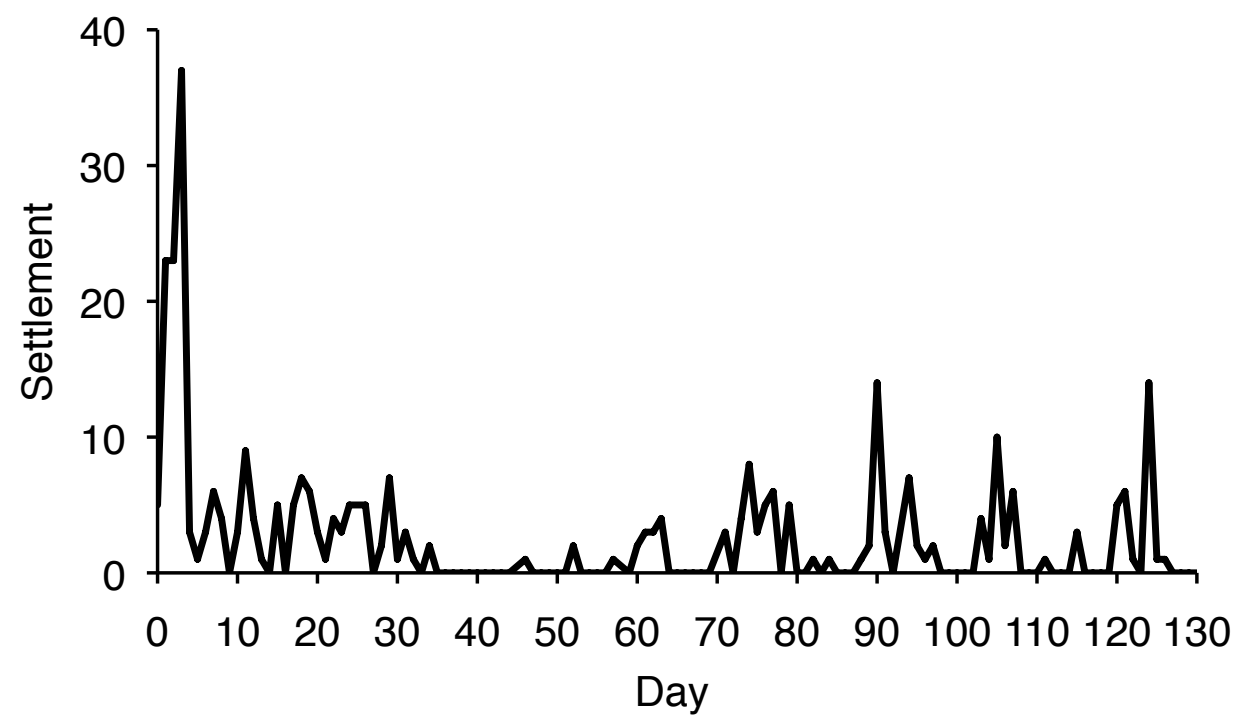

Fig. 14. The settlement measured at daily intervals on one natural substrate quadrat during winter and spring of 2007. A total of 15 such natural substrate quadrats have recruitment patterns that compose the recruitment window in Fig. 3a. The days correspond to those days in figs 3 and 6. 


\section{Chapter 5}

\section{Conclusion}

The research presented in this thesis was entirely conducted on a single shoreline only tens of meters wide on the Buzzards Bay coastline of Woods Hole, MA. Gardiner beach has been my laboratory for over the past three years, and I have focused on a variety of benthic processes right at the edge of the transition from the pelagic to the benthic phases of the barnacle lifecycle. This transition is limited to the developmentally important life stage, the cyprid (Walley and Rees, 1969). Focusing so intently on metamorphosis is perhaps a symptom of working with the intertidal barnacle, Semibalanus balanoides, since it is a model organism in the field of marine ecology that is best suited to address early benthic life stages of marine organisms with dispersive larvae. It has also been a conscious choice, as I hesitated to tackle measurements of barnacles in the water column. Clearly, planktonic based measures of S. balanoides abundance has been a successful avenue of research in the past (Bertness et al., 1996, Bertness et al., 1992), and it should be an area of increasing focus in time to come.

I believe that my shore based measurements have proven to be tractable and useful for addressing intricacies in this pelagic to benthic transition that have enduring consequences for the survival barnacles after they have settled in the rocky intertidal. I have demonstrated how features elemental to the physical environment, such as the wind that causes wave energy and transfers heat in the intertidal when it is exposed, and temperature, that varies from daily to seasonal time scales, are fundamental to the transition from the plankton to the benthos. In part, the details of this transition have 
enduring influence on recruitment patterns because of settlement choices and habitat selection behaviors of the barnacles upon settlement. Once barnacles make choices during settlement, the decisions are permanent and cannot be retracted. The fact that barnacles do not move after settlement just happens to be a life history trait that makes it possible to track the consequences of hypothesized settlement choices, in terms of the survival of settlers to juvenile and adult stages. Still, these hypothetical behaviors of settling larvae can only be inferred by these studies, and it is important to understand the limitations of these studies and how they fit into the larger framework of marine sciences.

A historical debate in marine benthic ecology is whether the supply of larvae or post settlement processes may determine the distribution and abundance of marine animals (Connell, 1985). The studies that I conducted for my thesis contribute to the growing body of evidence that this is a false dichotomy (Gimenez, 2004). The transition between the pelagic and benthic phases, as I have discussed above, are critical for barnacle survival to adulthood, and there may be a continuum of processes that bridge both of these phases.

There has been growing interest in the field of marine ecology to explain large scale recruitment variability with large scale oceanographic processes (Diehl et al., 2007). This thesis is perhaps the antithesis to this avenue of research as the largest spatial extent of my field studies is on the order of tens of meters! Nonetheless, I garner oceanographic patterns like changes in wind and temperature that are governed at very large scales to explain small-scale recruitment variability. Perhaps my studies contribute 
to the concept that large-scale physical features of the environment affect recruitment patterns, but it is not clear to me whether the processes that I have elucidated for Gardiner beach would scale up to regional scales. A lot of what explains recruitment at Gardiner beach is unique to Gardiner beach, for example, swell wave energy is limited to a low range at Gardiner beach, and chop wave energy may be the only wave energy that is energetic enough to inhibit barnacle settlement. Just several kilometers from Gardiner beach on the open coastline, swell wave energy reaches much higher values that would cause categorically different settlement dynamics to occur. In this case, the fact that the intertidal barnacle inhabits so many different intertidal habitats might make it a poor case study to examine the spatial scaling or recruitment patterns with physical variability. It seems that one would want to start with a habitat specialist that, for example, only lives on high-energy wave exposed beaches. This may be why Diehl et al. (2007) focused on the sand crab, Emerita analoga, rather than the rocky intertidal barnacle species that occurs where they work. The feature of the rocky intertidal barnacle that makes it unique among marine animals is that it is possible to track the settlement and survival of individuals, which was the key to the genesis of the recruitment window concept (Pineda et al., 2006). As I discuss in chapter 4 , the recruitment window is uniquely suited to integrating patterns of recruitment variability at larger scales, while, as I show in chapter 2, it maintains the integrity of small scale patterns of recruitment variability. No attempts have been made so far to address the generality of the recruitment window concept to locations other than Gardiner beach, 
and it would be a worthwhile endeavor to describe patterns in the recruitment window at regional and biogeographic scales.

\subsection{References}

Bertness, M. D., Gaines, S. D., Stephens, E. G. \& Yund, P. O. (1992) Components of recruitment in populations of the acorn barnacle Semibalanus balanoides (Linnaeus). Journal of Experimental Marine Biology and Ecology, 156, 199-215.

Bertness, M. D., Gaines, S. D. \& Wahle, R. A. (1996) Wind-driven settlement patterns in the acorn barnacle Semibalanus balanoides. Marine Ecology Progress Series, 137, 103-110.

Connell, J. H. (1985) The consequences of variation in initial settlement vs. postsettlement mortality in rocky intertidal communities. Journal of Experimental Marine Biology and Ecology, 93, 11-45.

Diehl, J. M., Toonen, R. J. \& Botsford, L. W. (2007) Spatial variability of recruitment in the sand crab Emerita analoga throughout California in relation to wind-driven currents. Marine Ecology Progress Series, 350, 1-17.

Gimenez, L. (2004) Marine community ecology: importance of trait-mediated effects propagating through complex life cycles. Marine Ecology Progress Series, 283, 303-310.

Pineda, J., Starczak, V . \& Stueckle, T. A. (2006) Timing of successful settlement: demonstration of a recruitment window in the barnacle Semibalanus balanoides. Marine Ecology Progress Series, 320, 233-237.

Walley, L. J. \& Rees, E. I. S. (1969) Studies on the larval structure and metamorphosis of Balannus balanoides. Philosophical Transactions of the Royal Society of London, 256, 237-280. 